\title{
The Ontological Politics of Disablement: Heidegger, Disability, and the Ontological Difference
}

\author{
by \\ Thomas James Abrams, M.A.
}

A thesis submitted to the Faculty of Graduate and Postdoctoral Affairs in partial fulfillment of the requirements for the degree of

Doctor of Philosophy

in

Sociology

Carleton University

Ottawa, Ontario

(C) 2014, Thomas Abrams 


\begin{abstract}
What does it mean to be disabled? To answer this question, this dissertation uses Martin Heidegger's concept of the 'ontological difference', the difference between human existence and that of everything else. I argue that a key issue facing disabled people, and thus disability studies, is the administration of the experience of disability via objective categories; to be disabled is to be administered. To make this case, I look to three diverse sites: tax forms, artwork and physical therapy. In each case, the ontological difference becomes manifest. In each case we see ontological politics at work, where bodies are shaped in particular ways (and not others), where lives are pulled in particular ways (and not others). I suggest we can reformulate disability politics as problems of ontology.

I pursue my argument as follows. I begin by outlining what I call a 'metatheoretical pragmatism', arguing the worth of theory lies in its ability to connect experience in new ways. Secondly, I arrange the dominant theoretical approaches in disability studies as 'ontological vectors', which I compare with Heidegger's phenomenology in the following chapter. In chapters three, four and five, I examine tax forms, artwork, and physical therapy; in each case we find ontological differentiation, where objective categories shape, and are shaped out of, human experience. In the final chapter I review the worth of these investigations, and outline my future research, a move from existential phenomenology to political economy, using the example of Ontario disability labour supports.
\end{abstract}


For Rob. Rest in peace. 


\section{Acknowledgements}

This dissertation would not appear as it does without a great deal of help. Thanks to Dr. Carlos Novas, for repeatedly reading each portion of this project (over and over and over), for his guidance, and especially his patience during comprehensive examinations. Thanks to Dr. Rianne Mahon, whose guidance, kindness, and confidence made my graduate studies possible and truly pleasurable. Thanks to Drs. Bruce Curtis and Alan Hunt for their wisdom, dedication, and much needed chiding. Thanks to Dr. Bernhard Leistle, whose phenomenology seminar deeply shaped what is written below. Thanks to my friends and colleagues Aaron Henry, Dr. Seantel Anaïs, Helin Burkay, Egemen Özbek, and Tom Everett. Talking about ideas with you is much more fun than writing them down. Most of all, thanks to Baalqis Hassan, whose love and support means the most of all. This list could go on forever; to those named and those I missed, thanks for your help. I am in your debt.

Some of the material for this dissertation has been integrated from earlier articles, in print, accepted for publication, or under review in the following academic journals:

Chapters one and three contain material adapted from two sources: Abrams, T. (2013). Being-Towards-Death and Taxes: Heidegger, Disability, and the Ontological Difference. Canadian Journal of Disability Studies, 2(1), 28-50, and Abrams, T. (2014). Re-reading

Erving Goffman as an Emancipatory Disability Researcher. Disability Studies Quarterly, 34(1), online. 
An earlier version of chapter four will appear as: Abrams, T. (forthcoming 2014). Boon or Bust? Heidegger, Disability Aesthetics and the Thalidomide Memorial. Disability \& Society, DOI:10.1080/09687599.2013.848784

Chapter five is currently under review: Abrams, T. (under review). Flawed by Dasein? Phenomenology, Ethnomethodology, and the Personal Experience of Physiotherapy. Human Studies.

Finally, an earlier version of chapter six has been accepted for publication, and will appear as: Abrams, T. (forthcoming 2014). From Homines Inhabiles to Homo Economicus and Back Again: Michel Callon, Distributed Agency and the Ontario Disability Support Program's Employment Supports. Journal of Cultural Economy, DOI:10.1080/17530350.2013.870085 


\section{Table of Contents}

$\begin{array}{ll}\text { Abstract } & \text { ii }\end{array}$

Acknowledgements iv

Chapter One: Literature Review 10

Historical Materialism and the Social Model 10

Foucault and Post-Structuralism 19

Embodied Phenomenology $\quad 26$

Actor-Networks of Disablement 31

Cyborgs and Situated Knowledges 36

Chapter Two: Martin Heidegger and the Ontological Politics of Disablement 45

Introduction $\quad 45$

Being and Time and the Early Heidegger 48

The "Letter on Humanism" 60

"The Question Concerning Technology" 64

Science and 'the mathematical' 68

Heidegger and the Body $\quad 71$

Embodied Times and Spaces since Heidegger $\quad 73$

Putting the Ontological Politics of Disablement to Work 81

Chapter Three: Being-Towards-Death and Taxes $\quad \mathbf{8 4}$

$\begin{array}{ll}\text { Introduction } & 84\end{array}$

The T2201 Disability Tax Credit Certificate 86

Phenomenology and Bureaucracy 88

Fibromyalgia and Muscular Dystrophy 91

Better Tax Policy As Better Disability Policy

Conclusion 98

Chapter Four: Boon Or Bust? Disability Aesthetics and The Thalidomide Memorial Introduction 100

Disability Aesthetics 101

Heidegger on Art $\quad 105$

"The Sick Child" 108

$\begin{array}{ll}\text { Conclusion } & 117\end{array}$

Chapter Five: Flawed By Dasein? Phenomenology, Ethnomethodology, and the Personal Experience of Physiotherapy 119

Introduction 119

The Twin Phenomenologies of the Ontological Difference and the Life-world 120

$\begin{array}{ll}\text { Ethnomethododology } & 127\end{array}$

Physical Therapy 134

Conclusions 139

Chapter Six: To Conclude: Stepping back, Stepping Forward 143

Introduction $\quad 143$ 
Four Ontolologies 144

The Ontological Difference 148

Three Cases of Ontological Differentiation 149

Stepping Back 153

Stepping Forward: From Existential Philosophy to Political Economy 158

Two Paths to Economic Agency 158

Distributed Agency and Marketization at Work in Ontario 166

Distributing Economic Agency in Ontario 173

Works Cited 


\section{Statement by Thesis Supervisor concerning the originality of material presented in the thesis and how included materials became part of the thesis}

To: Members of the examining committee

May 12, 2014

Dear members of the examining committee,

Thomas Abrams' dissertation titled "The Ontological Politics of Disablement: Heidegger, Disability, and the Ontological Difference" complies with the guidelines established in section 12.4 "Integrated Thesis Policy" of the Graduate Calendar of Carleton University.

Thomas Abrams has throughly integrated material from four (4) sole authored, peer reviewed articles into his dissertation. These articles are based on Thomas Abrams' original research that he conducted over the course of his doctoral degree and were solely authored by Thomas Abrams.

As Thomas Abrams states in his "Acknowledgements" section, Chapters One and Three contain material adapted from two of his sole authored, peer reviewed articles. These articles consist of the following: Abrams, T. (2013). Being-Towards-Death and Taxes: Heidegger, Disability, and the Ontological Difference. Canadian Journal of Disability Studies, 2(1), 28-50, and Abrams, T. (2014). Re-reading Erving Goffman as an Emancipatory Disability Researcher. Disability Studies Quarterly, 34(1).

In Chapter Four of his dissertation, Thomas Abrams includes material from a forthcoming manuscript: Abrams, T. (forthcoming 2014). Boon or Bust? Heidegger, Disability Aesthetics and the Thalidomide Memorial. Disability \& Society, DOI:10.1080/09687599.2013.848784.

Lastly, Chapter Six includes material from a forthcoming manuscript: Abrams, T. (forthcoming 2014). From Homines Inhabiles to Homo Economicus and Back Again: Michel Callon, Distributed Agency and the Ontario Disability Support Program's Employment Supports. Journal of Cultural Economy, DOI:10.1080/17530350.2013.870085.

As Thomas Abrams' thesis supervisor I can attest to the fact that Thomas Abrams has thoroughly integrated material from his published and forthcoming articles into the body of his doctoral dissertation.

Sincerely,

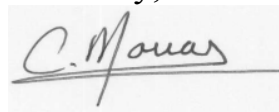

Carlos Novas 


\section{Introduction}

William James found the problem of being "the darkest in all philosophy" (1996, p. 46). Martin Heidegger, too, devoted his life to the problem of being. Heidegger's philosophy, along with James' observation, forms the backbone of my project. In what follows, I want to shed some light on the problem of being in disability studies. I argue that meditating on the question 'what is disability?' forms the very basis of the discipline. It forces us to rethink the nature of disability politics, about how and why disability is made meaningful in everyday life. The key concept found throughout these investigations is what Heidegger calls "ontological difference," the difference between human existence and the existence of everything else. The argument throughout is this: to do disability studies, we need to do ontological politics. ${ }^{1}$ My goal in this introduction is to outline why, exactly, people doing disability studies should care about ontology. Inspired by James' famous lectures, I'll provide a pragmatic argument justifying my ontological questioning, and the Heideggerian analysis employed therein. ${ }^{2}$

I have two answers to 'why should disability studies worry about ontology?' The first answer is simple and evasive. We don't need to start; we've already been doing it. As I argue in chapter one, we can read the major theoretical perspectives in disability

\footnotetext{
${ }^{1}$ I examine this concept in the next chapter more explicitly. For the moment, I'll use Annemarie Mol's (2002, p. viii) definition, "a politics that has to do with the way in which problems are framed, bodies are shaped, and lives are pushed and pulled in one way or another."

${ }^{2}$ I use this same pragmatic argument to justify my use of Heidegger, despite his Nazi politics, in chapter six. There I argue that if we can use Heidegger's work in a way opposing those horrid politics, to continue and improve the living situations of disabled persons, then reading his philosophy is warranted.
} 
studies as 'ontological vectors,' which emphasize particular understandings of what disability is, how we should go about knowing it, and what this means for improving the existence of disabled people. I outline four different vectors, the social model (or the historical materialist), the post-structuralist, the phenomenological, and finally the actornetwork and related feminist-cyborg ontologies. In writing about the different ontological positions, I am also giving the reader a description of the other questions that have made disability studies into the discipline (or inter-discipline) that it is. These include: 'how is physical and mental ability organized in capitalist societies?' and 'what is the relationship between disability research and social change?' In short, in doing disability studies, we are already doing ontological work.

My second answer to 'what should disability studies care about ontology?' is less evasive. By asking about how disability is organized, we are able to ask how disability could be organized more effectively. After I map out Heidegger's understanding of what ontology is in chapter two (as the study of human existence, rather than a metaphysical domain), it becomes evident that doing ontology means asking what makes human difference — physical, mental, or ontological — meaningful. Disability is not meaningful or manageable in isolation of the social, political, and economic environment in which it is performed and organized. In the main body of this dissertation, I look to how disability is made coherent in widely different aspects of everyday life. In disability tax forms, the aesthetic disclosure of disability, and physical therapy, we find three locations where ontological differentiation takes place-operatively defined as the movement from human experience to humans-as-manageable-objects, and back again. In mapping these 
sites of differentiation, we can ask critical questions about the cultural organization of ability and human difference.

While I provide a chapter-long meditation on theory and method, some remarks on philosophical outlook are warranted here. Throughout this dissertation, I use Heidegger's existential phenomenology as the basis for my meditations on disability and social theory. But on what basis have I chosen Heidegger? Why not another, more readable, philosopher (or sociologist, for that matter)? My reasons are selfish, and they are instrumental. They are instrumental in that I have organized my theoretical concerns on practical matters. Despite how obscure and terse Heidegger's prose may be at first sight (or second, third or fourth), I believe he lets us organize academic studies of disability in new and novel ways. We can practice disability studies in a way nobody has done so before, in reading him closely. My selfish reasons are as follows: I have read many philosophers, and many social theorists — and many other academic writers outside of these two categories. But none of them let me reflect on my own experience as Heidegger has. This may be because of his prose. Its obscurity means that any reader is continually looking to ground the text experientially. Past a few offhand remarks, Heidegger does not retreat from abstraction. There is a selfish circle at work here: I used my own experience of disability to make sense of Heidegger, and my reading of Heidegger to make sense of my experience of disability. ${ }^{3}$

\footnotetext{
${ }^{3}$ My experience of disability stems from my diagnosis of Becker's muscular dystrophy at age ten. Throughout this dissertation, I use this experience as a point of departure for theorizing. In chapter three I use this experience to speak about the categorization of disability in Canadian tax forms, and again, in chapter five, I use my experience of physical therapy treatment to put the ontological difference to work, showing how
} 
Both of my reasons for reading Heidegger rely on a meta-theoretical pragmatism. Theories - philosophical or otherwise - are valuable in the way that they help make sense out of disordered experience. In Pragmatism: A New Name for some Old Ways of Thinking (1978), James called this approach 'radical empiricism', and suggested that it need not logically follow the teachings of pragmatic philosophy. In my reading, it does. The worth of the analysis here will be judged in my ability to take Heidegger and effectively describe the experience of disability. The worth of disability studies as a whole lies in the ability to make that experience better, to help disabled people live meaningful lives, to question how human ability and potential are culturally shaped, and, ultimately, what they can be. In both of these tasks, disability studies and disability theory are ontological, through and through.

The organization of this dissertation proceeds as follows. I begin by mapping the state of disability theory along four ontological vectors. I've already described them, but I'll review them here in further detail: I begin with Michael Oliver and the so-called British social model. This way of understanding of disability emphasizes barriers preventing participation in society. Next, I turn to the Foucauldian and embodiedphenomenological approaches. Foucauldian approaches seek to isolate how disability has been managed historically, how different kinds of societies have viewed physical and

\footnotetext{
'symptoms' of muscle disease are derived from the interaction order. I make no claims to wholly encapsulate the disability category with this experience. Disability is extremely broad. As we shall see throughout this dissertation, one of the key challenges facing disability studies and disability policy is the organization of various embodiments within 'disability', as an umbrella term.
} 
mental difference, and how they could be governed differently. Embodied phenomenology looks to how bodies are shaped culturally, and how the experience of disability is not restricted to the organic body proper. Following Maurice Merleau-Ponty, embodiment bleeds into the world, and does not easily fit into dualistic categories of inside/outside, or mind/body. Finally, I look to Actor-Network Theory (ANT) and Donna Haraway's related cyborg ontology. There, disability is seen as an emergent outcome, a network result. Disability is not, ANT and Haraway argue, simply a biological or social problem. It is enacted in network processes. Haraway uses the idea of the cyborg to question the basis of traditional identity politics. She moves from abstract networks to crucial questions of emancipation and political action.

In chapter two, I read Martin Heidegger's philosophy as providing disability studies a theory-methods package. Heidegger's work provides me the core concept that permeates this dissertation, the ontological difference. Heidegger argues that what it means to exist as a human, Dasein, is different than the existence of mere objects. This is the ontological difference: between being and Dasein. In Being and Time, Heidegger argues that the times and spaces of human existence are different than the measurable times and spaces of physically extended, temporally bound things. The ontologically closest times and spaces are found in the way that we care for tasks in the world around us. Restated: 'disability' is not static. It found in the doing of tasks, in the way we care for things. Following Heidegger, I call this the 'care structure', and suggest it lets us reconsider disability in new ways. This is the theory. In the methods section, I discuss how Heidegger's later preoccupation with the technological world tells us how to 
do disability studies. It tells us to look for places where the human experience of disability is shaped into a manageable object. His focus was on the dehumanizing experience of technology, whereas I look to the administration of disability and how it can be made more human. I call this process 'ontological differentiation', and use the concept throughout the remainder of the project. I conclude this chapter with a discussion of two Heideggerian thinkers, ${ }^{4}$ Drew Leder and Michael Schillmeier. These two thinkers allow a more 'updated' reading of Heidegger, and one more charitable to his contemporaries, Maurice Merleau-Ponty in particular. Schillmeier and Leder provide fresh opportunities for phenomenological research, and serve to highlight others Heidegger callously neglected.

In chapters three though five, I put Heidegger's ontological difference to work. I focus on three different sites where the boundaries between human existence and disability, as a culturally organized object, are broached. In chapter three I examine tax forms. These forms are not, I argue, benign reflections of a world 'out there'. Rather, they are key sites where the experience of disability is shaped into a cultural object. In the T2201 Disability Tax Credit Certificate, being-disabled-for-tax-purposes reflects a partial reading of human experience. My use of the ontological difference is twofold here. First, Heidegger's work provides a critique of the measurements of disability used, as functional inability in a particular body. Secondly, Heidegger's care structure provides a task-based alternative to these sorts of measurements. Past offering a philosophical critique, the ontological difference tells us how we can make these kinds of forms more

\footnotetext{
${ }^{4}$ I critically question what it means 'to be a Heideggerian' in chapter six, below.
} 
human. To show how this task-based understanding of disability is preferable to current CRA measures, I explore two distinct types of disabilities, fibromyalgia and muscular dystrophy. The "proof generating enterprise" (Titchkosky, 2001) involving the T2201 is biased toward visible, static and physical conditions. I ask how we could alter the form (and forms like it) to eliminate these institutional preferences, using Heidegger's work.

In chapter four I move to an emerging area of disability studies: disability aesthetics. As we will see in chapter one, disability studies has historically focused on economics and exclusion, leaving sensuous apprehension behind. Chapter four argues that 'the sensuous' is an important site of disability politics. After reviewing some work founding 'disability aesthetics', I outline Heidegger's writings on artwork. There we find that the ontological difference provides the key to Heidegger's understanding of artwork. The experience of artwork cannot be described as an isolated epistemological subject viewing an objective work of art. Rather, art provides a site where Being is brought forth, where truth is disclosed as beauty. Following Heidegger's lead, I examine the recently unveiled thalidomide memorial, presented by Chemie Grünenthal to the global victims of the drug's effects, born over fifty years ago today. ${ }^{5}$ I argue that Heidegger gives us the tools to dissect the memorial, the framing provided by the company, and the immediate reaction by thalidomiders (the name claimed by victims of the drug). In short, the company has attempted to disclose thalidomide as part of a past medical tragedy. It happened, and there is nothing we can do past express sorrow and remain vigilant.

\footnotetext{
${ }^{5}$ As will be made clear in chapter four, my use of 'victims' follows the use of those who claim victim-status. The thalidomide tragedy, again their term, causes us to reconsider the role of victimhood and tragedy in disability studies. Outside of this dissertation, I pursue this argument further in "Taking Tragic Measures?" (Abrams, 2014).
} 
Victims, on the other hand, demand recognition and compensation for their lives as currently disabled persons-wronged in the here and now. I suggest that an understanding of truth as disclosure is attentive to this conflict, and suggest it has important lessons for disability studies' politics of tragedy. I end by questioning what future disability aesthetics might look like.

Chapter five asks about processes of medicalization. The term is frequently used: a) to address how disability is treated solely as a medical issue, rather than a social and political one (Oliver, 1990); and, b) to discuss how medical causality is used as an ideological guise for that exclusion (Hughes, 2000). To speak about medicine-or 'biomedicine' - abstractly is not, I argue, of much worth to disability studies. Rather, our concern should be on particular sites of medical intervention, places where medical causality is invoked (like the T2201 'proof generating enterprise' discussed in chapter three). I use my own experience of physical therapy as one such site. 'Medical symptoms', I argue, do not exist in themselves. They must be carved out of daily human existence, shaped in the phenomenological life-world. They are the outcome of ontological differentiation, accountable to medicine's practical rubric. Accordingly, in "Flawed by Dasein," I provide a hybrid phenomenological-ethnomethodological apparatus to describe how symptoms are cultivated in the social order. This lets us critically reflect on calls by physical therapists for 'client-specific methods'; client-hood is an artifice where the body is already enframed by physical therapy's objectively present rubric. I end the chapter by reflecting on medicalization more generally. 
In "Stepping Back, Stepping Forward" I conclude the dissertation. There I address the usual concluding questions, about the role of theory and the future of my subdiscipline (or 'interdiscipline', depending on who you ask): disability studies. After this, I discuss Heidegger's troublesome membership in the Nazi party, and assess how much his horrid politics colour his philosophical teachings, and our reception of them. My answer matches the pragmatic meta-theory guiding my reading of his philosophy as a whole: if we can do more good than ill using his work, so be it. Past the usual concluding work, I sketch out the project that I want to pursue in the future. In the future, I want to move from existential philosophy to political economy. This 'move' is a shift, not an about-face. There are many important lessons I learned in writing this dissertation that I do not wish to forget. To show how I will apply these lessons in the future, I use the example of the Ontario Disability Support Program's (ODSP) Employment Supports. Here, disabled existence is literally put to work: the provincial government operatives a program where disabled Ontarians are outfitted to participate in the workforce. It is a site where Heidegger's ontological difference can be matched with recent advances in the economic sociology of disability. Here we find a familiar face: Michel Callon, whose ANT work I address in chapter one. I ask how the ODSP Employment Supports could be improved, in terms of how human existence is shaped into disability-for-ODSP-purposes, and how the program could meet material needs more efficiently and humanely. In chapter six I don't propose research to happen at a later point. I do it. 


\section{Chapter One: Literature Review}

In this chapter I seek to situate my ontological investigations within the interdisciplinary field of disability studies. Though there are numerous ontological frameworks employed in the field, I examine four: the historical materialist, the poststructuralist, the phenomenological, the actor-network and related feminist-cyborg

ontologies. None of these ontological vectors is used exclusively; they overlap frequently. I begin with the social model, formulated in UK disability activist circles. Its defining work, Michael Oliver's Politics of Disablement (1990), is one of the most cited books in disability studies. Each of the vectors to follow have defined themselves in relation to it. I then outline the Foucauldian, Embodied Phenomenological, and ActorNetwork theory ontologies, and conclude with the related work of Donna Haraway. Hers spans the four ontological vectors most widely, and will serve to tie together the themes found in the other three.

\section{Historical Materialism and the Social Model}

Historical Materialism has been the dominant theoretical thrust of critical disability studies, and is the chief theoretical approach against which other perspectives must reconcile. Its discussion will take up a plurality, of the four theoretical perspectives that I examine in this chapter. Here I focus on the so-called 'British social model', named as such because of its deep ties to UK disability activism (Oliver, 1983; 1986; 
1990). The social model is built on a strict ontological divide between disability and impairment, formulated within the Union of The Physically Impaired Against Segregation's Fundamental Principles of Disability (1975). From the Principles:

[Disability] is a situation, caused by social conditions, which requires for its elimination, (a) that no one aspect such as incomes, mobility or institutions is treated in isolation, (b) that disabled people should, with the advice and help of others, assume control over their lives, and (c) that professionals, experts, and others who seek to help must be committed to promoting such control by disabled people. ... In our view, it is society which disables physically impaired people. Disability is something imposed on top of our impairments, by the way we are unnecessarily isolated and excluded from full participation from society. Disabled people are therefore an oppressed group in society. $(1975$, p. 4)

This ontological division of impairment from disability would later form the basis of the social model, named by Michael Oliver (1986). Oliver's project, most effectively presented in The Politics of Disablement (1990), seeks to underpin the UPIAS definition of disability (disability-as-oppression-and-distinct-from-impairment) with an historical materialist theoretical framework. In line with the UPIAS goal, an operative definition of disability for political action, Oliver intended to reform the academic sociology of disability in the service of this task.

Particularly crucial to understanding Oliver's work is his 'personal tragedy view of disability', perpetuated in and through capitalist social relations. In advanced capitalist societies, ability is the ability to work, to participate in wage labour. Impaired individuals are unable to fit the able-bodied-worker mold, and are excluded from social life. The 'ideology of individualism' manifests in capitalist society, where the exclusion 
of disabled persons is causally related to their impairments, and not to disabling social structures.

The requirements of the capitalist economy were for individuals to sell their labour in the free market and this necessitated a break from collectivist notions of work as the product of family and group involvement. It demanded nothing less than the ideological construction of the individual. [...] Hence, individuals always existed but only as part of larger social groupings whether they be families, clans or communities. It was only with the rise of capitalism that the isolated, private individual appeared on the historical stage. (Oliver, 1990, p. 44)

For Oliver, individualism and capitalist wage labour are historically concurrent. In order to do disability studies, we need to do political economy. Tragedy is not an inherent part of living with impairments; rather, it is an ideological product of disabling society, the outcome of disabling capitalist social relations that unnecessarily oppress impaired persons.

The social model's ontological isolation of impairment from disability has epistemological consequences as well, both in terms of how we know disability, and how the academic research on disability is to be pursued. In "Changing the Social Relations of Research Production?” (1992a) Oliver maps out the research agenda for future critical disability studies. Just as wage labour excludes disabled persons, disabling social relations are at work in the academy, where professional disability experts have historically dictated the disability research agenda without the consultation of those so studied. Oliver argues that neither 'positivistic' nor 'interpretive' social science has placed disabled persons at the forefront of the research agenda. 
Disability research should not be seen as a set of technical, objective procedures carried out by experts but part of the struggle by disabled people to challenge the oppression they currently experience in their daily lives. Hence the major issue on the research agenda for the 1990s should be; do researchers wish to join with disabled people and use their expertise and skills in their struggles against oppression or do they wish to continue to use these skills and expertise in ways which disabled people find oppressive? (Oliver, 1992a, p. 102)

With Colin Barnes (1996; 1999), Oliver established the so-called 'emancipatory research paradigm'. In this framework, disability studies are studies of oppression, guided by and for the oppressed.

The emancipatory paradigm is based on a combined ontological and epistemological presumption that disabled persons are most effectively equipped to guide research into their social situations. ${ }^{6}$ Restated: in order to do research into disability qua oppression, we must look to the oppressed. This means, understandably, both a

\footnotetext{
${ }^{6}$ A point frequently reinforced in the 'current issues' section of Disability \& Society, the UK journal edited by Oliver until his retirement. For two examples, see Barnes (1996; 1999). Here it would be easy to compare the epistemological-ontological relation embedded within the social model to other forms of historical materialist identity politics, such as Nancy Hartsock's Marxist-feminist standpoint epistemology (1983). Such a comparison would overlook the role that 'nature' plays in these two politics. Hartsock is deeply indebted to Marx and Engels' dialectical materialism. She quotes the German Ideology: "As individuals express their life, so they are. What they are, therefore, coincides with their production, both with what they produce as with how they produce. The nature of individuals thus depends on the material conditions determining their production" (As quoted in Hartsock, 1983, p. 286). Hers is a very close reading of Marx and Engels' dialectics, whereas social model theorists want impairments, as natural biological pathology, completely off of the emancipatory agenda. Their historical materialism is only loosely philosophically comparable to Marx's. For the social model, impairment has nothing to do with oppression. We will return to standpoint epistemology below through the work of Donna Haraway.
} 
commitment to the reality of oppression and the abandonment of claims to value neutrality.

If disability research is about researching oppression, and I would argue it is, then researchers should not be professing 'mythical independence' to disabled people, but joining them in their struggles to confront and overcome this oppression. Researchers should be espousing commitment not value freedom, engagement not objectivity, and solidarity not independence. There is no independent haven or middle ground when researching oppression: academics and researchers can only be with the oppressors or with the oppressed (Barnes, 1996, p. 110).

The emancipatory research paradigm has been enacted numerous times in instances of 'gatekeeping', where proponents evaluate the worth of previous work for their antioppressive project. ${ }^{7}$ Both Barnes and Oliver have been active in this role. Next I focus on their treatment of one author, Erving Goffman, whose contributions are so declined. This will serve as a transition into critiques of the social model, and the other ontological vectors introduced earlier.

The emancipatory research paradigm presents Goffman's work in two forms. In the first, we find citations of his Asylums (1961), used to represent the deplorable conditions in which the disabled were placed. Here Goffman's work is applied in an essentially historical light, focusing on institutionalization. Since the barriers producing

${ }^{7}$ Here I am pursuing the trajectory developed in my master's thesis (Abrams, 2009). There, I examined how the social model's influence continues to impact the translation of adjacent sociological theory into UK disability studies; in many cases significantly warping the theoretical work so irrupted. There I focused on the work of Michel Foucault and the Phenomenological Sociology of the Body. Similarly, I turn to the interpretive sociology of Erving Goffman below. 
disability today are of a different sort than in the immediate postwar period, the Asylums Goffman is of little utility, past an offhand reference to the history of exclusion.

There is a second Goffman, relating to his Stigma; notes on the management of spoiled identity (1963). Here Goffman is grouped into the 'interactionist school' of American sociology, which for the most part attempted to account for the interaction between deviants with their labelers. In short, Goffman is received as a social psychologist of 'the encounter'. As one might suspect, this is a Goffman who apparently subscribes to the same methodological individualism that Oliver (1992a) labels reactionary and oppressive (as per its ideological function). $\mathrm{He}$ is then treated accordingly. From The Politics of Disablement:

Thus, while stigma may be an appropriate metaphor for describing what happens to individual disabled people in social interactions, it is unable to explain why this stigmatisation occurs or to incorporate collective rather than personal responses to stigma. [... Disabled] people have not found stigma a helpful or useful concept in developing and formulating their own collective experience of disability as social restriction. To begin with, it has been unable (so far) to throw off the shackles of the individualistic approach to disability with its focus on the discredited and the discreditable. In addition, its focus on process and interpersonal interactions ignores the institutionalised practices ingrained with social relations (in the sociological sense [rather than in the face-to-face encounter]). And finally, therefore, they have preferred to reinterpret the collective experiences in terms of structural notions of discrimination and oppression rather than the interpersonal ones of stigma and stigmatisation. (Emphasis mine. Oliver, 1990, pp. 66, 68)

Additionally, Oliver argues through the interpretation provided by UPIAS member Vic Finkelstein (1980) that this methodological individualism is unavoidable in Goffman's 
interactionist analysis, because stigma is effectively reducible to the individual so marked.

A combination of these two 'Goffmen' is found in Barnes and Mercer's introductory text Disability (Barnes \& Mercer, 2003). Taking cue from Oliver's reading, the two present Goffman at once as an historian of disablement and naïve social psychologist of deviance.

A general feature of this interactionist literature is its concentration on the defensive manoeuvrings of disabled people. This suggests that those stigmatised are apparently firmly wedded to the same identity norms as normals, the very norms that disqualify them [...]. However, there are exceptions: the treatment of disabled people is not always represented as benevolent, and not all disabled people take over the values of nondisabled people. In his study of life in a psychiatric institution, Goffman $[\ldots]$ acknowledges that asylum inmates are 'colonized' and their supposed 'helpers' also act as jailers. He also outlines a continuum of potential responses to incarceration: from 'true believers' to 'resistors'. None the less, these examples are submerged beneath a general emphasis on achieving social acceptance and accommodating to the demands of 'normals'. (Barnes \& Mercer, 2003, p. 8)

Goffman does not have a place in the new 'social relations of research production'. He is, rather, located in the old order of social research, which serves to ignore the structural conditions in which disablement occurs. He cannot see oppression for what it is.

I do not find this reading particularly convincing, nor should anyone who has reviewed more of Goffman's work than the few selections cited by Oliver et al. Their reading is restricted to Asylums (1961) and Stigma (1963), and they make no reference to Goffman's wider corpus. Their accusation of methodological individualism misses the 
important work done in Interaction Ritual (1967) and Relations in Public (1971), particularly the essays "Mental Symptoms and Public Order" and "The Insanity of Place" (respectively, the latter included as appendix). In both cases, personhood is thematized as the basis of face-to-face interaction, a result of social interaction, rather than the preformed origin. Symptoms of mental illness are always, Goffman argues, located first in the interaction order (though of course they may eventually be traced to pathological organ states). They are not purely organic. Further, while Barnes and Oliver seek uniformity among disabled persons at any cost (in the name of solidarity), Goffman asks important questions about the wide varieties of disability as they manifest differently in the encounter. The emancipatory paradigm labels Goffman's work reactionary because he discusses individuals as possessing stigmatization because of stigmatized behaviour, as in the case of 'the mentally ill'. Here they bracket criticism of the social model (most effectively summarized in chapter three of Shakespeare, 2006), critical of the costs of individual-impairment-free disability politics. Wholly removing discussions of impairment from disability rights activism, as in the "Universal Design" approach, fails to examine how particular accommodations might be rival, or how individual disabled persons might benefit from discussions or other disclosures of their own impairments (a theme that I return to in chapter four). Goffman points us to inconsistencies in such an approach by analyzing mental illness' unique generation and enactment within the interaction order. In short, the social model—with its focus on disability as oppression and as an irreducible, homogenous category — comes with price tags. Its adherents label Goffman as a liability, when he should be tagged as an asset. 
I shall not dwell on critiques of the social model here. My reasons are both organizational and pragmatic. They are organizational in that I am not interested in a critique of the social model in the abstract. Rather, I am interested in how the social model deals with the problem of the ontological difference, and how Heidegger's work provides alternate answers. I will need to outline that problem beforehand, and do so in the next chapter. I will address these ontological implications throughout this paper as pertinent. My 'pragmatic' reasons: the social model has been pivotal in bringing critical disability studies to its current form. ${ }^{8}$ When asked 'what are the primary problems facing disabled persons' the social model adherent replies: "Barriers. Barriers create disability. Barriers oppress impaired persons." This is an exceptionally simple approach to the sociology of disability. It is crude, but equally effective. I by no means want to discount this emphasis on extra-personal barriers. But—and this is a big 'but' - there are occasions where the social model's primary focus on barriers does not fully account for the translation of human Being into disability categories. The social model does not say very much about the particulars of filling out disability tax certificates, the politics of medical tragedy as manifest in artwork, or the cultivation of symptoms in physical therapy practice. ${ }^{9}$ While exclusionary environments and attitudes do arise in each of these cases, they are fundamentally problems of inclusion. In each case, the primary

\footnotetext{
${ }^{8}$ Here I use 'pragmatic' in line with William James' (1978) use of the term. For a review of pragmatism as a philosophy of science, see Hacking's Representing and Intervening (Hacking, 1983, p. chapter 3)

${ }^{9}$ Oliver (1990) does address the issue of government survey forms, which is quite close to my area of interest. There, he is interested in how census forms define disability as an individual rather than personal problem, in how the ideology of individualism is manifest in the process of accounting. In this way, he is still very much true to the social model's formulation of the disability/impairment dichotomy. My interest is further upstream, addressing how human experience is accountable as disability in the first place, before it can be allocated to either the disability or impairment categories by the social model.
} 
question is not: 'how are disabled persons excluded?' but rather 'what experience is included in this particular disclosure of disability?' immediately followed by 'how could this disclosure be different?' These questions require alternate theoretical frameworks to be addressed most effectively. For this reason, I turn to the post-structuralist, phenomenological and actor-network approaches to disability and its ontology.

\section{Foucault and Post-Structuralism}

Post-structuralist approaches in disability studies examine how disability categories have been historically constituted, emphasize discontinuities in how disability has been addressed historically and outline how disabled persons are governed in “societies such as ours" (1978, p. 10). They pursue what Oksala (2010) calls Foucault's "politicization of ontology". Here, "[p]olitics is not only a struggle over resources and

values. It is a more fundamental battle for truth and objectivity. Politics discloses a world: It becomes essentially a struggle to realise [sic] a unique world through the definition of what there is." (Oksala, 2010, p. 462)

As in the case of the social model, most authors in the field address Foucault's writings directly or in a second-hand fashion (as seen in Oliver's Politics, op cit.). Instead of addressing Foucault's work in general, here I will focus on three prominent writers in disability studies, namely, Tanya Titchkosky, Michael J. Prince, and Bryan S. Turner. The first two authors provide an outline of Foucauldian perspectives on ontology, and a good introduction to Canadian disability studies and disablement in this 
country. Turner's work attempts a synthesis of Foucauldian and phenomenological social science, providing a theoretical bridge between sections two and three of this literature review.

Tanya Titchkosky's Reading and Writing Disability Differently (2007) applies a post-structuralist lens to how disability is made meaningful in the "everyday life of print" (11). While Foucault is a prominent resource from which she draws, her theoretical pool is extremely expansive, including Dorothy Smith, Judith Butler, Donna Haraway, among others. ${ }^{10}$ These motley thinkers are used to demonstrate how disability is textually constituted in Canadian society.

The textual production of disability as a problem is based on coming to know disability through biomedically informed discursive practices. These biomedically based discourse reflect that which conducts the conduct of governments so as to generate policies and practices that make differential embodiments intelligible as, and thus a matter as, 'individual citizens with disabilities (2007, p. 151).

In Reading's third chapter, Titchkosky makes extensive use of Foucault's 'bio-power', outlined in the first volume of his History of Sexuality (1978). Foucault uses the term to refer to the mechanisms through which sexuality—as an historically emergent discourse and regime of practices - enact and manage the human body at both the individual and species level. These are the 'anatomo-politics of the human body' and 'bio-politics',

${ }^{10}$ Here I cite only explicitly Foucault-inspired interlocutors. Titchkosky draws inspiration from many phenomenological writers as well. I will refrain from discussing phenomenological perspectives and their underpinning ontology until the following section. 
respectively. ${ }^{11}$ Titchkosky uses the concepts to illustrate how disability is defined both as an individual medical problem, and as the attribute of a population. She outlines the mechanisms of bio-power at work in Canadian government surveys, and the anatomopolitics of the human body in the T2201 Disability Tax Credit Certificate (she examines an earlier version of the same certificate that I critique in detail in chapter three). In both cases, disability's ontology is neither given nor immutable. It is enacted in such a way that it ignores barriers, physical or bureaucratic, and more importantly is a site where disability politics can be put to work.

Titchkosky's political ontology of disability borrows from another prominent Foucault-inspired writer, feminist theorist Donna Haraway. Her concept of the "god trick" represents the process through which textual production, which is always produced in a culturally-entrenched commonplace or topos, has its situated heritage erased, so as to produce the illusion that the perspective it presents is a 'view from nowhere'-an objective, unbiased and de-situated location (Haraway, 1994). For Haraway, and thus for Titchkosky, this is impossible. All texts are socially situated doings. They represent the partial perspectives of their authors, and rely on other adjacent texts, similarly influenced, for support. In terms of disability: the objective, context-free facts presented "about" disability perform this "god trick". I use "about" since for Titchkosky disability is only made a socially relevant entity through intertextual production. Not only this: facts purportedly "about" disability are not only alienated from the authors who produce these textual accounts, but disability-as-fact is also alienated from the embodied social contexts

${ }^{11}$ Both concepts are introduced in part 5 of Foucault's History of Sexuality, "Right of Death and Power Over Life." (pp. 135-160) 
in which it is experienced and produced, as well. Titchkosky cites the "god trick" in her analysis of Canadian federal policy documents "about" disability:

[Here to] think about disability is to think of some individuals with some functional problem; it is not to think about how the notion 'functional' is a socially organized term with a highly contingent usage that presupposes a rather mechanical version of the body and is sometimes even used to imagine embodiment as somehow separate from the socio-politico milieu within which bodies always appear. (2007, pp. 55-56)

For Titchkosky, these texts perform two sorts of erasure: the cloaking of the social relations in which the documents are produced, and the elimination (or, stated more charitably, 'bracketing') of the social conditions in which disability is experienced by those so characterized. In this manner Haraway and Titchkosky continue Foucault's politicization of ontology. They show how disability is enacted through text, always the result of human activity, and how that action becomes obscured in light of the immutable truth of disability as present in bodies and in the Canadian population.

Michael Prince's “Canadian Disability Policy: Still a Hit-and-Miss Affair” (2004) draws heavily from both Titchkosky and Foucault. It aligns his greater project of examining Canadian disability governance with the post-structuralist politicization of ontology. ${ }^{12} \mathrm{He}$ employs two Foucauldian concepts: 'bio-politics' and 'governmentality'. I have already addressed the former. Foucault uses the latter in reference to the various mentalities that underlie liberal governance, to trace the deployment, organization and management of freedom. For Foucault, the governmentalized state administers

12 See especially Absent Citizens: Disability Politics and Policy in Canada (2009). Prince's political sociology of disability aligns a classic Canadian political economy stance approach the dividends of critical disability studies literature. 
population through freedom, in the deployment and management of health, economic welfare and citizenship. ${ }^{13}$ Foucault's freedom is not, then, a transcendental attribute possessed innately by all human beings. Rather, freedom is an emergent property of governing practices that allocate subjects a degree of autonomy within a circumscribed domain. As outlined in the Birth of Biopolitics:

Liberalism as I understand it, the liberalism we can describe as the art of government formed in the eighteenth century, entails at its heart a productive/destructive relationship [with] freedom. [...] Liberalism must produce freedom, but this very act entails the establishment of limitations, controls, forms of coercion, and obligations relying on threats, etcetera.

[...]

Freedom is something which is constantly produced. Liberalism is not acceptance of freedom; it proposes to manufacture it constantly, to arouse it and produce it, with, of course, [the system] of constraints and the problems of cost raised by this production. (Foucault, 2008, pp. 54-55)

At the heart of Foucault's political ontology of liberalism is an unpacking of 'free subjectivity', which is deployed through the art of government. In a lecture less than a year before his death, Foucault further outlined the governmentality-freedom relationship:

I intend this concept of "governmentality" to cover the whole range of practices that constitute, define, organize, and instrumentalize the strategies that individuals in their freedom can use in dealing with each other. Those who try to control, determine, and limit the freedom of others are themselves free individuals who have at their disposal certain instruments they can use to govern others. Thus, the basis for all this is

13 Foucault used 'governmentality' in reference to all liberal government projects that manage the population and individual bodies through freedom. This means, in part, looking past the state as the sole governor of conduct through liberty. Institutionalized medicine is, for instance, another such governing apparatus. Simply: the state is not the only game in town. With this made clear: Prince is a professor of Public Policy (currently at the University of Victoria). We should not mistake his disciplinary focus with governmentality's conceptual horizons. 
freedom, the relationship of the self to itself, and the relationship to the others. (Foucault, 1997, p. 300)

For Foucault, liberal government implies both a discursive apparatus in which (free) subjectivities are conceived, and a regime of practices that enact these subjectivities in bodies so conceptualized. Bio-power and the advent of governmentality are historically concurrent.

Prince uses Foucault's governmentality to address the manner in which disabled citizenship — often characterized in terms of 'autonomy' and 'freedom'—is discursively produced within Canadian public policy in the past twenty years, and to critically analyze the extent to which these goals of autonomy and freedom have been realized. Frequently, they have not. Prince calls this the 'déjà-vu discourse on disability'.

After two decades of disability policy making, there is a strong sense that we have been here before. I call this phenomenon the 'déjà-vu discourse of disability. It entails the official declaration of plans and promises by governments and other public authorities, followed by external reviews of the record, and then official responses with a reiteration of previously stated plans and promises. (2004, pp. 66-67)

This déjà-vu discourse serves to outline and reiterate what the responsibilities of Canadian governments are and what the responsibilities of Canadian governments are not.

This discourse naturalizes the limited scale and pace of reforms in policy and services [...]. More dangerously, the discourse not only perpetuates a pattern of relentless and incremental changes but also conceals the erosion and decline in existing programs and benefits to persons with disabilities. The language of shared social responsibility for addressing disability issues further legitimates a limited role by the Canadian state and places duties on individuals and families themselves as well as on other 
institutions, most notably the corporate and voluntary sectors. (2004, pp. 77-78)

Just as Foucault sees liberalism — and, in the Birth of Biopolitics, neoliberalism-as a mentality of government that constantly produces and orients freedom, (neo)liberal disability governance in Canada demarcates particular types and spaces of freedom for disabled Canadians.

A perfect example of this liberal freedom-demarcation is found in the recently federally organized Panel on Labour Market Opportunities for Persons with Disabilities' Rethinking DisAbility in the Private Sector (2013a). The report serves to make a 'business case' for employers to hire disabled persons, cited frequently in Federal Budget 2013's changes to Canadian labour market policy. There is a liberal mentality underlying the report: businesses, once informed about the small costs associated with workplace accommodation, ${ }^{14}$ would do well to hire disabled employees. Those companies that participated in sanctioned surveys noted that disabled employees tend to have higher retention rates, "improve company morale" and "increase workplace safety" (Canada, 2013a, p. 15). In short, once the truth of employment accommodation's cost is made clear to the private sector-on advice elicited from other private sector employers - the state can step back and allow market freedom to take its course. Secondly, in accordance with Haraway's "god trick", the report seems to eliminate the social and material barriers that prevent disabled individuals from making it to the labour market in the first place. It treats 'employment' as a homogenous condition, obscuring the times-and-spaces in

\footnotetext{
${ }^{14}$ The report cites a "one time expenditure of $\$ 500$ " for instances where workplace accommodation is required.
} 
which disabled employees work (frequently those of the service sector). In sum, the report both deploys an understanding of what disability is, incapacity to work, defines a location where it is governed as freedom, and introduces a set of practices-indirectly through education or directly through policy intervention-through which it can be distributed to that environment.

Bryan Turner's "Disability and the Sociology of the Body" (2001) attempts to suture together the post-structuralist approach sketched here with the phenomenological one discussed in the following section. Though it is well known that Foucault explicitly distanced himself from his Marxist-existentialist contemporaries on questions of human existence, Turner (2001, p. 255) argues that reconciliation between "ontological foundationalism" and "cultural constructionism" is both possible and beneficial to the sociology of disability. Contrary to Oksala (2010), Turner's Foucault is more historian than philosopher: he reads Foucault as a historian of knowledge and administrative practices, rather than as an anti-Platonist nominalist philosopher denying humanity's

ultimate essence. Though this project may not be true to Foucault's stated anti-realism, it allows Turner to align work in medical sociology, the sociology of the body and critical disability studies.

\section{Embodied Phenomenology}

As in most 'embodied' sociology and critical disability studies, Turner's ontological commitments stem from a reading of Maurice Merleau-Ponty. I begin this 
section with a discussion of Merleau-Ponty's work, emphasizing his concept of embodiment and its ontological underpinnings. Following this, I turn to the phenomenological disability studies literature, and outline how Merleau-Ponty's work has been received. This will both illuminate the state of the dominant literature in disability studies - the goal of this chapter-and provide a base against which I can contrast outline the phenomenology of Martin Heidegger, the goal of the second.

Merleau-Ponty's 'embodiment' is best outlined through his critique of perceptive psychology found in the Phenomenology of Perception (1962). Departing from Kurt Koffka and the Gestalt school, Merleau-Ponty takes inter-war empiricist and neo-Kantian psychology to task for their incomplete explanations of perception. Merleau-Ponty argues that perception is irreducible, and that individuals always encounter the world through the body, the basic unit of sensation and experience.

When we come back to phenomena we find, as a basic layer of experience, a whole already pregnant with an irreducible meaning: not sensations with gaps between them, in which memories may be supposed to slip, but the features, a layout and a landscape or a word, in spontaneous accord with the intentions of the moment, as with earlier experience (1962, p. 25).

The body is the primary aperture through which the world gains significance; human being-in-the-world is defined first in terms of its embodiment. "Our own body is in the world as the heart is in the organism: it keeps the visible spectacle alive; it breathes life into it and sustains it inwardly, and with it forms a system." (Merleau-Ponty, 1962, p. 115) Those explanations of perception that would divide the body from the world are 
misled from the outset. It is not only psychology that commits this fallacy: the disregard of the body's role in experience is endemic to the Western philosophical canon. This is expressed most extremely in René Descartes' metaphysics, which reduce the contents of the world to their physical structure. Merleau-Ponty argues, in contrast, that the ontology of the human body as lived cannot be encapsulated solely in terms of anatomy or biology.

Merleau-Ponty's ontology is this: human being in the world cannot be defined in terms of an isolated epistemological subject located in a body, made of extended stuff, that then perceives the world as sensuous.

The union of body and soul is not an amalgamation between two mutually external terms, subject and object, brought about by arbitrary decree. It is enacted at every instant in the movement of existence. (Merleau-Ponty, 1962, p. 102)

Human being is to be defined in terms of a way of being, always grounded in the body, where the world gains its coherence through the senses' unifying function. When we look at a figure, our body has already drawn together a world of significance before it is known to us, as demonstrated through Gestalt psychology. This is contrary to the belief that our body passively represents a pre-formed, outside world. The body unites the inside and the outside; it is more than just a heap of organs united by a nervous system.

Merleau-Ponty's somatic phenomenology has been widely applied in the sociology of the body, which has then delivered it to disability studies. Turner's (2001) chapter is one example of this. Crossley's "Merleau-Ponty, the elusive body and carnal sociology" (1995) is another. Crossley seeks to reconcile the sociology of the body—a de 
facto sociology of what is done to the body—with 'carnal sociology'. This is "concerned with what the body does and it stresses and examines the necessarily embodied base of the praxical-symbolic constituents of the social formation" (Crossley, 1995, p. 43). The distinction between the two sociologies signifies the elusive nature of the second type, even when the first is being pursued: we often lose what the body does when we treat it as a passive, a-cultural entity. Crossley's aim is to get both parts of the somatic story working together. He seeks a 'carnal sociology of the body'. Merleau-Ponty's somatic phenomenology aids Crossley in this task.

His 'body-subject' is always-already situated and decentred in relation to a historical world. On this basis I suggest that Merleau-Ponty's various writings could serve as a cogent point of departure for the carnal sociology of the body (1995, p. 45).

Merleau-Ponty serves to complement the sociology of what is done to the body with a phenomenological account of what the body does. Crossley extends Merleau-Ponty's philosophical objections to Cartesian metaphysics into a sociological critique of culturally entrenched notions of mind/body dualism. Crossley's project has commonality with Tuner's, extending a philosophical argument about the nature of the body to a sociological argument about the nature of the social world. They progress from embodied sociology to social fact.

Bill Hughes and Kevin Paterson (1997; 1999) bring the ontological and sociological critique found in Turner and Crossley's work to disability studies. They use the carnal sociology of the body in their ontological critique of the social model, and its divide between impairment and disability. 
In the social model, the body is rendered synonymous with its impairment or physical dysfunction. That is to say, it is defined - at least implicitly, in purely biological terms. It has no history. It is an essence, a timeless, ontological foundation. Impairment is then opposite to disability: it is not socially produced. (1997, p. 329)

Hughes and Paterson argue that this rigid biology/sociology divide is untenable philosophically, socially, and sociologically. The social model does not take into consideration what it means to be disabled, about how cultural institutions causally interact with impairment (something ignored by the social model and other dualist disability studies).

Crossley, Turner, Hughes and Paterson share a great number of similarities. I will suggest three. First, they all share a similar understanding of what Cartesianism is: the categorical division between thinking substance and extended substance. We are knowing subjects, made up of thinking substance, located within bodies made of extended stuff. Mind/body dualism is the logical consequence of this substance dualism. Secondly, each thinker suggests that these related dualisms manifest within modern institutions that regulate bodies and minds as distinct entities, medicine first and foremost. It is not simply a philosophical division. Cartesianism exists as a Durkheimian social fact, independent of our consciousness, and restraining our behaviour. It is a cultural outcome, rather than a biological given. Finally, each author argues that the phenomenological concept of 'embodiment' provides a theoretical alternative to the Cartesianism rampant within modern thought and institutional practices. This concept is drawn from the work of Maurice Merleau-Ponty. Merleau-Ponty provides us a better 
account of how humans live their bodies, and how these bodies interact with their cultural and historically constituted environments.

This section is not meant to describe the entirety of the phenomenological tradition, applied within disability studies or without. On the contrary, I will return to phenomenology in the next chapter. There, I map out Martin Heidegger's notion of the 'ontological difference', which forms the theoretical and methodological core of the chapters that follow. Heidegger's philosophical project not only rejects Cartesian ontology, but also the residual Cartesianism found within his French phenomenological contemporaries, Merleau-Ponty included. Briefly, Heidegger argues that it is not a divide between thinking and extended substance that is the chief obstacle to a close reading of human existence, it is the doctrine of substances in the first place that passes over the uniquely human way of being. For Heidegger, Descartes' metaphysics do not simply misread the experience of the human body. They misread human existence.

\section{Actor-Networks of Disablement}

The final ontological vector that I want to examine in this chapter is that of actornetwork theory (ANT). Whereas both the Foucauldian and phenomenological work examined above depart from the social model's materialism, ANT embraces it, though in a more contingent manner. In what follows, I outline the basics of ANT's ontology. Next, I review recent ANT work on disability, demonstrating what this ontological vector 
can do for disability studies, focusing on Annemarie Mol's (1999) concept of “ontological politics".

The conceptual core of ANT is, unsurprisingly, the actor-network. It is also the key to ANT's ontology. Actor-networks are heterogeneous assemblies of ingredients from myriad origins, some 'natural' and some 'social', some 'human' and some 'nonhuman', that make up the world. I place these words in scare quotes on purpose: actor-network theorists argue that natural or social things are not pre-defined entities, but are rather the outcome of network interactions, instances of what John Law (1987) calls "heterogeneous engineering". A simple example: the visually impaired subject is not an isolated actor, but is herself a heterogeneous assembly of various elements: a white and red cane, eyes diagnosed by medical professionals, and so on and so forth. Actornetworks are themselves assemblies of other actor-networks: the CNIB (formerly the Canadian National Institute for the Blind) is an assembly of employees, offices, websites, philanthropists and their donations, and, of course, eyes with reduced vision. The actornetwork is at once a node and a network, simultaneously a singular object and an association linking things together. Each networked ingredient is itself a network on to its own, a temporary arrangement of heterogeneous elements that cohere into an actor. Accordingly: actor-network sociology does not study society; it studies actor-networks ('society' being but one).

Moser and Law's "Good Passages, Bad Passages" (1999) is one of the first attempts to bridge the ANT framework with empirical disability studies. They use ANT 
to describe the contingent nature of ability and disability by focusing on the life of a disabled woman, 'Liv'. Drawing on Law's concept of 'heterogeneous engineering' (outlined above), they argue that disability should be thought of as an actor-network outcome, rather than as a strictly natural or social thing. Rather than ability or disability, they focus on the materially situated 'passages' that produce either state: "Dis/ability is about specific passages between equally specific arrays of heterogeneous materials. It is about the character of the materials which en/able those passages." (Moser \& Law, 1999, p. 201) Not only is Liv's dis/ability the result of actor-network interaction, ${ }^{15}$ but so to is her subjectivity.

[Pleasures] and pains, or so we are suggesting, have in part, perhaps in large part, to do with passages. They have to do with difficult passages that are made easy, or easy passages that are then made difficult. Or they have to do with what we might think of as 'necessary passages'--by which we mean passages that are, as it were, set for subjects in the material and discursive conditions which order relations. Which help to constitute normative subjectivity. Which order what will come to count as the passages that are important. Or simply taken-for-granted, at any rate by those who are normally competent. Or, to put it differently, by those who happen to take the form of relatively standardised technico-body packages (Moser \& Law, 1999, pp. 203-204).

Moser and Law argue that subjectivity is not a transcendental attribute of all human beings - it is cultural artifice expressed in and through socio-material passages. Liv, who cannot speak, is often excluded from interactive moments requiring that capacity. In these moments, subjectivity is denied. ${ }^{16}$ So too is she excluded from environments that

${ }^{15}$ Here I could write the 'actor-network interaction order' in reference to Moser and Law's use of Erving Goffman in the passages piece. I cannot think of an uglier term, however. It is only for this reason that I have not.

${ }^{16}$ Robillard (1994) provides an ethnomethological approach to these same problems, in his personal reflection on a three-month stay in an intensive care unit. His inability to 
cannot accommodate her wheelchair, which prevents rational or irrational conduct from occurring at all. In both of these cases, participation in social order is passage-based; the presence of the subject is an organizational consequence.

The ANT approach is particularly useful because it can be used to examine both the personally- and institutionally-organized ontology of disability. Annemarie Mol's The Body Multiple: Ontology in Medical Practice (2002) examines the way that atherosclerosis is enacted as an object in 'Dutch hospital Z'. She takes an ethnographic approach to the discovery, examination and treatment of the vascular condition, arguing that atherosclerosis has an enacted ontology —it exists insofar as it is put to work. It is put to work differently in the pathology laboratory, in the outpatient clinic, and in the epidemiological study. Each is a different thing because they are put to work differently. Just as Moser and Law see disability as the outcome of passage-organization, so too is atherosclerosis an actor-network product. Its existence, its ontology, is a network outcome. Thus, "to be is to be related." (Italics in original. Mol, 2002, p. 54)

Mol's enactive approach to medicine is built conceptually on what she calls 'ontological politics' (2002, p. viii). ${ }^{17}$ As with the Foucualdian and phenomenological vectors, Mol understands ontology differently than simply 'that which is'. Similar to Oksala's commentary on Foucault, ontological politics are about how reality shapes and is shaped through human and nonhuman forces. This is admittedly vague, but necessarily

speak due to severe muscular dystrophy also impacted his presence-as-subject in decision-making processes. I return to his work in my hybrid Heideggerianethnomethodological approach to physiotherapy symptoms below.

${ }^{17}$ See also her book chapter of the same name for an essay-length exploration (1999). 
so. At the outset of the body book, Mol addresses medicine through this lens: "I contribute to theorizing medicine's ontological politics: a politics that has to do with the way in which problems are framed, bodies are shaped, and lives are pushed and pulled into one shape or another." (2002, p. viii) Ontological politics are not about the "who gets what' of a material reality allocated by outside political actors, as in the 'ministry of natural resources'. It is about how we organize ourselves (and our material allies) in the world-and how it pushes back.

Callon and Rabeharisoa's $(2004 ; 2008)$ work on the French Muscular Dystrophy Association (AFM) brings Mol's enactive, political ontology to the case of disabled persons' organizations. They provide a history of the organization, of how French patients and their parents assembled myriad dystrophies into a coherent and more effectively managed condition, and how the patient-controlled scientific council directs research (using the dividends of the charity's fundraising activity). ${ }^{18}$ We can compare this with the materialism of the social model. Whereas historical materialist approaches attempt to dissociate the natural from the cultural to get to the truth of disablement, the causality here is blurrier: in the AFM we find an instance of the co-production of scientific and social order, a mutual shaping of things usually categorized under the

\footnotetext{
18 'Patients' is their word. Writers in Disability Studies prefer to use 'clients', due to the hierarchy implied in the former term. Callon and Rabeharisoa's work challenges the traditional hierarchy, since it is those with the condition who are directing the nature of the condition's research. I employ the term 'patient' in reference to their work simply to maintain consistency, as the term is less important than the concept.
} 
'nature' or 'society' categories. So, while both can be called materialisms, the role that the material plays in shaping social order is distinct. ${ }^{19}$

\section{Cyborgs and Situated Knowledges}

I want to conclude this section (and the body of this literature review) with a return to the work of Donna Haraway, particularly her "A Cyborg Manifesto: Science, Technology, and Socialist-Feminism in the Late Twentieth Century" (1991, pp. 149-182). I do so for two reasons. First, Haraway's essay allows us to return to a theme introduced in the 'social model' section of this chapter, the ontology-epistemology relationship, by way of her commentary on feminist social epistemology. Second, as evidenced by her inclusion in two sections of this literature review, her work draws from more than oneif not all four - of the ontological vectors. It will allow me to conclude this review on an integrative, rather than divisive, note.

Haraway's “A Cyborg Manifesto" (1991) is a difficult, and yet equally rewarding, read. Similar to the ANT-ontology above, Haraway argues that the current state of the human being blurs the lines between the natural, the social and the technical: "By the late twentieth century, our time, a mythic time, we are all chimeras, theorized and fabricated hybrids of machine and organism; in short, we are cyborgs. The cyborg is our ontology; it gives us our politics." (1991, p. 150) Cyborgs are the product of the highly

${ }^{19}$ I must continue to emphasize that the social model's historical materialism and Marx and Engels' dialectical materialism are different entities. The nature/culture divide is not found in the latter. 
technological postmodern age, one where traditional emancipatory politics lose their traction, because the dualisms on which they rest-nature/culture, sex/gender, ability/disability ${ }^{20}$ - fail to reflect the state of human embodiment and social practice.

From one perspective, a cyborg world is all about the final imposition of a grid on the control on the planet, about the final abstraction embodied in a Star Wars apocalypse waged in the name of defence, about the final appropriation of women's bodies in a masculinist orgy of war [...]. From another perspective, a cyborg world might be about the lived social and bodily realities in which people are not afraid of permanently partial identities and contradictory standpoints. The political struggle is to see from both perspectives at once because each reveals dominations and possibilities unimaginable from the other vantage point. Single vision produces worse illusions than double vision or many-headed monsters. Cyborg unities are monstrous and illegitimate; in our present political circumstances, we could hardly hope for more potent myths of resistance and recoupling. (Haraway, 1991, p. 154)

The project is both descriptive and prescriptive: Haraway's cyborg describes the extent to which human being has been reformed in and though technoscience, and presents a site where we can formulate the emancipatory politics needed for the cybernetic age. This age presents new forms of oppression, and requires new strategies of resistance.

Haraway's discussion of feminist identity politics brings her to the same subject found in Oliver and Barnes above: the ontology-epistemology relationship underlying the emancipatory research agenda. Beginning in the "Manifesto", and later expanded in her famous essay on situated knowledges, ${ }^{21}$ Haraway argues that earlier feminist

\footnotetext{
${ }^{20}$ Haraway provides only passing statements on disability in the essay, making far more frequent reference to race, gender, sexuality and class. I address the ability/disability dichotomy below through disability studies' use and criticism of her manifesto.

21 "Situated Knowledges: The Science Question in Feminism and the Privilege of Partial Perspective" (1988). Both the "Manifesto" and the knowledge essay were reprinted in
} 
epistemologies have enacted the "god trick" in their search for a single point from which to critique phallocratic institutions and ideology. A particularly good example is Nancy Hartsock's "The Feminist Standpoint: Developing the Ground for a Specifically Feminist Historical Materialism" (1983). Hartsock argues that because women exist in a unique position within the capitalist political economy - producing both use-value in the home and exchange-value in the market - their vantage point can and must be used as a starting point for emancipatory politics. The feminist standpoint is "an important epistemological tool for understanding and opposing all forms of domination" (Hartsock, 1983, p. 283). ${ }^{22}$ Hartsock uses the feminist standpoint to expose both the sexual division of labour and phallocratic ideology more generally. ${ }^{23}$

Feminisms like Hartsock's have been criticized for their totalizing tendencies, excluding differences in sexual orientation, race, class, physical ability, and geographic

Simians, Cyborgs and Women (1991), though the former first appeared in Feminist Studies (1985).

${ }^{22}$ Note the use of feminist versus female - the feminist standpoint is achieved not naturally given.

${ }^{23}$ On my use of 'sexual division of labour': as outlined earlier, neither 'gender' nor 'sex' fully encompasses the reaches of Hartsock's argument, because she suggests that this and other dualisms are the product of 'abstract masculinity', the ideological consequence of phallocratic society's privilege of exchange value over its domestic corollary. "The epistemological result if one follows through the implications of exchange is a series of opposed and hierarchal dualities - mind/body, ideal/material, social/natural, self/othereven a kind of solipsism-replicating the devaluation of use over exchange. The proletarian and Marxian valuation of use over exchange on the basis of involvement in production, or labor, results in a dialectical rather than dualist epistemology: the dialectical and interactive unity (distinction within a unity) of human and natural worlds, mind and body, ideal and material, and the cooperation of self and other (community)." (287) With that made clear: I use 'sexual division of labour' because Hartsock does. 
location from the analysis of their ideal-type woman. ${ }^{24} \mathrm{~A}$ common reaction to these criticisms had been to extend the subjugated franchise to include the experience of other marginal groups, "though analogy, simple listing, or addition" (1991, p. 160). In both the "Cyborg Manifesto" and "The Science Question in Feminism", Haraway argues that this strategy is insufficient: it attempts to formulate a final, definitive and exclusive account of oppression by way of its experience, and a final, definitive and exclusive strategy to end it. The 'important epistemological tool for combating all oppression' reproduces the practices it intends to combat, obliterating the differences held by members participating in oriented social action (be it emancipatory, liberatory, or otherwise). It enacts the god trick.

There is no way to "be" simultaneously in all, or wholly in any, of the privileged (i.e., subjugated) positions structured by gender, race, nation, and class. [...] Subjugation is not grounds for an ontology; it might be a visual clue. (Haraway, 1988, p. 586)

Haraway argues that any emancipatory approach restricting itself to a single viewpoint is shortsighted. Hartsock's focus on the ideal type alientated labourer is one such example. In contrast, the cyborg is by its nature always hybrid, an assemblage of myriad viewpoints from the outset. Because of this hybridity, it epitomizes the epistemological pluralism underlying Haraway's emancipatory politics.

Disability studies has approached Haraway's cyborg with cautious optimism. She is cited in both Moser and Law's passages paper, and in Titchkosky's analysis of

\footnotetext{
${ }^{24}$ See, for example, Harding (1991), Collins (2000), and Mohanty (2003). For Hartsock's deliberation on such challenges, see her "Postmodernism and Political Change: Issues for Feminist Theory" (1989).
} 
Canadian policy documents. Others have been more critical. Tobin Siebers' Disability Theory (2008) acknowledges the theoretical utility of Haraway's cyborg for disability studies, but argues that it does not thematize disability's marginal status sufficiently.

Haraway's cyborgs are spunky, irreverent, and sexy; they accept with glee the ability to transgress old boundaries between machine and animal, male and female, mind and body. [...] Haraway is so preoccupied with power and ability that she forgets what disability is. Prostheses always increase the cyborg's abilities; they are a source only of new powers, never of problems. The cyborg is always more than human - and never risks to be seen as subhuman. To put it simply, the cyborg is not disabled. (Siebers, 2008, p. 63)

This is a good point. Haraway's reflections on disability are rather roseate. In her discussions of prosthesis, for example, she does not consider the variety of reasons why disabled persons may use them. Quite often, prostheses are used to 'look normal', rather than simply to make up for a lack of function In these cases, prostheses make problem bodies look less problematic, saying more about an intolerant society than a technological solution to a functional problem. ${ }^{25}$

Siebers is right: Haraway does not focus on oppression within her manifesto. I believe we can accept this fact while still taking home some valuable lessons for emancipatory disability politics. I will focus on two. First, she tells us to stop wasting ink over a grand-theory of oppression. Not every case is the same, why try and distill these disparate experiences needlessly? We lose the materially-situated aspects of

${ }^{25}$ Donna Reeve (2012) argues that such prostheses are a site of 'psychosocial oppression' when they are used only to mask visual difference. 
oppression when we do. An 'objective' description is one that looks at as many casesfrom as many vantage points - as possible. Her intersectional epistemology tells us to look for the wide variety of oppressions that disabled persons face, whereas the social model's liberatory gaze only looks to experiences shared by all disabled people. In line with her concept of the god trick, we need to make explicit the social location where emancipatory statements are made, and the interests of the groups that make them. The history of the social model is a good example: the UPIAS formed to eliminate physical barriers, accounting for the social model's difficulty dealing with mental illness.

Secondly, Haraway allows disability studies to have an adult conversation about medical technology. Writing from a feminist technology studies perspective, Haraway is well aware of the challenges posed by 'medicalization' to women, disabled persons and other marginal groups. But Haraway's cyborg imagery is one that accepts this challenge, rather than declines it. I place 'medicalization' in scare quotes because it is a needlessly lazy sociological abstraction when presented as a self-contained villain. It allows theorists to eschew empirical studies of medical intervention, instead drawing broad generalizations about an ephemeral institution. ${ }^{26}$ It performs the god trick. In the chapters that follow, I limit its use, instead focusing on particular instances of medical intervention whenever possible. These arise in the doctor's office, where a medical professional must sign the T2201 tax credit certificate (chapter three), or the rehabilitation clinic, were symptoms of muscle disease are cultivated and treated (chapter

${ }^{26}$ In chapter four I call this the 'biomedical boogeyman', at once everywhere and nowhere. 
five). There is more to these stories than oppression by biomedicine, and Haraway helps me tell them.

Donna Haraway draws on each of the three other ontological vectors discussed in this chapter and, thus, offers me a convenient way to conclude it. Though she is reacting to her contemporaries in feminist theory, the ontological presuppositions are similar. Her reaction to Hartsock's standpoint epistemology brings her to the same terrain charted in the social model; whereas Hartsock's theory is focused on the process of labour extraction, Oliver and Barnes focus on exclusion from the labour market. Oppression in the labour market is an important topic, but Haraway does not see it, or its ideological outcomes, to be the single most important issue facing women in the era of the cyborg. She draws from the early ANT work in science studies, and outlines how the human being is never purely natural or purely social. Today's woman (and today's disabled person) is an emergent product of myriad scientific, technical, social, natural and nonhuman forces. She invokes Foucault's politicization of ontology in her concept of the god trick and situated knowledges. Haraway's cyborg mirrors her writing style—she jumps between various theorists at a roaring pace, weaving complex threads between thinkers with little in common. It is a theoretical game of cat's cradle (Haraway, 1994).

Let's review the ontological vectors before I conclude this chapter. I began this chapter with a discussion of the UK social model, outlining the historical materialism of Michael Oliver. The social model draws an ontological divide between disability and impairment. Impairment is biological and disability is social (exclusion). The role of 
disability studies is to eliminate the barriers that produce disability. The biggest barrier of all is capitalism. I argued that the social model does not address mental illness - and Erving Goffman's sociology of mental illness - very effectively. Next, I turned to the political ontology of Michel Foucault, charting the discourses and practices that shape human subjectivities. Michael Prince and Tanya Titchkosky have applied his work to disability in the Canadian context. Here we encountered Donna Haraway for the first time.

The work of Bryan Turner served as a transition from the section on Foucault to the section on phenomenology. His project sought to align Foucault's archeology of subjectivity with the phenomenological interpretation of human being. His work, as with that of other phenomenologists in disability studies, is deeply indebted to MerleauPonty's somatic philosophy. We will return to the phenomenological tradition in the following section, where I outline the philosophy and method of Martin Heidegger. In the final two sections of this literature review, I turned to ANT and Donna Haraway's cyborg ontology. The two projects are very similar. ANT is interested in studying the interaction of actor-networks, heterogeneous assemblies of human and nonhuman, natural and social components. ANT presents a fundamental challenge to theories of social order that do not take 'the material' seriously. It traces the production of disability as a culturally contingent, materially situated process. We retuned to Haraway, who I read as part of the ANT tradition, ${ }^{27}$ bringing this focus on network materiality to feminist social

${ }^{27}$ Bruno Latour does as well, citing Haraway's manifesto frequently in his We Have Never Been Modern (1993). 
epistemology. Disability studies, as we have seen, has cautiously embraced her cyborg ontology.

Here I have tried to sketch the lay of the land, the predominant ontological vectors in the sociology of disability. 'The lay of the world' might be more apt. In the next chapter of this dissertation, I turn to the phenomenology of Martin Heidegger, a fifth and final ontological doctrine, one that forms the main body of this integrated dissertation. 


\section{Chapter Two: Martin Heidegger and the Ontological Politics of Disablement}

\section{Introduction}

In chapter one, I mapped out four ontological vectors permeating the sociology of disability. One of those was the phenomenological ontological vector, which drew extensively from the work of Maurice Merleau-Ponty. In this chapter, I present an alternate phenomenological ontology, that of Martin Heidegger (1889-1976). Мy presentation of Heidegger's work should be understood as a hybrid 'theory/methods package' (Clarke \& Leigh Star, 2008). That is, I argue that Heidegger's ontology offers a new theoretical approach to the sociology of disability, and gives new insights on how to do the sociology of disability. The theoretical component draws mostly from his earliest and most famous work, Being and Time (1996). ${ }^{28}$ There, Heidegger sketches out the basis of his fundamental ontology of human existence, or Dasein. This is where we find his fundamental distinction between human existence, Being, and the existence of the other contents of the world, beings. Being and beings have differing 'ways of being'. ${ }^{29}$ Heidegger (1996, p. 211) names this distinction the "ontological difference". The ontological difference is the key theoretical concept permeating this dissertation, and is crucial to understanding Heidegger's utility for the sociology of disability.

\footnotetext{
${ }^{28}$ I say 'mostly' because Heidegger's pioneering work on Art, which forms the basis of chapter four, is not found within Being and Time. See Heidegger $(1973 ;$ 1993c).

29 This use of ontology as a 'way of being in the world' is quite similar to MerleauPonty's use of that term. This is clearly due to Heidegger's significant influence on the French philosopher.
} 
Heidegger's work is typically divided into two stages. The first, epitomized by Being and Time, demonstrates an interest in the fundamental aspects of human existence. $^{30}$ The later Heidegger's main concern lies in human existence as lived in the modern world (after 'the turning', German: Kehre). Particularly interesting to disability studies is this period's focuses on science, technology and medicine. ${ }^{31}$ The later Heidegger still maintains an interest in human being, but emphasizes its contemporary form, rather than transcendental aspects. The later Heidegger and the transition away from Being and Time offer both theoretical concepts and methodological imperatives. Theoretically, the period offers us Heidegger's well-known argument of how human being is 'enframed' in the modern technological age. ${ }^{32}$ Within the later period, Heidegger frequently dwells on the threefold relationship between scientific rationality, human Being, and the place of philosophy. In this period, the ontological difference is not simply a philosophical distinction: it is also a methodological imperative. It can be used to trace how human Being becomes understood as mere being. In the chapters that follow, I ask how everyday human life becomes organized into an organizationally manageable being, and how this process could occur more favourably.

This chapter will proceed as follows. First, I outline the ontological project found in Being and Time. This will not only introduce his work to disability studies-a

\footnotetext{
${ }^{30}$ Obviously, I think that the completed section offers disability studies a great deal. Being and Time is not, however, the only work that shows Heidegger's interest in a fundamental ontology of Dasein. Nor is it the only work from the early Heidegger that I use. For other key work in this period, see Heidegger (1992; 2001a; 2011)

${ }^{31}$ For a discussion of each, respectively, see Heidegger (1977a; 1993d; 2001b).

${ }^{32}$ I return to this theme later in this chapter, and in the conclusion to this dissertation.
} 
discipline justifiably weary about abstract philosophy's pedantic tendencies—but will also provide us some theoretical infrastructure for the chapters that follow. How? Daring gross oversimplification, Being and Time argues that the ontological assumptions underlying the Western philosophical tradition have ignored what it really means to be human. ${ }^{33}$ Whereas Heidegger is interested in putting philosophy on the right track, my interest is in making the administration of disability more human. Beginning with my own experience filling out the T2201 tax form, I found that Heidegger's critique of Western Philosophy helped me make better sense of my own experience of disability. In the first section of this chapter, I aim to show this to others in sociology and disability studies. Being and Time is the best place to begin this task.

In the second section of this chapter, I turn to Heidegger's later work, beginning with the Letter on Humanism (1993a). This will help strengthen the dividends of the first section, as that essay is Heidegger's response to the French philosophers. Particularly important is Heidegger's critique of 'subjectivity' as a philosophical concept. In the Letter he argues that Sartre, Merleau-Ponty and other contemporary French phenomenologists failed to understand the full implications of his critique of René Descartes (seen in the last chapter). The French existentialists, he argues, tried to overcome Descartes' philosophical legacy without unpacking the theory of 'the subject'. In short, they tried to combat Descartes with more Descartes. Rather than simply pointing to the irony of that situation, I use Heidegger's critique of subjectivity to further

\footnotetext{
${ }^{33}$ Best demonstrated in Heidegger's extensive discussion of René Descartes' ontology at the beginning of Being and Time.
} 
emphasize the importance of his 'ontological difference', and to outline his philosophies of the body, science and technology, and artwork.

Finally, mirroring the structure of the previous chapter, I turn to some work within both embodied philosophy and the sociology of disability that have applied Heidegger's work. As in the chapters that follow, it is important to end on a practical note. I place emphasis on two key thinkers, Drew Leder and Michael Schillmeier. Obviously, there has been a great deal of relevant philosophical and sociological work since $1927,{ }^{34}$ and it would be folly to ignore it. Both Schillmeier and Leder offer us a concrete application of Heidegger's work to contemporary debates about embodied being and the experience of disability (both personal and cultural). As with Donna Haraway in the previous chapter, Leder and Schillmeier allow us to conclude on an integrative, rather than divisive, note. My first task is to outline the fundamental ontology presented in Being and Time.

\section{Being and Time and the Early Heidegger}

\footnotetext{
${ }^{34} 1927$ is the German publication date of Sein und Zeit. Though English readers first received the work in the Macquarry and Robinson's (1962) translation, Heidegger's work received attention before that by prominent English-speaking philosophers. See Gilbert Ryle's (1929) pessimistic, yet comprehensive review in Mind. We will read about the initial French reception of Sein und Zeit below.
} 
Rather than outline Heidegger's most important work in its entirety, I merely want to trace the themes within Being and Time that will be encountered below. ${ }^{35}$ Accordingly, I divide this section into three, digestible, portions. First I turn to the worldliness of human Dasein, the famous being-in-the-world, as it is disclosed in the times-and-spaces of care. Here we find the ontological difference. Next, I outline Heidegger's critique of Descartes' understanding of world, and of Western philosophy's underlying 'substance ontology' more generally. This will allow some preliminary comparison with the phenomenology discussed in the previous chapter (to be continued in the following section). Finally, I end with Heidegger's discussion of truth, found towards the end of Being and Time's first division. There I will outline Heidegger's reformulation of truth as disclosedness to Dasein, which will serve as a bridge between his earlier and later work.

After a lengthy introduction (for a project never fully completed), Being and Time begins by outlining the problem of 'world'. Dasein is not, Heidegger argues, simply a thinking subject placed into a world made up of other subjects and three-dimensional things. Human existence, as a way of being, extends itself into a region filled with things used to achieve everyday tasks. These things, and the tasks for which they are intended, make up Dasein's world. When we attend to particular tasks, things are disclosed in a frame of reference, and are 'ready-to-hand' for Dasein. ${ }^{36}$ In Heidegger's famous example, the hammer-in-use is not reducible to a chunk of space-time. It is the hammer-as-

\footnotetext{
${ }^{35}$ For a book-length discussion, see Dreyfus (1991). For a chapter-length introduction, see Dreyfus and Wrathall (2005).

${ }^{36}$ German: Zuhandenheit.
} 
disclosed-in-carpentry. Or, to use Dreyfus and Wrathall's (2005, p. 6) culinary example, wire whisks and frying pans appear to Dasein as they do because we deal with them in an omelet-making way. In both cases, the hammer and the kitchen tools are disclosed as tools for Dasein's tasks in everyday concern, or 'care.${ }^{37}$ Care is Dasein's primary mode of being, its way of being-in-the-world. ${ }^{38}$

So far, we have discussed two modes of being: Dasein, the human way of beingin-the-world, and the being of useful things, or handiness. In moments of breakdown, a further mode of being is disclosed, presence-at-hand. ${ }^{39}$ Whereas the useful hammer is ready-to-hand, the hammer that breaks during its course of use becomes a merely present hunk of materials. It is removed from the initial frame of reference, from when it was initially disclosed as handy. This mode of being, of 'objective presence', is what is expressed in our usual reference to objects. They lack relevance or purpose; they just are. The ontological difference is the distinction between a world described in terms of objectively present contents and their properties, and the Being of Dasein. ${ }^{40}$ While we can always see objects as merely present even if they can be used for tasks, they are first disclosed to us as useful and then are given secondary signification. ${ }^{41}$

37 Sorge. Heidegger uses the term extremely widely, to describe any moment of attendance-to, worry-for, or concern-about.

${ }^{38}$ Heidegger (Heidegger, 1996, p. 53)

${ }^{39}$ Vorhandenheit.

${ }^{40}$ This is the distinction between the 'ontic' ("of or relating to entities and the facts about them; relating to real as opposed to phenomenal existence": OED) and 'the ontological', relating to Being as a whole.

${ }^{41}$ Heidegger (1996, p. 62) 
Care, as Dasein's primary mode of being-in-the-world, discloses the experience of space closest to human Being. In our daily life-course, Heidegger argues, things are 'near' and 'far' to us not in terms of meters, inches or centimeters, but are 'over there', 'on the table' or 'a short walk'. ${ }^{42}$ The spatiality of Dasein is determined first and foremost by utility. The objectively-measurably closest things can be the 'farthest' from us, in the cases of an 'out of service' elevator. Or, as Heidegger writes in "The Thing" (1971), the hydrogen bomb thousands of kilometers away can be the first thing on all of our minds, nearest to all of us. As with the distinction between handiness and objective presence, we can later quantify this spatiality in terms of measurable distance, but this measurement is an abstraction from spatiality in its ontologically primary form. ${ }^{43}$ Inches, centimeters and yards are second order abstractions of Dasein's spatiality. The difference between measurable space and the spaces of care is the ontological difference.

In light of the Being of Dasein as care, we must reconsider time as well. In the first instance, temporality is not disclosed as measurable clock time. Rather, the ontologically primary mode of time is found in our capacity to be ec-static, to 'run ahead of ourselves' and to 'dwell on our past.' The temporality closest to Dasein has an 'I canand-will-again' structure. Dasein is "futural" in that we are always pouring ourselves into the tasks that we will perform, based on past instance of care. "Time is the "how"

\footnotetext{
${ }^{42}$ Heidegger (1996, p. 96)

43 "The things at hand of everyday association have the character of nearness. [...] The structured nearness of useful things means that they do not simply have a place in space, objectively present somewhere, but as useful things are essentially installed, put in their place, set up, and put in order. Useful things have their place, or else they "lie around", which is fundamentally different from merely occurring in a random spatial position. [...] Place is always the definite "over there" and the "there" of a useful thing belonging there." (1996, p. 95)
} 
(1992). For Heidegger, clock time is derivative of this ontologically primary way of living in our own future, through the means cultivated in our past, through the care structure. As in Heidegger's conception of space, the objectively present understanding of time in terms of minutes and seconds is an abstraction from the temporality of Dasein. Heidegger's time and space are both founded in care; they are inextricably linked as timespace, or Zeitraum. Where past spaces are deployed in future goals, we find the temporal way of being of Dasein. ${ }^{44}$

In the previous chapter, I argued that the 'embodied phenomenology' vector in disability studies tends to define itself negatively, in terms of a rejection of so-called 'Cartesian dualism' (the distinction between thinking substance and extended substance). Descartes' metaphysics, the phenomenologists argue, do not accurately describe the human experience of the body. Here is a typical statement, taken from Descartes'

\section{Meditations:}

Now, first of all, I observe that there is a great difference between the mind and the body, $[\ldots]$ that the body of its nature is endlessly divisible, but the mind completely divisible: for certainly, when I consider the mind, or myself in so far as I am purely a thinking thing, I can distinguish no parts in myself but understand myself to be a thing that is entirely one and complete. And although the whole mind appears to be united with the

\footnotetext{
${ }^{44}$ For Heidegger, the temporality closest to Dasein is found in being-towards-death. This concept is crucial to a comprehensive description of Heidegger's philosophy; he devotes a full chapter on death in division two of Being and Time. I do not, however, discuss death explicitly in this dissertation. I will say, however, that death also presents a case of the ontological difference. Whereas animals perish, only human beings live towards their death; human Dasein is always being-towards-death. Death as non-living and livingtoward-death as a persistent condition, which we can embrace or flee in vain, is the ontological difference. Death for Dasein also individualizes: my death is uniquely mine. Others cannot experience my death in the same way as it grounds my own being. For a comprehensive discussion, see Hoffman (1993).
} 
whole body, if the foot is cut off, or the arm, or any other part of the body, I know that nothing is therefore subtracted from the mind. Nor can the faculties of willing, perceiving by the senses, understanding, and so forth be said to be parts of the mind, since it is one and the same mind that wills, that senses, and that understands. On the other hand, however, no bodily or extended thing can be thought by me that I cannot divide into parts, without any difficulty; and I therefore understand it is divisible. This point alone would suffice to show me that the mind is altogether distinct from the body, if I did not yet sufficiently know this for other reasons $\left(2008\right.$, pp. 60-61). ${ }^{45}$

For Heidegger, embodied phenomenology is on the right track, but its critique of Descartes does not go far enough. Whereas the embodied camp argues that Descartes' division between thinking and extended substance is the problem, Heidegger argues that the problem is Descartes' notion of substances in the first place. ${ }^{46}$ The basic problem is not 'what substance is the human body made of?' (one, the other, both), but what is passed over by the primacy of 'substance' writ-large?

Heidegger's argument is that Descartes' metaphysics rely on a notion of substance that cannot account for the primordial time-spaces of Dasein. They presuppose a knowing subject that is wrenched from the world a priori and then thrust back into it in moments of sensation. In so doing:

Descartes leaves the meaning of being contained in the idea of substantiality and the character of "universality" of this meaning

\footnotetext{
45 See also Descartes' posthumous "Treatise on Man" in The World and Other Writings (1998).

46 Ian Hacking clarifies the medieval logic of substance. "Every substance is characterized by a 'principal attribute.' That is, a property such that if something is of that substance, it must by logical necessity have that attribute. As we all know, occupying space, or being extended, is a principal attribute. So is thinking. They are logically distinct. What you say about anything extended is different than what you say about anything that thinks. A logical distinction. A grammatical distinction. (Hacking, 2005, p. 158)
} 
unexplained. Medieval ontology left the question of what being itself means just as unquestioned as did ancient ontology. [...] The meaning of being was unclarified because it was held to be "self evident." (Heidegger, 1996, p. 97)

We can see this at work in the passage by Descartes presented above. There, the cognitive task 'thinking' is done by an immaterial mind, a mind that is not always already directed toward a particular task. Our thinking mind directs our body in the world, made of extended substance. ${ }^{47}$ For Heidegger, the opposite is the case. The human mind is only a 'thinking thing' after we have attended to, and reflected on, the performance of a particular task as care. Heidegger argues that we experience the world in the carestructure first, and only later can this experience be explained in terms of the mindful, calculative manipulation of an outside world made of extended substance. Descartes understands the world singly in terms of objective presence, and not the threefold modality of being (presence-at-hand, readiness-to-hand, and Dasein) outline in Being and Time. Descartes' tacit acceptance of substance ontology passes over the everydayness of human being.

If Heidegger's argument is accepted, that Descartes' thinking subject cannot encapsulate the basic experience of human being, we must extend the argument made by the embodied phenomenologists. Mind/body dualism is derivative of a more primary problem, the reduction of all things to the ontology of objective presence. Once this move is made, to interpret the things of the world only as substance, we pass over the care structure that encapsulates the way of being human. Yes, this move is in the philosophy

${ }^{47}$ This scheme is what Gilbert Ryle (1949) would famously call the 'doctrine of the ghost in the machine'. 
of Descartes, but it is found in many others as well. When we, like the phenomenologists cited in the previous chapter, argue that Cartesian dualism must be overcome, we miss the forest for the trees. The primary task is not rejecting an argument made only by Descartes; it is rejecting ontological doctrines that fail to see human being as Dasein, based in the time/spaces of care. ${ }^{48}$

By rejecting the knowing subject as the basis of human being-in-the-world, Heidegger reconsiders the basis of 'truth'. In Being and Time sec. 44, Heidegger establishes the commonality between the generally accepted definition of truth—"that which is in accordance with fact or reality" (OED) - with that found in the Western philosophical tradition, from Aristotle to Kant. ${ }^{49}$ Both the philosophical and commonplace versions of truth, Heidegger argues, overlook a more fundamental relationship, that between truth and Dasein. Heidegger calls this form of truth "aletheia", what the pre-Socratic Greeks understood to be the 'un-hiddenness' of beings. ${ }^{50}$ Things can be 'in accordance with fact or reality' and 'known' only after they have been disclosed to Dasein:

${ }^{48}$ Clearly social scientists opposing 'Cartesian dualism' do not only wish to discredit Descartes; they oppose cultural institutions which base practice on a strict divide between mental and bodily substance. My hope is that we can shed 'Cartesian dualism' from the sociological vocabulary, and simply refer to the 'mind/body problem', since the divide has much more to do with contemporary cultural organization than Descartes' work in the $17^{\text {th }}$ century.

${ }^{49}$ Heidegger finds this same treatment of truth in Plato's Republic in his "Plato's Doctrine of Truth" (1998), though the relationship between Being and Truth would occupy Heidegger throughout his career. We will return to the problem in each of the chapters to follow, as well as in the discussion of Heidegger's later work below.

${ }^{50}$ I take this translation from Guignon (1983). It is standard within English-speaking Heideggerian scholarship. 
in knowing, Da-sein gains a new perspective of being toward the world always already discovered in Da-sein. This new possibility of being can be independently developed. It can become a task, and as scientific knowledge can take over the guidance for beings-in-the-world. But knowing neither first creates a "commercium" of the subject with the world, nor does this commercium originate from an effect of the world on a subject. Knowing is a mode of Da-sein which is founded in being-inthe-world (Heidegger, 1996, p. 58).

Heidegger's argument is this: in order for something to be known, it must first come into its own being as-knowable-for-Dasein. This happens in the relevance-structure of care. "When truth is seen not as correspondence to reality, but as an unfolding event through which reality first emerges, the whole idea of representation comes to appear as a sideeffect of a more basic "self-manifestation" of Being." (Guignon, 1990b, p. 106) Only once disclosed to Dasein are inner-worldly beings' truth-status up for grabs. ${ }^{51}$

Both Schatzki (2005) and Guignon (1983) argue that aletheia is deeply tied to Heidegger's perspective on Being-with-others (Heidegger uses the German Mitsein or Mitdasein; Schatzki uses 'sociality'). If it is accepted that the basic form of truth is derived from our engagement in the world as care, then similar modes of care will have similar modes of relevance (and disclosures) of beings. We encounter truth in a similar mode as do other humans because they care-for-the-world in the same manner. "Beingtogether with another means: encountering one another in the surrounding world with which we are jointly concerned" (Heidegger, 2011, p. 20). Moreover, the being of others is inherently disclosed as we comport ourselves in the world through care. Sitting at a table with settings for others, for example, even if unoccupied by them, discloses the

51 My use of 'up for grabs' for truth-status is inspired by Ian Hacking's "'Style' for Historians and Philosophers" (1992). 
world as shared with others in a routine task. ${ }^{52}$ In the what-for structure of care, we find the would-be time/spaces of other persons.

One of the most common instances of the disclosure of others in routine care comes in the use of language. Others are made present linguistically in various ways. Obviously, others beings-in-the-world are made present when we speak with them.

To speak about is to talk about something, in such a way that we are talking about is co-revealed as we speak. As a theoretical act, knowing is only one and not even an original manner of revealing. To 'talk about' something means to say something about something. But talk says that something is speaking to and with others. And, as a mode of speech, talking about something with others is to talk things out and to and to say what is on one's mind. Oneself, that is, a given being-in-the-world, is corevealed as one speaks. These two equally primordial characteristics show speaking to be a fundamental way of being-together-with-each-other-inthe-world (Heidegger, 2011, p. 21). ${ }^{53}$

In this manner, to speak with another both discloses (at least): a) the beings or states of affairs under discussion, and b) those bringing beings to light in the conversation. Speech takes place against the backdrop of language, understood past simply logical

\footnotetext{
${ }^{52}$ We find an unusually clear statement - for Heidegger - on the co-disclosure of others and the world in The Concept of Time (2011, p. 18): "As 'being-in-the-world', Dasein is at the same time being together with others. The aim here is not to assert that mostly we do not exist as single persons, that others are also present. Rather, 'being together with others' implies an ontological characteristic of Dasein that is equiprimordial with 'beingin-the-world'. This aspect of Dasein persists even if no one else is actually spoken to or perceived. Since 'being together with others' is equiprimordial with the fundamental characteristic of Dasein as 'being-in-the-world', we must be able to read off of the ordinary 'being there' of others (with whom we live in the world) from the manner in which we encounter the surrounding world[.]"

${ }^{53}$ Here, 'to say what is on one's mind' should be taken not as 'the external representation of the subjective states in a conscious mind in a body'. Rather 'mind' should be taken as 'one's attention', as a mode of concern or directedness. For an similarly expanded version of mind in cognitive science and the philosophy of mind, see Thompson's Mind in Life: Biology, Phenomenology and the Sciences of Mind (2007).
} 
structures and etymology, but more widely as a ready-to-hand system of naming and telling, giving a relevance-structure to extra-discursive forms of life. ${ }^{54}$

The truth-language relationship can be best described using the example of chemistry. Chemistry, as an organized scientific enterprise and thought style, ${ }^{55}$ requires beings be disclosed within a strict rubric of objective-presence, in terms of atoms, elements and compounds (and so on). This disclosure is made possible through a specialized discourse, both in terms of the concepts used to describe the activity of entities so disclosed, and for individual chemists to pursue chemistry as a materially equipped laboratory-based enterprise. This frame of reference must be accepted a priori

54 This sentence requires clarification on two points. First, I use 'forms of life' to intentionally draw comparison between Heidegger and the later Wittgenstein. The linkages are an extremely common topic of philosophical comparison: for an extended discussion, see Guignon (1990a).

Secondly, my use of 'discourse' will surely lead many to make a connection with the archaeological work of Michel Foucault. While there are many important similarities between the two, there are notable differences. Foucault's interest is in how discursive formations order the world, how particular statements can be 'within the true' at a particular historical moment. For Heidegger, language has a more fundamental relationship to existence. In its non-thematic use (i.e. everyday talk versus academic inquiry) language is ready-to-hand like any other tool. It is related to the primary mode of disclosedness of beings which then can be analyzed as per Foucault's discursive formation as 'within the true', through linguistic anthropology or the like. For Heidegger naming is one of the essential structures of human Being, whereas for Foucault the basis of (objectively present) human being is discursively produced. The difference is rooted in Foucault's nominalism versus Heidegger's existentialism. When the later Heidegger turns to the anthropological organization of modern society, rather than as party to the fundamental structures of human existence, the two perspectives on naming coalesce.

${ }^{55}$ I borrow 'thought style' from Ludwik Fleck's Genesis and Development of a Scientific Fact, "the entirety of intellectual preparedness or readiness for one particular way of seeing and acting and no other." (1979, p. 64) Thought styles are resident within thought collectives, "a community of persons mutually exchanging ideas or maintaining intellectual interaction, we will find by implication that it also provides the special "carrier" for the historical development of any field of thought, as well as for the given stock of knowledge and level of culture." (1979, p. 39) 
in order for chemistry to be pursued and communicated through research networks. Here, language or discourse extends past what chemists explicitly write, to their materially equipped somatic practices, either through paper tools or experimentally, as per the what-for instrumentality described in Heidegger's fundamental ontology. ${ }^{56}$

A sticking point: Heidegger maintains that this understanding of truth was held by the presocratic Greeks. What proof do we have that this is the case? My answer: little. But, following William James' "radical empiricism", I think the question can be solved (at least, shown to be trivial to our goals) pragmatically. ${ }^{57}$ We have little proof that the pre-Socratics saw truth in light of the self-disclosedness of beings. But, we can accept Heidegger's understanding of truth in this way so long as it allows us to connect various parts of our experience—or the experience of disability—in novel ways, while retaining the explanatory potential of previous formulations. In the chapters that follow, I argue that Heidegger's aletheia helps us discuss the experience and cultural distribution of disability more effectively than the generally accepted (OED) definition of truth. This is the same tactic pursued by Guignon, in Heidegger and the Problem of Knowledge.

Whether or not this etymological association is accepted, the point that Heidegger is making is important. He wants us to see that "truth" in the sense of propositional sense is possible only against a background of "truth" in the sense of an "opening" or "clearing" of the intelligible world which arises from Dasein's logos and is deposited in the public language of a historical people (1983, pp. 199-200).

\footnotetext{
${ }^{56}$ I take 'paper tools' from historian of science Ursula Klein (2001). Her prototypical example is the chemical formulas used by Jakobus Berzelius (1779-1848), which allowed $19^{\text {th }}$ century chemists to map the chemical reaction in a uniform way.

57 James develops this doctrine most effectively in Pragmatism (1978), though it also serves as his philosophy of science underpinning his magnum opus, the Principles of Psychology (1918).
} 
This pragmatic reading is not, of course, going to follow the spirit of Being and Time. To connect philosophical reflection to practical problems would infuriate Heidegger, as it would reduce genuine thinking to a human resources problem, reducing Man—and for Heidegger, Dasein surely is male - to a governable object, part of what he would later call the "standing reserve" in the "Question Concerning Technology" (1993d). So, while I do not wish to describe disabled personhood in solely 'objectively present terminology, I think an expanded description can make those lives better. Heidegger would not agree - and that is just fine.

\section{The "Letter on Humanism"}

In Being and Time, Heidegger's critique of the ontology of objective presence is directed at the western philosophical tradition (to Descartes and Kant most explicitly). In the next section of this chapter, I want to examine Heidegger's critique of his French phenomenological contemporaries in the "Letter on Humanism" (1993a). This will serve to both distinguish his approach from the phenomenological ontological vector presented in the previous section, and provide a bridge between his earlier and later works, where science, technology and the body are discussed directly, rather than as a mere consequence of Being and Time's fundamental ontology.

In the "Letter on Humanism" (1993a) Heidegger contrasts his analysis of Dasein with the phenomenology of Jean-Paul Sartre and his French contemporaries. There, 
Heidegger argues Sartre's existentialism roots human freedom in man's [sic] subjectivity. The history of subjectivity, Heidegger maintains, is in fact the history of humanism. This tradition fails to account for Being of mankind because it reduces him to a rational animal - a mixture of animal body with thoughtful rationality that considers an objectively present world outside of itself - and cannot account for the Being of Dasein as care.

Humanism is opposed because it does not set the humanitas of man high enough. Of course, the essential worth of man does not consist in his being the substance of beings, as the "Subject" among them, so that as the tyrant of Being he may deign to release the beingness of beings into an all too loudly bruited "objectivity" (1993a, p. 251).

Here Heidegger extends his critique of Descartes and the ontology of objective presence found in Being and Time to the humanist project writ large. In the "Letter", Heidegger traces the history of humanism from the early roman period to Sartre's Marxist existentialism.

However different these forms of humanism may be in purpose and in principle, in the mode and means of their respective realizations, and in the form of their teaching, they nonetheless all agree in this, that the humanitas of homo humanus is determined with an already established interpretation of nature, history, world, and the gound of the world, that is, of beings as a whole. (1993a, p. 225)

Whereas in Being and Time, Heidegger makes little reference to contemporary philosophy (past the correspondence between Dilthey and Count Yorck von Wartenburg), the "Letter" extends the critique of objective presence from the formulation of world to man's place within it. 
So Heidegger's "Letter" represents a rebuff of his French phenomenological contemporaries. What does any of this mean for the sociology of disability? This: Heidegger's critique of humanism translates into a critique of subjectivity in the social sciences. I contend that the subject-object relationship permeates each of the ontological vectors discussed in the previous chapter, in one way or another. The social model treats disability as an objectively present condition keeping impaired subjects from living decent lives. The Foucauldian perspective engages the subject-object problem differently, proposing that the management of subjectivites has produced a variety of disabled personhoods throughout history. Restated: disability has been objectively presented differently in various historical periods. The French phenomenological tradition, delivered to disability studies by way of Merleau-Ponty, proposes that the embodied experience of being unites the subject and the object in one. As Merleau-Ponty would later argue in the "Working Notes" to the Visible and the Invisible (1968), his analysis of embodied being did not go far enough in eschewing the trappings of subjectivity, because it began in the consciousness-object distinction. Finally, ActorNetwork theories of disablement suggest that subjectivity is itself an organized achievement—an enacted, network object. They do not thematize how human beings establish meaning at all, either 'subjectively' or otherwise. The actor-network does not ask: what does it mean for humans as actor networks to understand them as such (or otherwise)? In short: none of these four vectors deal with the problems of the ontological 
difference, or transcend the understanding of world as objectively present environment which Heidegger attributes to the humanist tradition. ${ }^{58}$

While each of the four ontological vectors treat subjectivity and objectivity differently, they do not understand the being of Dasein to be Being-in-the-world, as care. If the "Letter on Humanism" is to be summarized in a single sentence, it should be this: subjectivity cannot account for the Being of Human beings. Subjectivity is an abstraction of a deeper, more meaningful, relation of man to his world. ${ }^{59}$ Or, as stated in Heidegger's turgid prose:

${ }^{58}$ Actor-Network Theorists would contest this claim. Their objection would look like this: theirs is not a humanist tradition because they do take a humanist subject as their point of departure. Their approach is 'post-human', through and through. However, in their reaction to humanist social science, they only engage with the manner in which objectively present entities cohere. Actor-Network Theory's "second empiricism" (Latour, 2004) investigates the objectively present twice. It does not understand the world as 'being-in-the-world', and thus extends the ontology of the objectively present, albeit in new and novel ways. For this reason, we can say that the specters of humanism haunt the actor-network enterprise. It does not, as Heidegger would say, "treat the humanitas of homo humanus high enough". I attempt a theoretical rapprochement of the two traditions in the final chapter of this dissertation, by comparing Heidegger's technological 'enframing' with Michel Callon's economic sociology and its associated concept of 'framing'. For a similar attempt, see Pickering (2005; 2009).

${ }^{59}$ I use androcentric terminology intentionally to further emphasize that Heidegger's formulation of Dasein does not offer much opportunity to distinguish between male and female, or men's or women's, existence. Aho (2007) argues that gender should be accounted for in terms of the world into which Dasein is thrown, into the kind of beings that we can be in public life, and when accounted for as such does not require a reconsideration of Heidegger's fundamental ontology. Restated: the basic structures of Dasein make experience possible, and gendered experience is dependent on this more fundamental constitution. We are humans first, and then gendered or sexed humans after this primordial disclosure of the world to Dasein. This is plausible, but never pursued in Heidegger sufficiently. Regardless, I worry that each of the examples in English translations I have seen use male-dominated professional instances to make their case (as in Being and Time's carpenter). Whereas Dasein could possibly be pre-gendered or presexed, Heidegger's demonstrative extensions tell another story. 
Man is never first and foremost a man on the hither side of the world, as a "subject", whether this is taken as "I" or "We". Nor is he ever simply a mere subject which is always simultaneously related to objects, so that his essence lies in the subject-object relation. Rather, before all this, man in his essence ek-sistent into the openness of Being, into the open region that lights the "between" within which a "relation" of subject to object can "be." (Heidegger, 1993a, p. 229)

Stated in either a single sentence or an entire paragraph, Heidegger's point is that the ontology of objective presence is present within the humanist tradition. My argument is that each of the four ontological vectors presented in the past chapter implicitly accept the same ontology underlying that tradition. Again, following James, my approach is pragmatic. Heidegger's work provides an alternate ontology to the humanist one, and this alternate ontology allows us to go places that the humanist understanding of world, space, time, and truth cannot. My pragmatic penchant for Heidegger's philosophy will find its justification when we go to these places - in the chapters that follow. It will not be found here. In what follows, I sketch out Heidegger's later reflections on technology, science, and somatic being, to prepare the reader for these proofs to follow.

\section{"The Question Concerning Technology"}

"The question concerning technology" (1993d) is one of Heidegger's most frequently cited essays. ${ }^{60}$ This is for a number of reasons. First, the essay is unique in

\footnotetext{
${ }^{60}$ In a metric that Heidegger would surely despise for reasons we shall she below, the essay nets 2,669 citations on scholar.google.com (accessed 29 January, 2014).
} 
that Heidegger retreats from his usual level of abstraction. ${ }^{61}$ Secondly, the essay is relatively self-contained, and one can — though I do not—read it outside of Heidegger's greater philosophical project. In this way, the piece is deceptively simple. In opposition to the self-contained approach, I read it against the project of Being and Time, discussed above.

Building on his earlier formulation of truth as disclosedness in Being and Time, Heidegger argues in "The Question" that the essence of technology does not lie in a particular technology, or 'the technological' at all. ${ }^{62}$ Rather, technology's essence lies in the frame of reference in which objects - and eventually persons - are drawn within the technological age. Heidegger argues that the essence is found in poiesis, or bringingforth, understood both in terms of natural growth and productive crafts. ${ }^{63}$

What has the essence of technology to do with revealing? The answer: everything. For every bringing-forth is grounded in revealing. [...] Technology is therefore no mere means. Technology is a way of revealing. If we give heed to this, then another whole realm for the essence of technology will open itself up for us. It is the realm of revealing, i.e. of truth (1993d, p. 318).

61 This is note wholly true: "The Origin of the Work of Art" shares this move to the concrete, albeit to a lesser extent. I discuss the "Origin" in further detail, in chapter four.

62 From "The Question": "the essence of technology is by no means anything technological. Thus, we shall never experience our relationship to the essence of technology so long as we merely represent and pursue the technological, put up with it, or evade it." (Heidegger, 1993d, p. 311)

63 "Through bringing-forth the growing of things of nature as well as whatever is completed through the crafts and the arts come at any given time to their appearance. [...] Bringing-forth brings out of concealment into unconcealment. [...] This coming rests and moves freely within what we call revealing. The Greeks have the word aletheia for revealing. The Romans translate this with veritas. We say "truth" and usually understand it as correctness of representation.” (1993d, pp. 317-318) 
In my discussion of aletheia as presented in Being and Time, I suggested that 'knowing' was a process grounded in the more fundamental structures of care. In the technology essay, Heidegger argues that the kinds of knowing disclosed in the everydayness of care are not unitary. They are multiple. There are multiple ways in which things can be known, and these multiple ways are rival. They crowd each other out. The bringingforth found in the technological mode of revealing is one that comes at the expense of other potential avenues.

Rational ordering and measurement are, Heidegger maintains, endemic to the technological age, and come at the expense of other ways of understanding and acting. The mode of human being in the technological age that crowds others out is called the "standing reserve". Just as modern technology presents a mode of relations in which objects are ordered, human beings are disclosed as orderable for modern technology. This 'flattening down' of human being to the objectively present-as a resource to be distributed, governed and augmented — is what Heidegger refers to as the 'enframing'. The essence of technology is found when human being is enframed as the standing reserve, and that which makes humans human is kept out of the equation. "The rule of enframing threatens man with the possibility that it could be denied to him to enter a more original revealing and hence to experience the call of a more primal truth" (p. 333).

At this point, most Heidegger scholars argue that Heidegger is not an antitechnology Luddite. Dreyfus (1993a; 2004), for example, argues that Heidegger is at once more pessimistic and more optimistic than this. Since Heidegger is interested not in 
technological objects, but rather in the technological mode of being, he is not inherently opposed to particular technologies. Rather, he is opposed to the understanding of existence reduced to calculability and measure in the name of efficiency, where these technologies are now used. There is hope in that we can gain a free relationship to technology when we understand the historicity of the technological mode of being, and engage in practices marginal to calculation, such as "friendship, backpacking in the wilderness, and drinking the local wine with friends" (Dreyfus, 1993a, p. 105). Heidegger is more pessimistic than the Luddite, Dreyfus argues, because of how difficult this task will be. It is not about merely mastering technologies that master us, but an entire ontological shift.

Is Dreyfus' reading plausible? Perhaps. In terms of Heidegger's personal practice, however, it falls short. Heidegger never used a typewriter, and spent most of his time sitting in Todtnauberg in a tiny hut, cut off from the modern world. His personal 'free relation to technology' was decidedly 'technology free'. A pragmatic question: do Heidegger's technological practices matter much to the sociology of disability? Not much. What is important is this: in the age of technology, efficiency and calculability are the fundamental forms of disclosure in which beings, human or otherwise, are understood. In terms of physical or mental difference, this means that disability is understood as an economic problem, costing the economy large sums of money per year. ${ }^{64}$ It is a problem in need of a technical solution. The strategic ordering, the sole disclosure of physical or mental difference as an economic tragedy—-these are the reasons

\footnotetext{
64 The Mental Health Commission of Canada (2013b), for example, suggests that mental health problems or mental illnesses cost the Canadian economy $\$ 50$ billion in 2012 .
} 
why reading Heidegger's work is important for the sociology of disability. I return to these issues in chapter six. As we have established the basics of Heidegger's philosophy of technology, we can turn to his similar approaches to modern science and the body.

\section{Science and 'the mathematical'}

Heidegger's perspectives on science are at once unitary and distinct following Being and Time. In Being and Time, Heidegger thinks about science existentially, rather than historically. He asks what makes the existence of scientific objects distinct from human existence. This difference, of course, is the ontological difference. Human beings question their own being, they exist in a world that matters to them, and the times, spaces, and truth processes ontologically closest to us are found in care. Scientific beings are disclosed differently, in the mathematical projection of nature. Heidegger takes classical physics as an example:

Only "in light of" a nature thus projected can something like a fact be found and taken in as a point of departure for an experiment defined and regulated in terms of this project. The "founding" of "factual science" was possible only because the researchers [who established the basis of classical physics, Newton primarily-T.A.] understood that there are in principle no "bare facts." What is decisive about the mathematical project of nature is again not primarily the mathematical element as such, but the fact that this project discloses a priori (Italics in original. Heidegger, 1996, p. 331).

In Heidegger's existential phase, science pursues ontic investigations (OED: of or relating to entities and the facts about them), whereas his work is ontological, investigating the nature of human Being-in-the-world. Physics requires that the world be 
disclosed in terms of objective presence so that it can be interrogated causally or statistically, in terms of matter, energy, motion, and so on. This kind of world is different from the human world, the life-world of Dasein.

In "The Age of the World Picture" (original lecture delivered 1938, German printing 1954, my copy translated 1977b), Heidegger pursues how 'the mathematical' develops throughout the Western philosophical and scientific tradition. Looking back to the Greeks, Heidegger argues that the mathematical is more than simply the numerical, rather it is found in the disclosure of beings: ${ }^{65}$

ta mathemata means for the Greeks that which man knows in advance in his observation of whatever is and in his intercourse with things: the corporeality of bodies, the vegetable character of plants, the animality of animals, the humanness of man. [...]

Only because numbers represent, as it were, the most striking of alwaysalready-knowns, and thus offer the most familiar instance of the mathematical. (1977b, p. 119)

The numerical is not the only manifestation of the mathematical—just the most common. What is particular about modern science is the object sphere in which nature is enframed.

Medieval science, Heidegger argues, constituted a different sort of empirical investigation than experiment. In Medieval science, "to know is not to search out; rather

65 If we were looking for a similarity with Foucault's 'discursive formation' in Heidegger, I would argue it comes closest with Heidegger's understanding of ta mathemata, grounded in a research tradition, rather than in Heidegger's understanding of discourse. 
it is to understand rightly the authoritative Word and the authorities proclaiming it." Experiment, and the grounding of nature in the physical object sphere, is missing. ${ }^{66}$

Experiment begins with the laying down of law as a basis. To set up an experiment means to represent or conceive the conditions under which a specific series of motions can be made susceptible of being followed in its necessary progression, i.e., of being controlled in advance by calculation. [...] Such representing in and through which the experiment begins is no random imagining. This is why Newton said, hypothesis non fingo, "the bases that are laid down are not arbitrarily invented (1977b, p. 119).

In citing Heidegger's scientific reflections, I am not terribly interested in the transition from medieval to modern science. ${ }^{67}$ I am interested, however, in how the modern technical age brings forth human experience under a rubric of objective presence, in the disclosure of entities as such. This occurs both in scientific experiment and technical practice, as seen in "The Question Concerning Technology." In what follows, I seek to find sites of ontological differentiation, instances where the experience of disability is made objectively present. This extends past the science of modern physics. In chapter five I apply Heidegger's reflections on science to physical therapy. This will require an explication of Heidegger's views on the body, found in the Zollikon Seminars (translated into English 2001b).

${ }^{66}$ Heidegger does not, however, provide any discussion of the materiality of experiment. His account comes close to the hagiographies against which the early Science and Technology Studies (STS) literature sought to critique (see Latour, 1988). Though this discussion is lacking, I do not think it is incommensurate with Heidegger's analysis. Andrew Pickering's work $(2005 ; 2009)$ is a particularly good example of an attempt to reconcile Heidegger's philosophy with recent STS contributions.

${ }^{67}$ If I were, I would be sure to cite Shapin and Schaffer's classic Leviathan and the Air Pump (1985). Hobbes, Boyle and the experimental life are noticeably absent from Heidegger's scientific history. 


\section{Heidegger and the Body}

In Being and Nothingness, Jean-Paul Sartre criticized Heidegger for his neglect of the body in Being and Time, spending barely six lines on the body. In the Zollikon Seminars Heidegger responded negatively to Sartre, and ignored his French contemporaries. ${ }^{68}$ Heidegger's line in the Zollikon Seminars looks something like this: the bodily being of Dasein is indeed something that can be investigated phenomenologically, but the somatic examinations found in French circles were mistaken. They failed to come to terms with the problem of the ontological difference. They treated the experience of the body as 'subjective' and the lived body as an objectively present thing. This was, in part, due to the inadequacy of the French language, which lacks the sophistication of the German linguistic division between Leib (lived body) and Körper (material body). ${ }^{69}$ In contrast to the French inability to understand Dasein's bodily way of being, Heidegger proposes an ontology of Dasein's "bodying forth".

One could understand the living body as a corporeal thing. I am seated here at the table, and fill this space as enclosed by my epidermis. But then we are not speaking about my being-here, but only about the presence of the corporeal thing in this place. Perhaps one comes closer to the phenomenon of the body by distinguishing between the different limits of a corporeal thing [Körper]

\footnotetext{
${ }^{68}$ Medard Boss, a Swiss phenomenological psychoanalyst, organized the seminars, held from 1959 to 1969. In the seminars, Heidegger engaged in annual three-hour discussions, twice a week for two weeks, with Boss' psychiatric and medical contemporaries, at his home in Zollikon.

69 "One often hears the objection that there is something wrong with the distinction between a corporeal thing and a body. This is raised, for instance, because the French have no word whatsoever for the body, but only a term for a corporeal thing, namely, le corps. But what does this mean? It means that in this area the French are influenced only from the Latin corpus. This is to say that it is very difficult to see the real problem of the phenomenology of the body." (Heidegger, 2001b, p. 89)
} 
and those of the body [Leib]. [...] The bodying forth [Leiben] of the body is determined by the way of my being. The bodying forth of the body, therefore, is a way of Da-sein's being (Heidegger, 2001b, pp. 85-86).

In the seminars, Heidegger argues that understanding the body as an objectively present, corporeal thing fails to account for bodying-forth. This (ontological) difference divides the phenomenological investigations of the body from the sciences. Because of their linguistic and ultimately Cartesian heritage, 'the French' failed to adequately understand the nature and disclosure of bodily Being.

Secondary literature on the seminars is far too generous to Heidegger's treatment of French somatic phenomenology. Aho $(2005$, p. 1) notes how Heidegger's discussion is "frustrating", because he does not engage with Merleau-Ponty directly, rather he lumps Merleau-Ponty in with the rest of the French phenomenologists dismissed in "The Letter on Humanism". Ciocan (2008) and Askay (1999) frame the potential-but-sadlyunrealized exchange between Merleau-Ponty and Heidegger as one of 'equiprimordiality' (to borrow Heidegger's grotesque phrase); for Merleau-Ponty, the body and the disclosure of world are ontologically co-constitutive, whereas for Heidegger, existence must be disclosed in order for bodily being to be at all. Ciocan and Askay only examine the content of the would-be-debate, and not the pretentious, ugly and arrogant way that Heidegger dismisses "the French", rhetorically lumped as a whole. While I have a personal preference for Heidegger's 'bodying-forth' over Mearleau-Ponty's 'embodiment' or 'flesh', there are a great deal of similarities between his potential position on the body and that provided by Mearleau-Ponty. There are differences as 
well- though Heidegger produces neither in his callous retort. The best synthesis is found in Drew Leder's The Absent Body (1990).

\section{Embodied Times and Spaces since Heidegger}

I want to conclude this chapter by reviewing some phenomenological work since Heidegger. I will end the chapter with a discussion of phenomenology in Leder's The Absent Body (1990) then Michael Schillmeier's Rethinking Dis/Ability: Bodies, Senses, Things (2010). I find Leder's work particularly compelling for two reasons. First, The Absent Body helps bring Heidegger 'up to date', since Sein und Zeit's publication in 1927. Heidegger's phenomenology is applied in tandem with other philosophers to the problem of embodied everyday life. ${ }^{70}$ Here we find both 'continental' phenomenologists (Edmund Husserl and Maurice Merleau-Ponty) and 'analytic' philosophers, like Gilbert Ryle and Michael Polanyi. ${ }^{71}$ In sum, Leder helps weave Heidegger's insights with those of his successors, while broadening the territories of phenomenological analysis. This is the first compelling reason to read The Absent Body. Secondly, Leder provides an extremely novel reading of Descartes, which is quite different than those found in embodied phenomenology or in Heidegger's writings. Leder reads Descartes as a protophenomenologist, who makes use of some aspects of embodied being, but misses

\footnotetext{
${ }^{70}$ I say Heidegger's 'phenomenology' because Leder cites only Being and Time (1927) and What is Called Thinking? (first German printing 1954), neglecting later works.

${ }^{71}$ Here I by no means want to reify a divide in another discipline. Each of these traditions, if they are indeed distinct traditions, influences the sociological work to take place below. For the philosophically inclined: both Drew Leder and Evan Thompson show the benefit of ignoring such a distinction.
} 
others. ${ }^{72}$ In attending to the body only when it emerges in disruption, we get the illusion that we are immaterial minds in an alien body. By expanding the scope of how we experience our bodies, we get a richer understanding of embodied sensation and activity.

Whereas the Zollikon Seminars represent Heidegger's pigheaded attempt to disregard his French phenomenological contemporaries, The Absent Body takes up Heidegger's missed opportunity. Leder takes Heidegger's insights on handy versus objectively present tools, and matches them with Michael Polanyi's attendant to-from structure, implicit in our use of instruments. From "Knowing and Being" (in the essay collection of the same name, 1969):

The rower pulling an oar feels the resistance of the water; when using a paper-knife we feel the blade cutting the pages. The actual impact of the tool on the palm and fingers is unspecifiable in the same sense in which the muscular acts composing a skilful performance are unspecifiable; we are aware of them in the tool's action on its object, that is, in the comprehensive entity into which we integrate them.

$[\ldots]$

The more fully we master the use of an instrument, the more precisely and discriminately we will localize at the farther end of it the stimuli impinging on our body while grasping and handling the instrument (1969, pp. 127-128).

For Leder, this same to-from relationship applies to our bodies. In attending to a particular somatic task, we body-forth without explicitly thematizing the somatic

72 A succinct statement from the Introduction: "It is often assumed that this dualist [Cartesian] paradigm is shaped by ontological commitments at the expense of attending to lived experience. However, I will argue against this view. I will suggest that experience plays a crucial role in encouraging and supporting Cartesian dualism. [...] I am not in sympathy with this dualist portrayal. Yet I seek a phenomenological account of why Cartesian-style dualism would be so persuasive. Only in such a way can we break its conceptual hegemony, while simultaneously reclaiming its experiental truths." (1990, p. 3) 
components that make that task possible. Attention shifts from the body to the object of attention. This is called "background disappearance".

Bodily regions can disappear because they are not the origin of our sensorimotor engagements but because they are grounded in the corporal gestalt: that is, they are for the moment relegated to a supportive role, involved in irrelevant movement, or simply put out of play $(1990$, p. 26).

Heidegger's famous hammering example, for instance, does not require us to think about the arm directing and hand clutching the hammer. We attend from the arm, from the hand to the hammer, and from the hammer to the nail. They are experienced as absent in their handy, equipmental use, receding from direct attention.

Leder, while drawing extensively from the Mearleau-Ponty, is critical of the French philosopher's initial restriction to perception, passing over interoception: ${ }^{73}$ "by virtue of his emphasis on the "higher" ecstatic regions of the body, the Merleau-Pontian subject still bears a distant resemblance to its Cartesian predecessor, never fully fleshed out with bone and guts" (p. 36). By extending philosophical analysis to internal bodily processes and the viscera, Leder demonstrates how bodily components recede from attention during everyday tasks. To borrow Heidegger's terminology, in moments of care, the ready-to-hand bodily organs recede from attention in service of an everyday task. In moments of breakdown, or bodies become present-at-hand in "dys-appearance" (as distinguished from the body that disappears when ready-to-hand). The viscera are a

\footnotetext{
${ }^{73}$ Interoceptive, adjective: "relating to stimuli produced within an organism, esp. in the gut or other visceral organs" (OED). As noted above, Merleau-Ponty was reflexively critical of the limitations of perception in his later work.
} 
prime example of how, when everything is running smoothly, bodily organs disappear in everyday life.

The difference between organic disappearance - as disclosed in care - and dysappearance, as the disclosure of body as objectively present in somatic breakdown, is key to Leder's re-reading of Descartes. Leder argues that Descartes' proto-phenomenological understanding of the body only addresses the body in terms of dysfunction and not the tofrom relationship found in everyday bodying forth. It is not mind-body dualism in itself that represents the fundamental problem with Descartes' reading of embodiment: it is a more primary problem where the body is only experienced in terms of error or failure.

Descartes is struck by the ability of bodily disturbances not only to give rise to error, but also to cripple the very search for truth. [...] The soul can only detach itself from a certain sort of body, one calm, healthy and awake. [...] This Cartesian epistemology might be termed a motivated misreading. That is, his conclusions are motivated by lived experience, albeit as misread into a reified ontology. The body draws his philosophical attention particularly at times of perceptual error, injury, madness, disease, fatigue, excessive passion, and pain. For it is at such times that the body opacifies, clearly exhibiting its role in experience. This skew of attention then encourages a dualist reading (1990, p. 132).

Unlike the phenomenologists outlined in the previous chapter, Leder reads Cartesian dualism pragmatically: it has purchase because it relies on somatic experience. Mind/body dualism is derivative of this partial reading of bodily experience. The mind is inhibited in times of bodily disappearance. However, once we expand the franchise of what counts as somatic experience- to both disappearance and dysappearence, and to where mind recedes in moments of organic activity and vice versa-the 
phenomenological alternative addresses the range of embodied experience more effectively.

Michael Schillmeier's Rethinking Disability (2010) matches both of The Absent Body's strengths, highlighted at the beginning of this section. First, Schillmeier's ActorNetwork theory-inspired empirical philosophy reads a broad range of thinkers-both philosophers and sociologists - in his empirical accounts of embodiment. Following Goffman, he aims to locate disability as it is routinely produced in the interaction order. Secondly, his work helps bring Heidegger up to date, albeit with the sociology of disability, as opposed to Leder's concern with the phenomenology of the body. While Leder brings Heidegger into contact with more recent thinkers of the embodiedphenomenological vector outlined in the past chapter, Schillmeier aims to produce a more robust ontological politics of disablement by following (sometimes) disabled people around. He engages each of the ontological vectors discussed earlier-with the notable exception of the social model, against which he mounts a chapter-length critique.

While I draw from Rethinking Disability extensively throughout this dissertation, here I want to address his application of Heidegger's ontology. This takes place most frequently in chapter five, "Time-spaces of In/dependence and Dis/ability" (previously published as Schillmeier, 2008). There, Schillmeier makes use of Heidegger's ontology of care to outline how disability, ability, dependence and independence are events, outcomes of particular socio-material configurations, disclosed within the interaction order. The location of Schillmeier's ethnography was the North of England, where he 
documented the emergence of blindness as an event in material exchange. The emergence of visual disability is located in the ontological difference, when the time-spaces of care are disrupted, and blindness is made objectively present. Thus, "[by] rethinking in/dependence and dis/ability as events, we enter the question of how in/dependence and dis/ability comes into being" $(2010$, p. 168$){ }^{74}$

In chapter one, we saw that the social model is deeply interested in 'the material', in terms of both the material obstacles facing disabled persons and the material existence of disabled persons under capitalism. Schillmeier takes up this task, but does so following the ANT tradition, asking how human-nonhuman assemblages produce disability within mundane economic interaction. He examines how blindness is enacted during currency exchange practices:

To become blind money, different temporal and spatial arrangements have to be mobilized. Blind money practices slow down and lengthen money transactions; blind people plan, select and earmark the money in use. [... It] is the assemblage of human and non-human configurations enacting blind times and spaces that disrupt, question, and alter the presence of visually enacted times and spaces. [...] Such a clash of different regimes of time and space disables when no translation, no mediation is possible.

\footnotetext{
${ }^{74}$ While I find Schillmeier's excessive punctuation, seen in this passage, to be slightly irritating, it is hardly fitting for anyone using Heidegger's archaic German terminology to criticize him. In both cases, the thinkers are trying to depart from their respective traditions linguistically. Schillmeier wants to highlight the contingent nature of disability, as emergent within a particular somatic-social-material assemblage, distinct from the ontological basis of the social model. Heidegger, as we have seen above, wants to pose the question of Being, one that has been either assumed or ignored throughout the Western philosophical tradition. Hence: "Dasein". In his recently retranslated Contributions to Philosophy (2012) Heidegger even avoided the word "Sein", using "Seyn" instead because of its philosophical heritage (English translators use "Being" and "Beyng", respectively). So long as it is understood that I want to pursue a materially situated, practice-based ontology of disability, I feel it unnecessary to follow this complicating linguistic departure.
} 
Through failed money transactions, blind people become disabled (2010, p. 159).

While 'the material' is not absent from the phenomenological vectors discussed to this point, ${ }^{75}$ Schillmeier's empirical philosophy brings materiality to the forefront. He is similar to Oliver in this sense. But he does so in line with the ontological difference.

Schillmeier puts Heidegger's phenomenological concepts to work explicitly when discussing the navigation of the local grocery store by informant 'Mary'. When past 'hows', such as the memorized time-spaces of the grocery store, allow smooth navigation through the aisles, Mary's blindness is ready-to-hand. "Memorized spaces" and "sensed spaces" coalesce:

When Mary finds and identifies the product she intends to buy, the different spaces (memorized and sensed spaces) are simultaneously present and appear as one space where multiple spaces are synchronizing. Memorized and sensed spaces translate into each other; they are timespace, so to speak (2010, p. 161).

When these times and spaces diverge, blindness as obstructed care is disclosed. Restated, Schillmeier reads Mary's experience alongside Heidegger's fundamental ontological project in Being and Time, arguing that blindness as an emergent mode of being is disclosed to the self and others when ready-to-hand relationships dissolve.

Following the concept of time-space, readiness-to-hand relations are primordial to present hand relationships [, as seen in Heidegger's Sein und

${ }^{75}$ To remind the reader: Heidegger, Ryle and Leder (by extension) have all discussed the 'equipped nature' of embodied being. Merleau-Ponty provides some discussion of the material in the Phenomenology of Perception, particularly "the blind man's stick." (1962, p. 165) 
Zeit]. [...] Ready-to-hand with others, the event of time-space makes beings become visible (present) to others and invisible (non-present) to themselves (2010, p. 167).

Schillmeier argues that to understand blindness as an event, we need to do numerous things. First, we must pursue it within the interaction order. We need to follow people around. Secondly, we need to take the material seriously. Sociologies like the social model annihilate times and places that make disability what it is-even when they are avowedly opposed to material barriers - because they only see the material as barrier. They keep already disabled people from doing things. This, as Haraway would argue, performs the "god trick". It hypostatizes disability as an abstract condition, produced by equally abstract capitalism. By following disabled persons in their everydayness, Schillmeier gives us a more human account of what disability is, and allows us to ask what types of humans are presumed and produced in the organization of economic markets. ${ }^{76}$ Both are considered in light of the ontological difference.

Both Leder and Schillmeier bring Heidegger's work to new places. Leder takes up the challenge that Heidegger declined in the Zollikon seminars: taking his French contemporaries seriously. Schillmeier expands the project empirically, asking how the ontological difference manifests in sensory expectations underlying routine economic exchange. If Heidegger had his way, he would strike his name from both projects. Leder's work, he would argue, does not go far enough to combat the dangers of subjectivity, just like the French thinkers he rejected in his "Letter". Here we need look

\footnotetext{
${ }^{76}$ A theme to which we will return in the final chapter of this dissertation, where I look to how economic agency is distributed within the Ontario Disability Support Program Employment Supports.
} 
no further than his use of Polanyi's epistemology. It tries to give objectively present, causal explanations for human knowing and being. It accepts psychology at face value. He would similarly reject the empirical and pragmatic nature of Schillmeier's project. Verifying philosophical reflection with observed phenomena is, he would argue, anathema to true meditative thinking and questioning, "the piety of thought" (Heidegger, 1993d, p. 341). It is positivism, pure and simple. The very basis of disability studies, improving the lot of those marginalized from everyday life, is the very stuff of modern technology. It is a base, engineering problem posed by the sociology of the inauthentic and inhuman public.

Obviously I do not share Heidegger's potential grumpiness towards disability studies as an academic enterprise, and the present use of his philosophical insights in this task. Even if he would oppose the connection, I find that the ontological difference has allowed me to make sense of my own experience of disability more effectively than the other ontological vectors in isolation. Following James' pragmatism, that's good enough for me. As noted before: Heidegger would disagree with this, and that is just fine. With this objection noted, let's recapitulate before moving on to the application of Heidegger's work to follow.

\section{Putting the Ontological Politics of Disablement to Work}

I began this chapter with a discussion of the divide between Heidegger's earlier and later work. The early Heidegger is concerned with the uniquely human way of being. 
Here the ontological difference manifests in care, in how we involve ourselves in the meaningful world into which human beings are thrown. The pre-reflective mode of human being, he argues, is something that has evaded Western philosophy since Plato. From the early Heidegger, I argue, we have a basic schema for what it means to be a person in the world (in this case a disabled person in the world). This is the early Heidegger's main theoretical contribution, making sense of Dasein, the ontological difference, and the times and spaces of care.

Heidegger's later work also presents some theoretical meat. There, he distinguishes his project from those of his French interpreters, and their humanist leaning. His tone, we saw, was unnecessarily dismissive and paternal. This was repeated in the ten years of Zollikon Seminars. He missed a key opportunity here, thankfully taken up by Drew Leder. Even though his reply was callous, it gave us some insights on bodyingforth in the world, and how we should distinguish an analysis of bodily Dasein from that of the instrumentally minded sciences. Here is Heidegger's key methodological contribution to this dissertation: pointing to key sites where ontological differentiation takes place. The doctor's office, the psychological laboratory, the economist's curvethese are places where the times and spaces of human conduct are translated into objectively present categories for technical analysis. In these spaces, the basic mode of being human is translated into a merely present technical object. By looking to places where disability is made objectively present, we can ask new questions. How could this translation take place more effectively? What sorts of embodiments are translatable more effectively than others? Finally, and most importantly, what is lost in translation in the 
first place? What role does disability studies play in the translation of disability, and in transformative loss? Taken as a whole, Heidegger's work offers us both theoretical and methodological principles that let us ask questions about disablement in novel ways.

The pivotal question: why should we believe any of this? Why read Heidegger at all? The answer that I provided was a pragmatic one. By thinking with Heidegger, we can talk about the experience of disability in new ways - while retaining the explanatory potential of previous frameworks (the four ontological vectors introduced in the previous chapter). While this justification can only be fully proven in doing the disability studies found in the following chapters, I showed how both Drew Leder and Michael Schillmeier employed Heidegger's work. Leder used Heidegger to ask crucial questions about the experience of the body. Schillmeier asked how disability is made up in everyday sociomaterial life. I take my pragmatic inspiration from these two authors' lead. Heidegger would not share this inspiration, and for the third and final time: that is just fine.

In the following chapter, I explore the ontological differentiation taking place in the Canadian federal income tax regime. I ask how disabled embodiment is shaped by the bureaucratic 'form of life' (to use a terrible Wittgenstein-inspired pun), in how medical verification organizes bodies and how they could be organized otherwise. This will be the first of four places where I put Heidegger's ontological difference to work. 


\section{Chapter Three: Being-Towards-Death and Taxes}

\section{Introduction}

Since the formulation of the social model of disability, disability studies has been interested in capitalism. The Politics of Disablement devotes an entire chapter to "Disability and the Rise of Capitalism" (chapter three). There, Oliver cites Marx, Weber, and Gramsci to establish how disability has been historically shaped by labour market formations. As we saw in the first chapter of this dissertation, Oliver's ideology of individualism is an historical product of alienating wage labour. I have no doubt that the history of disability is, in part, a history of labour market exclusion. But there is more to it than that. This chapter argues that equally important component is inclusion in the accumulation processes. ${ }^{77}$ As Henri-Jacques Stiker writes in his History of Disability:

To initiate an analysis of the social workings of disability by way of its integration is a method more critical, even more militant, than to address it in terms of exclusion. The motives and factors that lead to rejection, even when such rejection is hidden and subtle, are fairly obvious to the attentive. Integration passes more unnoticed (Stiker, 1999, p. 15).

Is my approach more militant than Oliver's? I doubt it. He wants to end disability by ending capitalism. He, as a Marxist, is critical of the exclusionary labour process, both historically and presently. Below I focus on another crucial aspect of capitalist state formation: taxation. In this chapter, I want to examine how the contemporary Canadian 77 And again in chapter six below, where I thematize the inclusion of disabled person
within the labour process through provincial policy intervention. 
federal income tax regime shapes disability into an objectively present entity. ${ }^{78}$ I read the criteria to count as a disabled Canadian as site of ontological differentiation, bringing the everydayness of disability into a manageable object. My argument unfolds as follows. I begin by briefly outlining disability tax policy in Canada. I then move to a close reading of the T2201 Disability Tax Credit Certificate (2011b). Here I interrogate how disability as experienced in day-to-day life is shaped into a coherent, objectively present, govern-able object in the form's qualification criteria. In the T2201 form, disability is understood as 'marked' or 'significant' restriction, and not as a mode of care. To demonstrate how some disorders are more effectively objectively presentable to the T2201, I then contrast my degenerative muscle disorder with a far less visible musculoskeletal condition, fibromyalgia. In terms of ontological differentiation, muscular dystrophy is much easier to read as disability in the T2201 rubric in comparison to fibromyalgia.

'Disability policy' in Canada is far from unified. Both federal and provincial governments are implicated in the government of disability (for an historical examination of disability policy in Canada, see Puttee, 2002). Here I do not want to deal with 'Canadian disability policy' as a whole, as the term is largely a misnomer. ${ }^{79}$ Instead, I want to examine disability tax policy, a federal responsibility, for which the $T 2201$ form is a point of entry. ${ }^{80}$ Briefly, successful application allows access to the Disability Tax

\footnotetext{
${ }^{78}$ For a critical account of tax policy as disability policy in Canada, see Prince (2001).

79 As health care is a provincial responsibility, its administration differs from place to place. Of course, disability is not a purely 'health' issue, as the T2201 demonstrates.

${ }^{80}$ Here I analyze the 2011 version of the T2201 form. The 2013 version is exactly the same in terms of criteria, though the disability amount has increased slightly. For a
} 
Credit, "a non refundable tax credit used to reduce income tax payable on [the successful applicant's] income tax and benefit return" (meaning it reduces an amount owed but is not paid out, currently valued at $\$ 7697$, Canada, 2011b). As such, the credit's value is only useful to offset owed taxes on earnings. Further, those who qualify are able to participate in targeted savings schemes, such as the Registered Disability Savings Plan, which supplement personal savings with a government contribution "intended to help parents and others save for the long term financial security of a person who has severe and prolonged impairment in physical or mental functions." ${ }^{81}$ What I want to examine here is the manner in which the lived experience of disability is made objectively present in order to qualify for these and similar income supports. Here we will engage the ontological difference. To do so, we turn to the qualification criteria.

\section{The T2201 Disability Tax Credit Certificate}

The $T 2201$ form aims to assess the extent to which individuals are restricted by their impairments in daily living. The form contains a general information section, completed by the applicant, and another aimed at describing the effects of impairment on the applicant-as-patient, completed by a relevant medical professional. My interest here is restricted to the second section. There, 'basic activities of daily living' are divided into seven facets: 'speaking', 'hearing', 'walking', 'elimination (bowel or bladder functions)', 'feeding', 'dressing' and 'performing the mental functions necessary for everyday life'

sociological analysis of the 2000 version, far less 'task-based' than the 2011 form examined here, see Titchkosky's "Governing Embodiment" (2003)

${ }^{81}$ For this and other similar programs, see Canada (2011a). 
(Canada, 2011b). Vision is included in a separate category from these activities, but assessed on identical criteria. Applicants qualify as disabled for tax purposes should they be 'markedly restricted' in one of these areas, or 'significantly restricted' in two or more aspects, such that they amount to marked restriction. 'Marked restriction' is defined (for practitioners) as follows:

all or substantially all the time, and even with therapy (other than lifesustaining therapy to support a vital function) and the use of appropriate devices and medication, either:

- your patient is unable to perform at least one of the basic activities of daily living (see above [paragraph]); or

- it takes an inordinate amount of time to perform at least one of the basic activities of daily living (Canada, 2011b).

The above is prefaced with the following qualification: "whether completing this form for a child or an adult, assess your patient relative to someone of a similar chronological age who does not have the marked or significant restriction" (Canada, 2011b). Here, practitioners are required not only to isolate the daily practices performed — or unable to be performed - by their patients, but also to relate that restriction to its absence in 'normal' subjects (for a comprehensive critique of similar 'normalization discourse', see Moser, 2000).

The dual-function of practitioners becomes clear when we examine the individual criteria for marked restrictions more closely. Below, I take 'walking' as an example (though any of the other categories could be similarly examined). There, several nonexhaustive examples are provided as instances of marked restriction in that faculty: 
- your patient must always rely on a wheelchair, even for short distances outside of the home.

- your patient can walk 100 meters (approximately one city block), but only by taking an inordinate amount of time.

- your patient experiences severe episodes of fatigue, ataxia, lack of coordination, and problems with balance. These episodes cause the patient to be incapacitated for several days at a time, in that he or she becomes unable to walk more than a few steps. Between episodes, your patient continues to experience the above symptoms, but to a lesser degree. Nevertheless, these symptoms cause him or her to require an inordinate amount of time to walk, all or substantially all of the time (Canada, 2011b).

In the above qualification, and especially in the second provided example, we see that the T2201 criteria seek to translate the daily tasks of living - here: walking — into objectively present terms that are taken to be representative of the relevant experience of impairment. In performing this translation, the practitioner must also make reference to an ideal competent subject in order to make evident the restriction facing the applicant. The T2201 qualification criteria require that the experience of disability be shaped into something countable, administrative, qualify-able - in short: objectively presentable. Both normal and disabled activities are characterized in objectively present terminology, with the difference between them labeled as 'marked', 'significant', or insignificant restriction (should the qualification fail). Up to this point, I have merely outlined the T2201 certificate. Next, we turn to the crucial question: what does Heidegger's phenomenology offer us in this case?

\section{Phenomenology and Bureaucracy}


There are several possible lines of phenomenological critique that could be applied to the T2201 case. First, following Merleau-Ponty's embodied phenomenology, one could argue that the form makes an arbitrary division between embodied subject and world, a division that does not align with the lived experience of intercorporeality. Secondly, one could argue that the $T 2201$ form is merely another instance of bureaucratic barriers oppressing the impaired, in line with Hughes' 'modern aesthetic of oppression', with its embedded norms of ability and competent subjectivity. My goals here are less ambitious. Clearly, any attempt to render disability objectively presentable comes with a price tag. These are the 'normal, natural troubles' encountered in accounting, discussed by Harold Garfinkel (1967). ${ }^{82}$ How could it be otherwise? Following Law and Singleton (2005), we can say disability is a 'messy object', which does not come in ready-made objectively-present packaging, that is made present through its management. In terms of phenomenological critique, then, I suggest the following: not all forms of organization are optimal when it comes to the management of disability. The T2201 form takes second-order descriptions of impairment to be representative of the experience of disability. Hence we have medical descriptions such as ataxia, ideal city blocks taken to be the basic measure of walking, and so on. The $T 2201$ form does not, however, measure routine tasks as routine tasks. It does not ask questions about the ability to navigate the grocery store, going to the bank, getting to the hardware store. If the subject cannot, where in the form do they indicate passages they cannot navigate at all? The form can analyze disability as present at hand, but it does not allow the applicant to indicate tasks of life that are 'out of hand', so to speak.

${ }^{82}$ I return to Garfinkel's accounting in chapter five, where I discuss how symptoms of muscular dystrophy are cultivated as symptoms in physiotherapy practice. 
To further focus on commerce: while the form does permit restriction to be noted in terms of the 'mental functions necessary for everyday life', it does not take calculative practices as a media-centered impairment. That is: it ignores the process in which unsafe currency_or other sociomaterial arrangements - can produce bad passages. It treats disability as a noun, and not as a verb: it focuses on the outcome, rather than the making of disability. This critique can be taken further. The form asks the doctor to make the experience of disability objectively present and compare it to the objectively present performance of non-disability, an example of what Titchkosky (2001) calls a "proof generating enterprise". Recall the caveat: "whether completing this form for a child or an adult, assess your patient relative to someone of a similar chronological age who does not have the marked or significant restriction" (Canada, 2011b). It does not, however, permit the admission of many situations faced singly by disabled persons. Dealing with the form itself can be taken as an example of this. How is it possible to compare the experience of an applicant to that of the non-applicant, in order to locate marked, significant or insignificant restriction? To recant an oft-cited trope: accessibility is more than simply architecture. While the T2201 criteria work quite well in some cases of physical disability_walking people can be easily compared to not walking people — it does not examine other processes of disablement so well. It does not ask questions about using the telephone, a computer, or discuss difficulties applicants have navigating modern bureaucratic passages. It is these and other similar processes that the $T 2201$ form should examine. 


\section{Fibromyalgia and Muscular Dystrophy}

Recall the temporality and spatiality of Dasein discussed in chapter two. In the T2201 Disability Tax Credit Certificate, we see how the time-spaces ontologically closest to Dasein are translated into objectively present, measurable time and space. This has particularly important connotations for conditions that are not permanent, visible and strictly physical. ${ }^{83}$ It is much easier to make these kinds of impairment objectively present than other conditions. To make my point, consider two contrasting disorders: muscular dystrophy and fibromyalgia. ${ }^{84}$ The times-spaces of muscular dystrophy are certain. In navigating the university, for example, a person with permanent muscle weakness knows which routes will yield barriers—stairs, inclines and the like—and those that will not (presuming, of course, that there are barrier-free courses available). So long as the university terrain is unaltered between visits, ready-to-hand routes mirror those of each previous care structure. As the condition is progressive, increased muscle weakness

${ }^{83}$ These are, coincidentally, the same sorts of conditions that formed the basis of the Union of the Physically Impaired Against Segregation, whose Fundamental Principles (1975) were discussed in chapter one, serving as basis for the social model's oppressionbased approach to disablement.

${ }^{84}$ From the Oxford English Dictionary: "Muscular Dystrophy. Noun. A hereditary condition marked by progressive weakening and wasting of the muscles." "Fibromyalgia. Noun. A chronic disorder characterized by widespread musculoskeletal pain, fatigue and tenderness in localized areas." López-Pousa et al. (2013) define fibromyalgia as "a syndrome that includes multiple symptoms such as pain, fatigue, sleep disorders, morning stiffness, loss of functional capacity, and mood alterations, as well as problems with cognition, memory and concentration. FM is a somatic syndrome that is more prevalent in women, and has been associated with a general decrease in quality of life, physical performance, and greater use of healthcare resources."

My diagnosis and experience of the former, (Becker's) muscular dystrophy, led to my application for the DTC via the T2201. Of course, there are many varieties of muscular dystrophy, many more severe than Becker's. I take this form as representative here, as it is the 'standpoint of the storyteller' (Frank, 2000). I admit that both my standpoint and my story would differ with a more severe form. 
will adjust this course and care-structure accordingly. The point remains: the times-andspaces of navigation with muscle disease are known, expected, and easily characterized within the 'restriction in walking' criteria as presented in the $T 2201$.

Contrasting fibromyalgia with muscular dystrophy demonstrates that the bureaucratic language of the $T 2201$ form accords 'marked' and 'significant' restriction to some conditions more effectively than others. In contrast to the constant time-spaces encountered in muscle weakness, fibromyalgia and other complex episodic disorders are marked by fluctuation and uncertainty. The consistency in the ready-to-hand nature of bodying-forth could not be more distinct than that of muscular dystrophy. The passages that are navigable in days of minor chronic pain are not traversable when it becomes excruciating, or when those diagnosed with the condition are unable to sleep, as 'sleeping' is not included as an 'aspect of daily life'. ${ }^{85}$ Being pain-free and rested are two requirements much farther 'upstream' than those presented in the T2201. One cannot walk around the university in an 'inordinate amount of time' when one cannot leave the house.

A second distinction between muscular dystrophy and fibromyalgia is found in Titchkosky's (2001) "proof generating enterprise", as in the clinical encounter where the T2201 form is presented and completed. Muscular dystrophy is verifiable via biopsy—in my case at age ten. It immediately discloses itself in numerous visible ways, in atrophied

${ }^{85}$ I would like to thank an audience member in a guest lecture delivered to Sociology 2035: Science, Technology and Society (Fall semester, 2013) for making this keen observation. 
muscles, skeletal deformations, and so on. Its static nature means that it can be immediately tested to verify marked or significant restriction: in my instance, a footstool was placed in the middle of the Carleton University Health Services examination room. My inability to climb it successfully was taken to represent my inability to navigate steps of similar height. ${ }^{86}$ It did not, in the opinion of the doctor, 'markedly restrict' me. But my inability to stand on one foot for a sufficient length of time easily translated into 'difficulty dressing.' Two 'significant restrictions' added up to 'marked restriction.' There you have it: I was disabled for tax purposes. The criteria in the Certificate are well suited to disorders of this type; muscular dystrophy is easily proven as disabling because of its stable, visible and verifiable existence. It is easily discussed, judged and administrated in terms of objectively present existence.

The "proof generating enterprise" for fibromyalgia is not as simple, for numerous reasons. First, consider the T2201's "Prolonged" requirement, "An impairment is prolonged if it has lasted, or is expected to last, for a continuous period of at least 12 months". ${ }^{87}$ The continuity of fibromyalgia and the continuity of muscular dystrophy could not be more different. My muscles will not improve (the opposite is the case, they will atrophy). Muscular dystrophy's impact on daily care closely aligns with the T2201's objectively present, annual timeframe. This is not the case in fibromyalgia. Because symptoms associated with the condition fluctuate in their intensity and bearing on

\footnotetext{
${ }^{86}$ This smacks of what Rabeharisoa and Callon (2004) call a 'proto instrument', such as the registers and recordings made by parents of children with muscular dystrophy, in the early history of the Association Française contre les Myopathies. We will return to the two sociologists in chapter 6, examining the distribution of economic agency and somatic ability in the Ontario Disability Support Program Employment Supports.

${ }^{87}$ Similar criteria is found in Ontario Disability Support Program Act (1997), section 4.1.
} 
everyday life, the condition often fails to meet this and similar temporal requirements (Lightman et al., 2009). Secondly, muscular dystrophy can be verified via biopsy. Fibromyalgia cannot. Lacking reliability of an assay, the functional diagnosis and existence of fibromyalgia is hotly contested in both medical and in lay circles (Oldfield, 2013). Those in seek of a diagnosis must frequently make use of online resources and peer support to locate those health care providers that will diagnose, accept and verify their disability as such (Crooks, 2006). Whereas the 'proof generating enterprise' for muscular dystrophy can be restricted to the examination room, the times and spaces of fibromyalgia are not so easily evaluated then translated into the T2201's objectively present understanding of what constitutes disablement. ${ }^{88}$

Finally, I want to address the gendered nature of the T2201's criteria using these two examples. ${ }^{89}$ The T2201 Disability Tax Credit Certificate presents a seemingly 'gender neutral' order of things. ${ }^{90}$ Both men and women, it seems, perform each of the 'seven aspects of daily living'; they walk places, make mental functions required for everyday life, go to the bathroom - and so on and so forth. But the criteria obliterate

88 Juuso et al. (2011) call instances like this the 'double burden' of living with fibromyalgia. They focus on women diagnosed with the disorder, though both men and women must struggle for verification in this example.

${ }^{89}$ I write this because fibromyalgia is disproportionately diagnosed in women, and Becker's muscular dystrophy almost exclusively in men.

${ }^{90}$ My use of 'gender' is not meant to imply a fundamental ontological division between biological sex and social gender. I could hardly do so with my rejection of the impairment/disability dichotomy found in the social model. It is not possible to have one and not the other. Rather, following both Butler (1993) and Garfinkel (1967), I understand 'sex' and 'gender' as both moral categories and regulatory ideals, 'performed' in the same sense as disability is organized, enacted and practiced in the interaction order, rather than as an immutable state of being. I return to Garfinkel's classic study of Agnes the 'practical methodologist' in chapter five, below. 
those tasks which are predominantly preformed by women. Housework or childcare, what Marxists like Hartsock (1983) call the 'production of use-values' in the home, are not evaluated by the $T 2201$ criteria. Disabled women, who outnumber disabled men in Canada (at $15.2 \%$ of the population, opposed to $13.4 \%$ respectively. Statistics Canada, 2007, Participation and Activity Limitation Survey 2006: Tables), predominantly perform tasks absent from the T2201 understanding of what daily life is. The point is simple, but extremely important: in their apparent gender neutrality, the tax form is gender biased, in its ignorance of the times and spaces where disability is put to work domestically. The T2201 Disability Tax Credit Certificate performs the same "god trick" discussed the first chapter of this dissertation. In the transition from daily existence to the objectively present disability categories enacted in the T2201, the socio-material times and spaces in which gendered care takes place are dismissed.

\section{Better Tax Policy As Better Disability Policy}

In the beginning of this chapter, I suggested that disability studies needs to address processes of inclusion, rather than simply its opposite. I examined some problems associated with including disability as an objectively present object. The same substance ontology that Heidegger seeks to overcome is put to work in the T2201 Disability Tax Credit Certificate. Now, obviously, there is no way of administering disability bureaucratically without it being shaped into an objectively present object. But—and this is crucial-there are different ways in which that shaping can occur. I conclude this chapter with three major changes drawing from my phenomenological analysis of the 
T2201 form. Bringing the form in line with the human way of being means taking both sides of the ontological difference into consideration. The first site of change relates to the categories to which experience is distributed. As noted in the previous section, the seven categories exclude the care predominantly performed by disabled women. By extending the categories to reflect the tasks necessary for everyday life — and including in those tasks domestic labour and childcare - the form can better represent the lived lives of disabled persons in Canada. This does not require a radical reconstruction of the form: both can be judged in the same objectively present language as 'walking', or the other aspects of daily life presented in the T2201's section B.

Secondly, and in line with the task- or process-based understanding of disability proposed above (and in this dissertation more widely), the form's duration requirement could be altered to better reflect the temporality of care, in terms of past 'hows' being applied to present tasks. Currently, the $T 2201$ takes an objectively present annual timeframe to represent the everydayness of disability. Again, I do not want to suggest we eliminate all vestiges of objectively present temporality from the form. But if the criteria provided a threshold of impairment—say four days per week—in which the impairment manifests and 'markedly' or 'significantly' inhibits daily tasks, then those diagnosed with episodic conditions are not at an immediate disadvantage when completing the form. Surely those medical professionals filling out the $T 2201$ and similar forms begin from the presumption that their patient is disabled, then ask: 'how can we make this work?' Such was the case in my 'proof generating enterprise.' The crucial point here is that 'qualified practitioners' should be able to pursue the same strategies for permanent and episodic 
conditions in that effort. By recasting disability as a form of care, as a lived process unfolding outside the confines of the examination room, the implicit bias towards permanent, visibly physical disabilities can be combated.

Finally, the form could be changed so that those whose being is disclosed as disabled can participate within that disclosure process. At the moment, the formation of the disabled person is black boxed. They enter their doctor's office with medical problems and twelve pieces of paper, ${ }^{91}$ and they come out disabled in potentia, the results depending on the Canada Revenue Agency's assessment of their situation. At no point do their own understandings of daily existence as disabled persons see print. Reforming the criteria to highlight disabling processes presents the opportunity for disabled persons to provide their own accounts of those processes. This provides more than nominal inclusion in the verification process. It provides valuable information about the modes of care where disability is (potentially) experienced as marked or significant restriction. This provides valuable policy information, both in terms of future categories that could be included within the T2201 rubric, and about the forms disablement takes in Canadian society. As it stands, the certificate is a band-aid solution. The T2201 Disability Tax Credit provides financial support to those who are disadvantaged in their daily lives because of their disabilities. It does little to address the conditions that constitute that disadvantage in the first place. Hearing the stories of disablement is the first step towards that path.

${ }^{91}$ The Disability Tax Credit Certificate numbers 12 pages total, with the first three addressed to the applicant, and the final nine reserved for the medical assessment of their impairment's impact on daily life. 


\section{Conclusion}

T2201 Disability Tax Credit Certificate is an imperfect assessment vehicle for an equally imperfect policy solution. In terms of phenomenological critique, however, it presents a good example of Heidegger's ontological difference, the difference between the experience-structure of being human and being categorized. ${ }^{92}$ In terms of disability, the T2201 takes the times and spaces in which disability is lived, and sanitizes them, to categories of marked, significant, or insignificant restriction. There are but seven (plus one, seeing) activities of daily living where disability manifests. Other persons do not figure into the criteria-stigma, discrimination, oppression are all absent from equation. Nor do the difficulties of dealing with bureaucracy figure into the form's rubric, a constant presence in the lives of disabled persons in Canada.

Rather than merely focus on the shortcomings of the assessment rubric (of which there are many) it provides us a chance to formulate Heidegger's analysis anew, with an eye to ontological differentiation, the process through which human experience is organized as - and translated into - an objectively present object. Here we have a methodological imperative, rather than a merely theoretical point. As the twin cases of fibromyalgia and muscular dystrophy demonstrated, some disorders are translated, or are 'objectively presentable', more easily than others. Visible, permanent, physical disabilities are better able to weather the $T 2201$ 's "proof generating enterprise" than other

\footnotetext{
${ }^{92}$ Perhaps "being, categorized" is more apt.
} 
forms of physical and mental difference. In sum, by focusing on ontological differentiation we can follow the translation of livelihood to marked and significant restriction, and ask how that process might be made more human.

A final question: will the T2201 Disability Tax Credit Certificate become a perfect instrument, once the three changes I proposed are implemented? Certainly not. I proposed these three small, incremental changes to the form because I feel they can make it slightly more human, without requiring a complete overhaul of the verification regime. They could be enacted tomorrow. That stated: the changes, like the form itself, are temporary solutions. They do not address the disproportionate number of disabled persons who live in poverty in Canada. They do not address the barriers that prevent disabled persons from paying income taxes in the first place. They only partially address the central role given to medical professionals throughout the verification process. Finally, and most importantly, they do not address the conditions that confine disability to problem bodies, and exclude problem socio-material environments where disability is experienced as 'marked' or 'significant' restriction. Until these problems are addressed, the form remains a flawed point of entry to a flawed system of disability governance. 


\section{Chapter Four: Boon Or Bust? Disability Aesthetics and The Thalidomide Memorial}

\section{Introduction}

Early sociological disability studies tended to focus on mainstream sociological topics: the structure of social life under capitalism, the organization of political and medical authority in advanced western societies, and the like. ${ }^{93}$ Recently, however, disability studies has extended its critical gaze to 'the aesthetic', both within artwork and in society more generally (Siebers, 2006; Hughes, 1999; Overboe, 1999). I want to demonstrate that Heidegger's ontological difference lets us address both of these concerns. In the past chapter I showed how bureaucratic forms demonstrate the ontological difference, in the way that they carve up everyday experience in an objectively present manner. Here I want to outline how Heidegger's aesthetics let us talk about the sensuous apprehension of disability in new and novel ways. These conversations can take place both in the art gallery, the traditional domain of aesthetics, and anywhere else in the lifeworld where disability is made meaningful. In each situation, I will argue, the aesthetic is a site of disability politics. This chapter unfolds as follows. I begin by reviewing some of the recent work in disability aesthetics. Here we find some new faces, Tobin Seibers and James Overboe, as well as an old one, Bill Hughes. Though they differ in their subject matter and theoretical perspectives, they each agree that disability politics extend to the sensuous apprehension of physical

\footnotetext{
${ }^{93}$ Best exemplified by the social model of disability.
} 
difference. Next, I add Heidegger's voice to the aesthetic discourse, and provide a review of his "The Origin of the Work of Art" (1993c) and "Art and Space" (1973). In both cases, Heidegger shows how beauty is disclosed in truth as aletheia. In the third, final, and largest section of this chapter I seek to apply Heidegger's aesthetics to a statue, "The Sick Child", unveiled at the August 31 $1^{\text {st }}, 2012$ apology by Grünenthal Group to the victims of Thalidomide (German: Contergan) ${ }^{94}$ In line with disability aesthetics, I argue that the sculpture has distinctly political connotations, in the aspects of the thalidomide tragedy brought forth, and those foregone. That is: the history of thalidomide, and the existence of thalidomide victims, is disclosed only as an historical tragedy rather than a contemporary disability issue. I end by asking how we might use Heidegger's aesthetics in future disability politics and research.

\section{Disability Aesthetics}

First I would like to engage some of the existing 'aesthetic' literature within the field of disability studies. Tobin Sieber's "Disability Aesthetics" (2006; 2010) has two goals. ${ }^{95}$ Siebers traces the representation of physical and mental deviance within the history of art, demonstrating the "rich and hidden role" that disability has played within

\footnotetext{
${ }^{94}$ I contacted Chemie Grünenthal in the hopes of including an image of the memorial in this paper. The company did not, however, see fit to provide me with one. This is regrettable. One wonders about the benefit of a memorial that is hidden from public view. A quick search on http://www.images.google.com will provide the reader with an image of the statue.

${ }^{95}$ See also Siebers (2010), for which the 2004 article of the same name serves as an introduction. There, Siebers argues that disability becomes an aesthetic in itself, crucial to the development in modern art. His work does not, however, engage with Heidegger's aesthetics. Here I seek only to supplement his ambitious project.
} 
Western art history (Siebers, 2006, p. 65). Secondly, Siebers seeks to establish a new disability aesthetics, one that challenges the guiding standards of beauty and rationality that have dominated the appreciation and production of works of art throughout the Western canon. He examines the textile sculptures of Judith Scott and the performance art of Paul McCarthy, two artists that epitomize the movement away from the historically dominant orthodoxy.

Disability aesthetics prizes physical and mental difference as a significant value in itself. It does not embrace an aesthetic taste that defines harmony, bodily integrity, and health as standards of beauty. Nor does it support the aversion to disability required by traditional conceptions of human or social perfection. [...] The idea of disability aesthetics affirms that disability operates both as a critical framework for questioning aesthetic presuppositions in the history of art and as a value in its own right important to future conceptions of what art is (Siebers, 2006, pp. 71-72).

Siebers does for aesthetics what disability studies has been trying to do for the academic investigation of disability more generally: problematize assumptions about 'normal' embodiment and behaviour, while challenging those cultural institutions that produce accounts of disability only 'as a problem' or 'as deviance' (For a comprehensive discussion of these and similar accounts, see Titchkosky, 2000). While historically art may have been such an institution, it need not be, as the cases of Scott and McCarthy illustrate.

In “'Difference in Itself”: Validating Disabled People's Lived Experience”, James Overboe (1999) touches on matters aesthetic, discussing his capacity as a technical advisor to a play, Creeps. In that role, Overboe advised a non-disabled actor, Tom McCamus, in his portrayal of a character with cerebral palsy. Borrowing from 
Baudrillard, Overboe argues that in Creeps, cerebral palsy becomes 'hyperreal', where "the concept of representation is no more, it's been replaced by simulation that is reality. [...] Tom's simulation had become "more real than 'real'" (1999, p. 19). By viewing McCamus' portrayal,

the audience with an able-bodied sensibility satisfies their 'desire' for the exotic 'disabled' by witnessing the simultaneous 'absolutely fake but real' spectacle of Tom's wild and savage disability and feel the heightened titillation of the exotic without risk. (Overboe, 1999, p. 20)

Just as exotic animals are simultaneously 'exemplified for' and 'purified of' their savagery in the zoo, Overboe argues Creeps allowed the audience the opportunity to engage disability as an object of desire, without any of the messy consequences associated with 'real' cerebral palsy. "Whenever the audience found his disability repugnant or grotesque they easily perceived Tom as having a non-disabled identity" (Overboe, 1999, p. 20). Here, Overboe demonstrates that disability aesthetics tells us a great deal about the audience's apprehension, as well as those so apprehended.

Bill Hughes $(1999 ; 2000)$ engages disability aesthetics in his analysis of the oppressive gaze of modernity, both within medicine and without. Drawing heavily on Foucault, Canguilhem, and the phenomenological tradition, Hughes seeks to highlight the ways in which vision— both individual and institutional—is disfiguring, and manifestly not a benign description of 'that which is' (Hughes, 1999, p. 156). Hughes hails both sociology and medicine as two modern institutions that participated in the formation, problematization, and management of 'the stranger'. These two institutions serve to constitute the strange through their partial vision. We find disabled people encountered in 
this role, as a problem to be managed through both assimilationist and exclusionary strategies (Hughes, 1999, p. 157).

In a subsequent paper, Hughes (2000) addresses medicine as an essential component of the modern 'will to order' the aesthetically undesirable. "To be or become invalid", Hughes argues, "is to be defined as flawed or in deficit in terms of the unforgiving tribunal of nature and necessity, normality and abnormality over which medicine presides." (Hughes, 2000, p. 558) This 'tribunal' has taken place at various sites historically, both in legal architecture (Hughes cites the UK Mental Deficiency Act of 1913 and the 1959 Mental Health Act) and state-medical practices, as found in the case of eugenics. Currently, he argues, the 'eugenic gaze' is to be found in the new genetics. It is here where he returns to aesthetics:

Increasingly, medical solutions to impairment can be interpreted as aesthetic solutions and genetics represents the promise of the final solution - the definitive elimination of prenatal congenital impairment and in consequence - as the causal logic of the medical model suggests - of disability itself (Hughes, 2000, p. 563).

Hughes does well to take 'the aesthetic' to the streets, as it were, and gives us a starting point to engage non-artistic forms of sensuous apprehension with Disability Studies' own - and equally partial-perspective. While I may not share Hughes' categorical attribution of a single gaze to medicine (we almost come to the point of a 'biomedical boogeyman', at once everywhere and nowhere) he admirably provides new terrain, and conceptual tools, for academic inquiry. 
It would be premature to give a definitive outline of what 'disability aesthetics' entails in its entirety. It is worthwhile to trace some general themes before moving on to the second section of this chapter. Here, I will suggest three. First, in each case, disability aesthetics asks us to move past the merely textual. Emphasis is shifted to the senses. In particular, the power and focus of 'the gaze' was interrogated (though only Hughes employed the term directly). In short, the gaze is not benign. No groupdramatic audiences, art historians, sociologists or medical practitioners-apprehends disability without a partial gaze. In each author, Siebers especially, we found that 'the aesthetic' was also a space in which disabled people can challenge this gaze. 'The aesthetic' is not a site free of contestation. Finally, disability aesthetics has a decidedly empirical component. While certainly informed by theory, it takes specific instances of sensuous apprehension as its object. Fitting the practical focus of disability studies more generally, to do disability aesthetics, we need to get our hands dirty.

\section{Heidegger on Art}

Heidegger's reformulation of aesthetic experience follows from his understanding of Dasein as being-in-the-world (as seen in chapter two). Mirroring Heidegger's fundamental ontology and the ontological difference, the times, spaces, and truths found in sensuous apprehension are not those of objective presence, at least not at first. Heidegger argues that any aesthetics that attempts to characterize 'the sensate' in a human-subject-perceiving-object framework does not accurately describe the experience

of artwork. Rather, the measure of artwork lies in its capacity to open up a world in 
which beings are encountered. It is a question of aletheia, of truth. "Art is then a becoming and happening of truth" (Italics in original, Heidegger, 1993c, p. 196).

Heidegger's most instructive example is a painting of peasant shoes by Van Gogh. The measure of this painting is not the ability to accurately represent a pair of shoes, as simple mimesis would demand. Rather, the greatness of Van Gogh's work lies in the manner in which it opens up a world for beings to be encountered in their being. Recall Paul Klee's famous trope: 'art does not reproduce the visible, it makes visible' (for a discussion of the two's aesthetics' similarities and differences, see Watson, 2006). What, then, is made visible in Van Gogh's painting?

A pair of peasant shoes and nothing more. And yet. From the dark opening of the worn insides of the toilsome tread of the worker stares forth. In the stiffly rugged heaviness of the shoes there is the accumulated tenacity of her slow trudge through the far-spreading and ever-uniform furrows of the field swept by a raw wind. On the leather lie the dampness and richness of the soil. Under the soles stretches the loneliness of the field-path as evening falls. In the shoes vibrates the silent call of the earth, its quiet gift of the ripening grain and its unexpected selfrefusal in the fallow desolation of the wintry field (Heidegger, 1993c, p. $159)$.

Simply, for Heidegger, art's essence is found in being-in-the-world. Art opens up a world in which truth, being, and beauty can be disclosed. Where once there were peasant shoes and nothing more, now we find beauty, "one way in which truth essentially occurs as unconcealment" (Heidegger, 1993c, p. 181).

In "The Origin of the Work of Art" we see Heidegger's anti-Cartesian exegesis of Being extended to the artistic work. Similarly, in "Art and Space" (1973) Heidegger 
extends his critique of Descartes' world, understood solely as extended substance or res extensia, to the case of sculpture. Building on the above work, he asks:

Once it is granted that art is the bringing-into-the-work of truth, and truth is the unconcealment of Being, then must not genuine space, namely what uncovers its authentic character, begin to hold sway in the work of graphic art? (Heidegger, 1973, p. 5)

For Heidegger, genuine space is not reducible to measureable quantity or absence, but rather should be understood in terms of 'nearness' and 'remoteness'. Things are near or remote not in spans of inches or centimeters, but to the extent that they are useful to us or weigh on our consciousness. Consider the following: during the time of Heidegger's later writing, the atomic bomb was the closest thing to everyone. The extinction of our species, previously unthinkable, became routine in day-to-day affairs. Or, to employ a disability studies example: the display in the grocery store that has had its location moved is the farthest from the visually impaired (for an excellent account, see Schillmeier, 2008). In both of these instances, proximity is ultimately reducible to care (widely defined, as in an object or manner of worry, concern, or attention) in the human way of being. As with the physics example, this is not to say that measurement in inches or centimeters is inaccurate, only that spaces of concern are ontologically prior to such measurement for Dasein. Spaces of utility and worry —as in the case of the store shelf and the atomic bomb - are closer to human experience than the measurement of distance between bodies of extended stuff. "Place is not located in a pre-given space, after the manner of physical-technological space. The latter unfolds itself only through the reigning of places of a region" (Emphasis mine. Heidegger, 1973, p. 6). 
Within sculpture, Heidegger's critique of subject-based aesthetics meets his fundamental ontological project, his exegesis of Dasein. The reconsideration of place is one crucial facet of his ontology. In the world opened in the encounter with artwork, new spaces are founded. Our concern is drawn from mundane beings to Being. In artwork, Dasein is access to beauty through truth as aletheia. Thus Heidegger's ultimate definition: "Sculpture: the embodiment of the truth of Being in its work of instituting places" (Heidegger, 1973, p. 8). Heidegger sees the sculpture both as a work of art, and as a site that discloses the type of space ontologically primary to human being, that of 'concern' or 'care'.

\section{"The Sick Child"}

In the first two sections of this chapter, I have engaged with 'the aesthetic' at a rather high level of abstraction. In the third and final section of this paper, I attempt to remedy this by taking a turn toward the empirical. Below, I briefly outline the history of thalidomide. I do so in order to situate the recent apology to the victims of the tragedy ${ }^{96}$ by the drug's initial manufacturer, Grünenthal group, on the $50^{\text {th }}$ anniversary of its removal from the German market. This apology was accompanied with the unveiling of a statue, named "The Sick Child". It is here where I seek to apply Heidegger's analysis to ask what is disclosed in the sculpture.

\footnotetext{
${ }^{96}$ I use the term 'tragedy' reluctantly: 'tragedy' seems to suggest that it is a part of past history, rather than a contemporary disability issue (as I argue in this chapter). Despite my reservations, however, it is the preferred term of use by many thalidomider groups (the term preferred by thalidomide victims). This takes precedence over my weariness.
} 
Much has been written on the case of thalidomide (see Annas \& Elias, 1999; Timmermans \& Leiter, 2000; Daemmrich, 2002; Franks et al., 2004; Melchert \& List, 2007). Here I only seek to provide a skeletal account, focusing mostly on the German experience. ${ }^{97}$ The basics, then: thalidomide was first synthesized in West Germany in 1954, and became a popular sedative worldwide. Initially, the drug was used primarily as a sedative-hypnotic and for the treatment of morning sickness (von Moos et al., 2003). The compound proved teratogenic, that is, resulted in significant embryonic malformation in children born to mothers taking the drug, within the first trimester especially. Working independently, Australian William McBride and German Widukind Lens first identified these properties, noting high rates of phocomelia ${ }^{98}$ in children of mothers who used thalidomide (McBride, 2004). It was not until 1961 (1962 in Canada) that the drug was removed from circulation due to its association with these effects (Franks et al., 2004, p. 1802). This affected an estimated 10000 children worldwide, forty percent of them in Germany (estimates vary due to terminated pregnancies. Daemmrich, 2002, p. 138).

In 1968, a criminal trial began, ending without a verdict 283 court days later. Daemmrich describes the events as follows:

97 This is not to say that the non-German experience is either unimportant or uninteresting. The United States, for instance, did not initially admit the drug to market. Only after the discovery of the drug's properties to treat leprosy and, later, forms of cancer (multiple myeloma) did the FDA grant approval for the drug's use, and only under extremely strict conditions (for a comprehensive examination, see Timmermans \& Leiter, 2000).

${ }^{98}$ From the OED: "a rare congenital deformity in which the hands or feet are attached close to the trunk, the limbs being grossly underdeveloped or absent." 
The Contergan trial began in January 1968 and ended three years later when prosecutors dropped the charges in exchange for Grünenthal's agreement to establish a fund for the children injured by Contergan. Created with an infusion of 100 million DM-half paid by the company and the other half by the federal government - the fund remains active to this day. As part of the settlement, the company and individual defendants were released from further criminal and civil liability (Daemmrich, 2002, p. 146).

Since the trial, Grünenthal has maintained that it employed all of the legally required means to test the safety of the drug before marketing the compound. That position has been maintained to this day, most recently articulated at the unveiling of the thalidomide memorial, by CEO Dr. Harald Stock. Found in German and translated into English on Grünenthal's Contergan information site ${ }^{99}$, the statement makes reference to the company's regret that the tragedy took place, and that it took 50 years for the company to engage victims 'person to person.' The company insists its legal and scientific innocence:

The thalidomide tragedy took place 50 years ago in a world completely different from today. The international scientific community, the pharmaceutical industry and governments, legislators and administrations have had to learn a lot from it. Throughout the world the tragedy influenced the development of new authorization procedures and legal frameworks, which seek to minimize the risks of new medicines for patients as much as possible.

Grünenthal has acted in accordance with the state of scientific knowledge and all industry standards for testing new drugs that were relevant and acknowledged in the 1950s and 1960s. We regret that the teratogenic

${ }^{99} \mathrm{http} / / \mathrm{www}$. contergan.grunenthal.info/. The thalidomide site is completely isolated from the company's main site, http://www.grunenthal.com/. In fact, as of time of writing, if one searches 'thalidomide' or 'contergan' on the main site, the only results pertain to a Grünenthal timeline. I must state that the translation is not mine, and I regret if I attribute statements to Stock that do not match the German original. 
potential of thalidomide could not be detected by the tests that we and others carried out before it was marketed.

$[\ldots]$

We wish that the thalidomide tragedy had never happened. It is an important part of our thinking and acting — today as in the future.

With this, the company unveiled a sculpture, named "The Sick Child", intended on demonstrating "development towards an ongoing dialogue" between victims and the company.

"The Sick Child" consists of two four-legged chairs, one containing a child with phocomelia, the other empty. The child's head is tilted back, crying out with an expression of agony. The empty chair's cushion is shaped with an imprint, suggesting the weight of an absent body. This is to illustrate the unborn victims of the drug, as suggested by a plaque on the bronze sculpture's base. It is here where I would like to apply both the disability and Heideggerian aesthetics discussed above.

We are now prepared to dwell on the crucial question: What is brought forth to being in "The Sick Child"? First, the sculpture presents the thalidomide victim as a child. This is the common perspective on the incident. Here we encounter a recurrent theme in the popular and medical literature on the subject: the thalidomide events constitute a tragedy, and it is a tragedy because it deformed (or worse) helpless children, their abnormal bodies taken as a testament to the potential dangers of pharmaceuticals. In this presentation, thalidomide becomes embodied in static time and space: it is restricted to the flesh of the phocomelus, and cast as a historical tragedy, something we can all wish "never happened". The statue is an apology to thalidomide babies, born no 
later than the 1960s and part of a sad, but immutable, history. This being is brought forth into a world we can do nothing about. We can do nothing but reflect, and be vigilant. This view, of course, is not the only way the story could be told. It is possible to change the lives of thalidomiders with money, with effort, with action. We can refuse to delegate the events to 'tragedy' and instead highlight the actual experiences, struggles and successes of thalidomiders existing in the world today. We can eschew the tired narrative of medical tragedy and instead reify contemporary disability politics. This fate is not cast in stone- - or in this case, in bronze.

My second critique stems from the depiction of the child. The child's cry of agony opens up a world in which disability is an object of sorrow. The child is suffering. That is, the child suffered in the past thalidomide tragedy. In her thorough analysis of Canadian policy documents discussed above, Titchkosky (2007) highlights the popular trope of disability as suffering. In this common view, disabled people do not suffer in any particular sociomaterial arrangement, from neglect, from poverty, from lack of accommodation. They simply suffer abstractly. For thalidomiders, as elsewhere, this is not the case. The primary source of suffering today comes from the significant resources thalidomiders require to live autonomously. An example: the yearly costs of the disability in the UK amount to an average $£ 41,174$, compared to the average government Health Grant of $£ 17,516$ (Trust, 2011). The president of Thalidomide UK, Freddie Astbury, responded to the memorial and Stock's accompanying statement accordingly:

There are a lot of people damaged by thalidomide struggling with health problems in the UK and around the world. [...] 
So we welcome the apology, but how far do they want to go? It's no good apologising if they won't open discussions on compensation. They've got to seriously consider financial compensation for these people. [...]

We just want people to live a comfortable life and that means [Grünenthal] have to pay for their mistake financially (BBC, 2012). ${ }^{100}$

The monument's suffering child eliminates the actual times-and-spaces of disablement (something that we can change) and replaces them with something essential and beyond human influence. Here, however, Grünenthal's narrative is disclosed: thalidomide babies suffered. Thalidomiders as disabled adults do not even enter the picture.

My third and final critique of the thalidomide memorial focuses on the theme of absence. Obviously, the empty chair next to the child is meant to signify the unborn victims of the thalidomide tragedy. This is one form of absence. Here I want to provide others. First, the statue's title- "The Sick Child"-implies the presence of 'illness', a pathological condition that exists in the absence of either the restoration of normal health, or death (excluding certain forms of chronic illness, of course). Disclosing the condition of thalidomiders as ill suggests that the problems they face are because they are sick (or died) in absence of a cure, of which we still have none. There is, of course, no strictly medical cure for the current effects of thalidomide. As such, German thalidomiders refused the illness narrative. Following the apology, Ilonka Sterbritz, a spokesperson for the German victims association, made this clear:

${ }^{100}$ Grünenthal and distributors of the drug have contributed to funds to compensate thalidomiders worldwide. This fact was highlighted in the company's August $31^{\text {st }}$ statement. However, as outlined by the Thalidomide Trust (op cit), these funds have fallen far short of the total costs of accommodation. Further, many of the costs are born by taxpayers, rather than by Grünenthal. 
Our members have given a very clear 'no' to this memorial sculpture with the title, 'The Sick Child'. A sickness can be cured, but defects caused by thalidomide cannot. Our arms and legs will not grow back (Sterbritz in Kämper, 2012).

This refusal is not strictly terminological. Thalidomiders demand alternate forms of absence be recognized in this story. They highlight both the fifty-year refusal for the company to engage them directly (I use 'engage' rather than 'apologize to' since Grünenthal did not admit liability for the defects) and the absence of material accommodation that Grünenthal could have provided them. Sterbritz makes this clear: thalidomiders do not anticipate a 'cure' for their 'illness'. In its absence, they demand recognition and accommodation.

Reflecting on the theme of absence also allows us to engage the politics of victimhood, and its relationship to the worldwide disabled people's movement. ${ }^{101}$ Thalidomiders, as the products of a human-made teratogen, often present themselves as victims of tragedy in order to elicit support or action on behalf of institutions, governments and the general public — as seen in their reaction to "The Sick Child". This sort of behaviour is opposed by Michael Oliver (1990) and other disability activists worldwide: promoting the so-called "individual tragedy model of disability" is anathema to the understanding and eventual elimination of the socio-material conditions that exclude disabled persons. In their public activities, thalidomiders straddle the border between the politics of tragedy and the politics of disability. Let's spend some time charting this terrain in greater detail.

\footnotetext{
${ }^{101}$ I would like to thank an anonymous reviewer of the original manuscript for raising this issue.
} 
Here I would like to highlight the Thalidomide Victims Association of Canada (TVAC), a group that participates in both forms of politics. In terms of tragedy, we find a characteristic statement on the association's website ${ }^{102}$, accompanied by images of a phocomelus and the drug's packaging:

\begin{abstract}
Remember us... KNOW YOUR MEDICATION
Thalidomide, a sedative prescribed to pregnant women to alleviate the symptoms associated with morning sickness, was marketed at the end of the 50's and early 60's, causing irreversible damage to fœtus development. More than a hundred Canadians were born with severe birth defects, forever affecting their quality of life. The Thalidomide Victims Association of Canada, in addition to working with its members, took on the mandate of educating the public on the devastating consequences of this medication that remains available for other medical purposes and promote caution and vigilance with the use of any teratogenic product.
\end{abstract}

Though the 'tragedy' described above is collective, rather than individual, it is presented as a cautionary tale: we must be careful, lest there be more victims of similar tragedies. It is also neutral to the social model's goals: besides stating that the TVAC 'works with its members,' any mention of the contemporary, materially situated lives of thalidomiders is noticeably absent. The TVAC is, however, also political in terms of disability politics. The group is member to the Council of Canadians with Disabilities, whose human rights approach to inclusion and barrier removal is directly influenced by the very same social model that seeks to discredit the tragedy model. ${ }^{103}$ Questions arise: are we at an impasse?

\footnotetext{
$102 \mathrm{http}: / /$ www.thalidomide.ca/

103 As seen in their recent submission to the Canadian Parliamentary Committee on Palliative and Compassionate care, found here: http://www.ccdonline.ca/en/humanrights/endoflife/euthanasia/Canadians-withdisabilities-we-are-not-dead-yet
} 
Are groups like the TVAC acting in a manner that is contradictory, hypocritical, or simply trying to have it both ways?

Following Heidegger's use of aletheia, my answer to these questions is no. In "On the Essence of Truth" (1993b), Heidegger elaborates on the notion of truth as disclosedness, as bringing beings out of concealment. Above, we found that art is one location in which truth is disclosed, where beings are encountered in their Being. Thus truth is not, in the first instance, the simple accordance of a statement with a state of affairs. It is, more fundamentally, the process of disclosure. For Heidegger, this process is one of self-disclosure. "The essence of truth reveals itself as freedom" (Heidegger, 1993b, p. 128). The question of freedom is fundamental to both disability politics and the politics of tragedy put forth by groups like the TVAC. Fundamentally, barriers faced by disabled persons are barriers to freedom. Exclusion is its opposite. In the case of the TVAC, the ability for thalidomiders to bring their own existence into the tragedy narrative on their own terms is also a question of freedom (decidedly not on Grünenthal's). Would disability activists have preferred that Randolph Warren, past TVAC president, had been silent at U.S. Food and Drug Administration and National Institutes of Health hearings on the return of thalidomide? He repeatedly asked: "what will you tell the thalidomide baby that will inevitably be born?" (Warren in Timmermans \& Leiter, 2000, p. 56) There is a clear difference from Warren's disclosure of the thalidomide events as tragedy and the version disclosed in "The Sick Child". The difference is freedom. Freedom is the basis of both disability politics and the politics of the TVAC. 


\section{Conclusion}

Throughout this dissertation, I have argued that the key to understanding Heidegger's philosophy is the concept of the 'ontological difference'. It is also crucial to my exegesis of the "Sick Child." In contrast to the Heideggerian viewpoint, emphasizing ontology as a way of being, one able to be changed, the statue presents the thalidomide events as immutable, the stuff of regrettable history we can "wish never happened." We can be thankful for the following: thalidomiders are active in contesting the version of the events presented in the 'past medical tragedy' narrative, criticizing the monument the moment it was unveiled. It is, I think, the role of academic disability scholars to support them in this role. I hope that this chapter contributes to their goals in some form or another.

A final question: what else can we do with Heidegger's aesthetics? Traditional activist disability scholarship has treated the aesthetic realm as a site of representationbased politics. Oliver, in The Politics of Disablement (1990, pp. 60-62), argues that disabled people in popular culture are depicted as either more or less than human. Shakespeare's "Cultural Representations of Disabled People” (1994), a critical response to Oliver's anti-idealist social model approach, treats the representation of disabled persons as a problem of Otherness. In both cases, the scene remains the same: the objective presence (or absence) of disabled persons in marginal situations. We saw in the first section of this paper that disability aesthetics are moving from the novel and the 
screen to sensuous apprehension more generally. Heidegger's aesthetics match this transition. By outlining 'the aesthetic' as a place where Being is disclosed, Heidegger too surpasses the politics of mere representation. The aesthetics of disability move from particular objects to the sights, sounds and smells of the life-world, where those objects are encountered as different in the first place. Heidegger's ontological difference helps us sketch out what it means to be in this kind of world. But, as Haraway's critique of the "god trick" makes clear, meaning does not come from the aether; meaning is made in particular times and places. To this, Heidegger adds that meaning is also accessed and made accessible in and through the senses. To do disability aesthetics means to make evident the kind of world where disability gains its meaning, to combat sensuous alienation. It is disability politics by other means, when mere representation will not do. 


\section{Chapter Five: Flawed By Dasein? Phenomenology, Ethnomethodology, and the Personal Experience of Physiotherapy}

\section{Introduction}

Critical physiotherapists are becoming increasingly weary of the dominant 'biomechanical' model underlying Western practice (Nichols \& Gibson, 2010; Shaw \& DeForge, 2012). In addition to advocating more holistic conceptions of life, embodiment and 'normal' function, reflexive critiques identify power asymmetries present in the therapeutic relationship (Eisenberg, 2012). Theoretical reflexivity has been accompanied with calls for 'emancipatory' practice, aimed at overcoming sociomaterial structures that inhibit persons' livelihoods, rather than merely attending to 'problem' bodies without the participation of clients so embodied (French \& Swain, 2004; Trede, 2012). One such structure is the hierarchical nature of the practitioner-client relationship, endemic to the biomechanical or biopsychosocial model (Eisenberg, 2012). Most of these calls have come, however, from physiotherapists themselves, rather than from those receiving their expertise. ${ }^{104}$ When clients are consulted, it is usually through statistical analyses of post hoc evaluations of 'patient' or 'client-centered rehabilitation', or through interviews performed by and for practitioners (see Cott, 2004; 2008). In both cases, authority remains exactly where it did before: the professional body. This chapter employs a hybrid phenomenological-ethnomethodological approach to argue that all models of physical therapy — be they 'emancipatory', 'client-centered', or 'biomechanical'—require

${ }^{104}$ Eisenberg (2012) is a notable exception. 
that bodies and their surrounding worlds become disclosed as objectively present. ${ }^{105}$ In applying the ontological difference to the experience of physiotherapy, I argue that both practitioners and clients participate in the process of medical-subject formation and the 'presencing' of the body-as-physiotherapeutic-object.

This chapter has two parts. In the first, I seek to show how ethnomethodology, as phenomenological social science, can be aligned with the existential ontology of Martin Heidegger. To do so, I turn to ethnomethodology's philosophical precursor, Husserl's phenomenology of the life-world. While Heidegger and subsequent Heideggerians critique Husserl for relying on an isolated epistemological subject as the basis for phenomenological philosophy (see Heidegger, 1982; Dreyfus, 1993b), I argue that there exists more common ground than this critique admits. In part two, I read Garfinkel's ethnomethodology as part of that enterprise, giving particular importance to his concept of 'accountability'. I provide a descriptive account of my own experience of physical therapy, one that gives further empirical support to the phenomenological concepts introduced in this dissertation. I conclude by providing some suggestions for further work in both client-centered physiotherapy and the sociology of disability, reviewing their central concepts of 'client specific rehabilitation' and 'medicalization', respectively.

\section{The Twin Phenomenologies of the Ontological Difference and the Life-world}

105 The reader will soon realize this 'hybrid' approach is actually quite unitary. Ethnomethodology is arguably the best empirical justification for phenomenological theory available to social science. 
Edmund Husserl (1859-1938) is often seen as the father of phenomenology. Heidegger served as Husserl's assistant at Freiburg, dedicating Being and Time to his friendship with his mentor. ${ }^{106}$ Husserl, who published six manuscripts in his lifetime and left a 40,000 page philosophical legacy, impacted many areas of philosophy, of which phenomenology is my concern here. His work is usually divided into three stages, though this threefold typology is contested (Mohanty, 1995). In the first, Husserl sought to establish the objective, logical foundations of logic and mathematics. In the second, Husserl developed the descriptive psychology of Brentano into a philosophical discipline, phenomenology. Finally, in the third stage, Husserl sought to explore the ontology of the life-world, extending phenomenology to the "social worlds of culture and history" (Smith \& Smith, 1995, p. 1). This ontology of the life-world is Husserl's closest point of connection with Heidegger and, via Alfred Schütz, is Husserl's primary influence on ethnomethodology.

Husserl's ontology sought to situate all human practical doings within the 'lifeworld', referring to the common world of meaning and reference, "the 'ground' of all praxis whether theoretical or extra theoretical" (Husserl, 1970, p. 143). In The Structures of the Life-world, Schütz and Luckmann (1973) highlight the "natural attitude" possessed by life-world residents, a practical stock of 'knowledge at hand' of the typical objects and

\footnotetext{
106 I do not wish to paint their relationship in a wholly roseate light. Heidegger succeeded Husserl's chair at Freiburg, the latter dismissed from his post due to his Jewish heritage. The historical record shows Heidegger's complicit role in that process, even having prevented Husserl from accessing the university's library following his removal from the chair.
} 
routines of day-to-day action. ${ }^{107}$ Husserl argues that both mundane and scientific activity take place within the life-world: both forms of activity require a practical know-how that serves as a frame of reference for sense making and problem-solving.

When science poses and answers questions, these are from the start, and hence from then on, questions resting upon the ground of, and addressed to, the elements of this pregiven world in which science and every other life-praxis is engaged (Husserl, 1970, p. 121).

Husserl argues that the self-evidence and objectivity of the sciences is one that is indebted to and formed within the pre-scientific life-world. Physical therapy, as I will argue below, is similarly organized, where practical meaning structures are enacted horizontally (between practitioners) and vertically (between practitioner and client). First, however, I seek an operative synthesis between Husserl's life-world and Heidegger's ontological difference.

Carr (1970) argues that Husserl's use of 'the life-world' is problematic precisely because it aligns these two very different regions of experience within the same term, the cultural and the pre-scientific (or pre-given, more generally). ${ }^{108}$ At times, Carr maintains, Husserl argues that the life-world exists prior to the discovery and formation of scientific knowledge. We make sense of the life-world through these forms of knowledge. At

107 Titchkosky and Michalko argue that in our societies, the 'natural attitude' towards disability is 'a problem in need of a solution' - most frequently 'solved' normalization. "Through the social act of normalisation [sic], disability becomes merely a problem that some people have. Ironically, being 'merely a problem' requires that disability never come to consciousness as anything but a problem" (2012, p. 133).

${ }^{108}$ Keen readers will note Carr is also the translator of the version of Husserl's Crisis used for this dissertation. In "Husserl's Problematic Concept of the Lifeworld" (1970), he examines Husserl's remarks on the 'life-world' both within that work, and in Husserl's wider oevre. 
others, the term describes those theories and the objects of knowledge cultivated by science, or within adjacent realms of experience. The life world is knowledge. It appears, at once, to be a sense-making scheme and a realm of immediate, shared experience we make sense of.

The question, then, is whether these notions can legitimately be combined under the title "life world," and if so, whether the resulting clarified conception can play the role in phenomenology that Husserl thought it should play (Carr, 1970, p. 332).

Implicit within Carr's 'question' are two arguments. First, that the ambiguity stems from Husserl's use of life-world (and not the constituent word 'World' or 'Welt'), and, secondly, that it is ultimately problematic for the concept to be ambiguous.

Luft (2004) suggests that there are (at least) two different approaches taken by Husserl in his attempt to sketch the basic meaning structures of human experience. One is the 'epistemological approach', whereby Husserl sketches the subjective conditions that make human experience possible. This is primarily found in his Ideas (1931). Second is the 'ontological approach', which examines how the world is encountered inter-subjectively (best found in the Crisis). Both, Husserl argues, are equally viable approaches to phenomenology, because each attends to the subject relatedness of all experience. ${ }^{109}$ However, the point at which the intersubjective world is taken into consideration varies. While they are not incompatable, Husserl himself did not

109 Keller (1999) argues that Husserl's methodological starting point was "private experience" (German: Erlebnis). Heidegger, in contrast, used Erfahrung. "This notion of experience lacks the connotation of private, subjective experience that is characteristic of the notion of Erlebnis" (1). 
demonstrate their compatibility. This has led to two different readings of Husserl. One can read him as a quasi-Platonist, whereby the intentional structures that make experience possible have an existence of their own. Alternatively, one can pursue the ontological reading, whereby the inter-subjective nature of the life-world assumes a primary role. Both are compatible because they each point to the subject-relatedness of human experience, though they have been pursued, to date, in opposite directions (as per the use of 'primary' in the previous sentence). Alfred Schütz, the chief phenomenological influence on Garfinkel's ethnomethodology, took the latter path in his attempt to align Husserl's phenomenology with the sociology of Max Weber. Dreyfus, on whom I rely extensively in chapter two, takes the former in his reading of Husserl.

Dreyfus (1993b) reads Husserl as a "methodological solipsist"110, defining his phenomenology as "the study of the intentional content remaining in the mind after the bracketing of the world, i.e., after the phenomenological reduction" (1993b, p. 19). ${ }^{111}$ Dreyfus makes two rhetorical maneuvers. First, he aligns Husserl's intentionality with that of John Searle, his frequent philosophical opponent. Thus, his target is the 'Husserl/Searle concept of intentionality.' Secondly, Dreyfus seeks to make a clear divide between this account of intentionality and that proposed by Heidegger. In doing so, he collapses multiple potential readings of Husserl into a single figure (again: aligned with Searle). The crux of his argument is this: both philosophers are epistemologists who causally irrupt 'the mental' into their accounts of human action. Action implies

${ }^{110}$ Dreyfus takes the term from Jerry Fodor, though Smith and Smith (1995) trace its origins to the work of Rudolph Carnap.

111 Here Dreyfus provides no citation to an actual work of Husserl's. 
intentionality — we intend when we pursue it—and intentionality implies mentality. The mental is 'inside' or subjective, and acts on other inside or 'outside' things. Human "action must be explained in terms of mental states with intentional content" (p. 19). Heidegger, by contrast, does not see intentionality as necessarily having any subjective or mental properties at all. Rather, human intentionality as directedness is first found in the times-and-spaces of care, which can then be described in terms of subjective mental states. In short, a singly epistemological understanding of intentionality passes over human being-in-the-world.

In contrast to Carr's question, which refers only to Husserl in isolation, I think the following needs to be asked instead: to what extent is Heidegger's philosophy, the philosophy of the ontological difference, compatible with Husserl's (and later Schütz and Luckman's) concept of the life-world? If Husserl's philosophy requires the presence of the rational epistemological subject (as Dreyfus' reading proposes), and Husserl's concept of the life-world is inalienable from the rest of his philosophy (as Luft argues), then the two are incompatible. On this point Heidegger is clear: the philosophy of the subject is one that passes over the basic structures of Dasein. It examines the human being in objectively present, rather than existential, terms. I do not think this is the case. That is, I do not feel as though there is any reason to accept why Dreyfus' overly epistemological reading of Husserl should take primacy over the ontological reading, to which Heidegger's ontological difference is decidedly more amenable. In this case, a rereading is still required. Instead of a subjective, internal 'stock of knowledge', there are the times-and-spaces of the care structure. Secondly, instead of 'intersubjectivity', we 
can read the life-world as the shared world of mitdasein. In sum, if we reconsider the 'world' component of the life-world alongside Heidegger's being-in-the-world, then the epistemological problem can be avoided, or at least shown to be derivative of the ontologically prior structures of care.

In Studies in Ethnomethodology (1967), Garfinkel demonstrates the existence of the life-world empirically, by showing the work that members do-not subjects, but members - to keep social order going in the face of engineered chaos. This could be described in terms of 'intersubjectivity', but it also can be described in terms of mitdasein, or the being-with-others described in Being and Time. The work that members perform could be described in terms of 'intentional action', but they also could be described in terms of care. This is how I read Garfinkel's work below. He does not make any recourse to 'the mental' as part of rational human conduct. In fact, he uses Schütz's classic paper "Rationality in the Social World" (1943) to show how rationality itself is accorded within the interaction order, rather than a requisite property to participate within it. The secondary ethnomethodological material I will consult will corroborate this, when Michalko and Robillard show how rational action is a secondary consequence of being-with others.

A brief review: so far I have outlined the phenomenological concept of the lifeworld. The life-world is the shared world of human activity, one that is ontologically prior to the scientific world of objective presence. I tempered this notion with Heidegger's critique of subjectivity, which locates that term within the ontology of 
objective presence. The temporality and spatiality closest to care are lost once the isolated epistemological subject is taken as the basis for human being. While Husserl's version of the life-world is grounded in subjectivity, Heidegger's can be said to be 'pre-subjective', as the ontology of the world is primarily found in care, which can later be labeled 'subjective' or 'intersubjective.' The objectively present is unavoidable, however; particular forms of practice necessarily treat the body as a living thing in the world reduced to objective presence. Physical therapy is one such practice.

\section{Ethnomethododology}

In phenomenology, we have some philosophical concepts in our hands. We do not, however, have any empirical justification for its application. By turning to ethnomethodology, we can find empirical justification for the concept of the life-world. Each of the ethnomethodological studies reviewed here will serve to support the phenomenological concepts found above, particularly the founding work of Harold Garfinkel (1967), and the work of Rod Michalko (1998; 1999) and A.B. Robillard (1994; 1996; 1999) will deliver us to the intertwined themes of medical intervention and the personal experience of disability.

The central text for all ethnomethological work is Harold Garfinkel's Studies in Ethnomethodology (1967). Its central theme is 'accountability', how participants in social settings-Garfinkel uses the term 'members' to avoid the pitfalls of 'rational subjectivity'-organize their actions according to background expectancies of those 
situations. "[Any] setting organizes its activities to make its properties as an organized environment of practical activities detectable, countable, recordable, reportable, tell-astory-aboutable, analyzable - in short, accountable" (Garfinkel, 1967, p. 33). The phenomenological 'stock of knowledge' is not simply an after-the-fact descriptor of past situations or things; it is the basis on which social order is made. "Not only does common sense knowledge portray a real society for members, but in the manner of a self fulfilling prophecy the features of the real society are produced by persons' motivated compliance with these background expectancies" (Garfinkel, 1967, p. 34). None of this can be settled theoretically, however.

To flesh out 'accountability', Garfinkel pushes common sense to its limits, "to start from familiar scenes and see what can be done to make trouble" (Garfinkel, 1967, p. 37). Garfinkel shows that even when challenged with a social setting that should make no sense whatsoever, members employ methods to restore accountability, and thus social order, even if futile. An example (outlined in Garfinkel, 1967, pp. 79-80): ten students were told that a counselor in an adjacent room would provide them yes or no answers to a series of psychological questions. They were duped: their 'counselor' was a mathematically randomized set of answers. Even when answers made no 'sense', the participants, who adapted their responses and line of questioning accordingly, treated the answers as sensible. In short, member's work was held accountable to the organized activity. This manufactured havoc should not simply be regarded as a prank. It demonstrates that indexical knowledge of any situation is formulated, presumed and 
deployed by members, implicitly or explicitly, to perpetuate social order. ${ }^{112}$ Even though the 'psychological' advice was contrary to common sense life-world knowledge, it was 'membershipped' to comply with it.

Chapter five of Studies in Ethnomethodology, "Passing and the managed achievement of sex status in an "intersexed" person part 1" (pp. 116-185) aligns Garfinkel's 'accountability' with the phenomenological themes presented above. ${ }^{113}$ The well-known essay is developed from thirty-five hours of interviews with 'Agnes' (a pseudonym), born with male physical attributes, assigned at birth and raised as such, and who, at the termination of the interviews, underwent surgery to physically reflect her 'normal, natural female identity'. The focus of the paper is on Agnes' 'passing', "the work of achieving and making secure her rights to live as a normal, natural female while having continually to provide for the possibility of detection and ruin carried on within socially structured conditions" (Garfinkel, 1967, p. 137). Garfinkel calls Agnes a 'practical methodologist' for disclosing the manner in which normal, natural sexuality is done in-and-as social order.

We learned from Agnes, who treated sexed persons as cultural events that members make happen, that members' practices alone produce the observable-tellable normal sexuality of persons, and do so only, entirely,

\footnotetext{
112 'Indexical' derives from the work of American Pragmatist philosopher C.S. Peirce: "of, relating to, or denoting a word or expression whose meaning is dependent on the context in which it is used" (OED). Garfinkel, of course, extends this to anything accountable-in-and-as-the-social-order.

113 I write 'aligns' as Merleau-Ponty is the only phenomenologist Garfinkel explicitly names in chapter 5. However, as the volume's introduction attests, ethnomethodology is very much influenced by various phenomenologists, particularly Alfred Schütz and Edmund Husserl. Further, McHoul (1998) discusses Garfinkel's similarities with Heidegger.
} 
exclusively in actual, singular, particular occasions through actual witnessed displays of common talk and conduct (Garfinkel, 1967, p. 181).

In addition to demonstrating how members make 'normal, natural sex' accountable, the case of Agnes also serves to elucidate Heidegger's ontological difference. In passing-always used in the active mode since the task is forever incomplete-Agnes experienced the time most authentic to Dasein. ${ }^{114}$ Her time is not clock time, but the same temporality that Heidegger describes in Being and Time, the linkage between former, present and future 'hows'. Agnes would 'case' all situations of self-presentation, including her interviews with Garfinkel, so that her passing could continue. In several described situations, such as a forthcoming physical exam for an employment application and a trip to the beach, Agnes would comport herself, or avoid situations entirely, so as to pass undetected. Her biography was also closely managed within the interviews, giving no indication of her past male biography to either physicians or Garfinkel, with fear that her sex reassignment opportunity might be compromised. ${ }^{115}$ In short, Agnes' 'practical method' was spatially and temporally directed towards a singular goal: being the natural, normal female she knew she always was.

${ }^{114}$ Heidegger uses 'authenticity' not in reference to a 'genuine, opposed to fake' state of being, but rather to ways of being where human Dasein is made most apparent-in accepting one's own being-toward-death, for instance. In Guignon's words: "authenticity is not so much a matter of the "content" of a life as it is of the "style" with which one lives. The distinction between authenticity and inauthenticity seems to hinge not on what one is in the sense of specific possibilities one takes up, but rather the how one lives" (1984, p. 334).

${ }^{115}$ See Raby (2000) for a critical examination of social science's use of the transsexualas-Other, both in terms of Garfinkel's interview with Agnes, and the paper's interdisciplinary legacy, in the decades since its initial publication. 
The final two ethnomethodological accounts I wish to discuss, Britt Robillard's and Rod Michalko's, bring 'accountability' to both disability and its therapeutic management. Robillard $(1994 ; 1996)$ writes from the standpoint of a sociologist with severe muscular dystrophy, in a wheelchair, unable to speak or move his vocal chords. ${ }^{116}$ In "Anger-In-The-Social-Order", he describes his work as a practical methodologist. "I am an expert on anger" he argues, "a virtual black belt in giving and receiving affronts to Alfred Schütz's assumptions that we are in a common, intersubjective world" (1996, p. 18). Robillard's means of interpersonal communication, letter board and lip reading assistant, breach taken-for-granted assumptions about the basis of rational conduct. Anger emerges when these assumptions are breached, for both would-be interactive partners and Robillard. He uses two instances of failed communication, a chance meeting at a mall and a dinner party, to make his case.

My failed attempts to initiate and maintain eye contact and conversation, as well as my unavoidably less than successful reliance on others to position me and translate for me, can be considered ethnomethodological demonstrations of the embodied commonsense knowledge used to 'do' a chance meeting in the mall and to 'do' a party. My anger and frustration was generated by the refusal of my body, even with the assistance of others, to exhibit the textual sings of participating in a chance meeting or party (Robillard, 1996, p. 28).

Robillard continues Garfinkel's work in making visible how accountability in social order is produced and maintained through practical actions. He is critical of accounts of 'rational conduct' that ignore the 'just-thisness' of situated, everyday life where they are

\footnotetext{
${ }^{116}$ My use of 'standpoint' does not presume any epistemological privilege to those with a standpoint over others without, only to note Robillard's location in the social order. I borrow this usage from Frank (2000).
} 
performed. ${ }^{117}$ To be seen and engaged as a rational, competent person requires more than 'subjective consciousness'. Bodies must be proximate (in the Heideggerian sense), oriented toward and accountable to the conversational order. As Robillard demonstrates, not all embodiments are equally accorded the membership requirements of interpersonal activity.

While these problems of accountability are demonstrated in routine social engagements, they become manifest in more dire circumstances. In "Communication Problems in the Intensive Care Unit" (1994), Robillard shows how his lack of a 'realtime' voice produced significant difficulty in making evident rational preferences for medical treatment. He makes the severity clear in five words: "This fieldwork is not recommended" (Robillard, 1994, p. 385). Robillard's laboriously formed sentences using the letter-board or trained lip-reader were incongruent with the temporally constrained visits from surgeons and nurses. ${ }^{118}$ As many conversations would have to elapse over several distinct visits, only nurses with longer tenures would be able to interact back-andforth with Robillard, whereas shorter placements left such communication impossible. We find empirical support for Heidegger's critique of subjectivity in Robillard's communication problems: rationality is only afforded to those accountable to the realtime communication order. Rational subjectivity is denied when socio-material environments exclude alternative communication techniques, as in Robillard's case.

${ }^{117}$ See especially chapter eight of Studies, "The Rational Properties of Scientific and Common Sense Activities" (pp. 262-284).

${ }_{118}$ Here, temporally refers both to 'elapsed clock time' and the temporality closest to Dasein as in Robillard's past 'hows' of communication used to determine present and future modes of conduct, albeit failed, using the letter-board. 
I wish to conclude this literature review with the work of Rod Michalko. His work is less ethnomethodological than Robillard's. Garfinkel is but one of motley sociologists and philosophers employed in Michalko's work. This is not a fault, as Michalko unites that tradition with the phenomenology I have cited above. Michalko's The Mystery of the Eye and the Shadow of Blindness (1998) spends an entire chapter on rehabilitation, arguing that it has as much to do with accounting for sighted norms as it does the "improvement" of the experience of blindness. Blindness is, by rehabilitative definition, an error in sight. Those undergoing therapy are made to 'see' their blindness as distinct from a sighted world, as "a sighted person whose sight is missing" (Michalko, 1998, p. 69). Children undergoing rehabilitation, for instance, are taught to pass as sighted by learning techniques of maintaining eye contact, without 'staring'. It is pedagogy of passing, to visually emulate the care of sightedness. ${ }^{119}$

Rehabilitation understands sight as embodied in an 'ideal actor.' This ideal actor is someone who is like every other sighted person insofar as he or she can see, and potentially do, what everyone else can see and do. This ideal actor is an actor who 'fits in' and, ideally, cannot be distinguished from any other actor on the basis of 'looking like' he or she can see. Rehabilitation's ideal actor moves through the world looking like everyone else who can see (Michalko, 1998, p. 93).

Michalko argues that rehabilitation speaks about blindness only in terms of a problem in need of a technical solution. Part of this solution is making the modes of care of

${ }^{119}$ Unlike Agnes, a 'sole proprietor' in passing, Michalko (1999) discusses passing as sighted with the aid of others in public situations, and the inability to do so with a guide dog or assistive devices that are 'essential emblems' of blindness. The quoted term stems from the study on Agnes, when she seeks to divide the possession of a particular sex organ from sexuality-in-passing. 
blindness look like those of the ideal actor, a task that can never be fully completed. Those under rehabilitation are made to look at their blindness through the eyes of others. The question becomes: "What does blindness need in order to fit in?" (Michalko, 1998, p. 93) Blind persons may achieve a passing grade, but they will never be granted full marks.

Let's recapitulate, before progressing to the final section of this paper. While Heidegger's philosophy is grounded in the ontological difference, ethnomethodology's core concept is 'accountability'. In the case of Agnes, we found that passing required a pragmatic understanding of the 'practical stock of knowledge' of others. Similarly, in Robillard, we saw that rational subjectivity is achieved or denied in navigating the lifeworld's times-and-spaces of communication. Finally, in Michalko's work on blindness and rehabilitation, we found that technical intervention into blindness-as-not-sightedness involves the application of ideal-type subjectivities to dissimilar forms of embodiment. Blindness is disclosed in rehabilitative practice as practical-lack-of-sight. In the final section of this paper, I want to take this conceptual framework and apply it to my own experience of physical therapy. There, we will find that physical therapy, too, must come to terms with the ontological difference.

\section{Physical Therapy}


My personal journey through physiotherapy unfolds as follows. Diagnosed with Becker's muscular dystrophy, a chronic neuromuscular disorder, ${ }^{120}$ at age 10 , my contact with medical professionals lapsed around age 18. My muscles had not atrophied to the point that explicit external attention was needed. Ten years later, my impairment manifests more frequently, causing difficulties in everyday life, from problems with inclines and stairs, to dressing while standing. Falling became a frequent problem. While applying for the Canadian Revenue Agency's Disability Tax Credit (see chapter three) I was referred to a neurologist, who assessed my condition in light of the records from ten years earlier. ${ }^{121}$ Following this examination, I was referred elsewhere: to a cardiologist, occupational therapist, and, aptly, to a physiotherapist. It was made evident that many of these referrals would materialize more quickly than others because of the increasing frequency of falls, a Bad Thing in the rehabilitation profession.

In light of muscular dystrophy's progressive nature, my physical therapy was palliative in nature, rather than restorative. ${ }^{122}$ My 'muscle disease', as it was classified, would not be cured. The sessions lasted five months. The structure of the hour-long sessions was generally as follows: a five-to-ten-minute 'hello' and review of the status of my muscle disease. "How many falls this week?" and "how are the exercises progressing?" were posed at the beginning of each session. The bulk of the sessions, forty or so minutes, consisted in an increasingly broad regimen of exercises designed to

\footnotetext{
120 'Via biopsy' — doctors find this fact very important, and repeat it frequently.

${ }^{121}$ As seen in chapter three, above.

${ }^{122}$ I will return to this point below, considering that rehabilitation frequently refers to the return to normal function (Michalko, 1998). While there are, of course, many persons who attend physical therapy with the aim of functional restoration, I believe they share many aspects with such palliative care.
} 
increase flexibility and, if possible, muscle strength. ${ }^{123}$ Handouts and equipment were provided to help with the performance of the regimen at home (twenty minutes daily, if possible). The meetings concluded with an opportunity for me to ask questions, 'things to look for' between sessions — such as falls and changes in my exercise potential—and scheduling for the next meeting.

In physical therapy both patient and practitioner are actively involved in producing the body-as-objectively-present, disclosed as a measurable thing rather than in care. My transition between 'muscular dystrophy diagnosed via biopsy at age ten' and 'muscle disease as treated by physiotherapy' is pertinent in this regard. ${ }^{124}$ Neurology had little to say about my muscular dystrophy, other than its etiology, pathology and likely trajectory. Stated otherwise: this is the muscular dystrophy disclosed by neurology. This is but one way in which the body is enacted as objectively present, as abstract from the environment in which it lives-literally extracted, in the case of 'diagnosis via biopsy'. Physical therapy, however, caused my body to emerge in lived, 'subjective' symptoms. ${ }^{125}$ In the 'review of my muscle disease' portion of our meetings, $I$ enacted the objectively present body while providing data for my therapist's hermeneutics. ${ }^{126}$ This allowed me,

${ }^{123}$ The number increased from five exercises after the first meeting, to a final twelve.

124 Obviously, the two are not wholly distinct, but the regime of practices surrounding each object is different. Here again, I take inspiration from Mol's The Body Multiple (2002).

125 Michalko similarly discusses how blindness is treated distinctly by ophthalmology and, once that subdiscipline can 'say no more', rehabilitation. See chapter 3 of his Mystery (op cit.).

${ }^{126}$ Leder (1990, p. 78) extends his Polanyian analysis of incorporation to show how the doctor's gaze is employed proximally to attend to our own bodies in medical care. "If we seek out a healthcare provider, this is hardly an abandonment of self-exploration. Rather, the treater's gaze provides an extension of our own. Through the mediation of another, 
in some form, to direct the treatment. In terms of practice, the difference is nontrivial. The initial referral to the physiotherapist, for example, suggested a search for assistive devices and little more. The justification: muscular dystrophy is here to stay, why would we engage in futile treatment? In disclosing my body as symptomatic of muscle diseasein-treatment, however, more than assistive devices came into play. Yes, muscular dystrophy is incurable, but the extent to which it impairs lived tasks, such as climbing stairs or carrying groceries, is impacted by many other physiological, material and social factors. While my muscle strength wouldn't increase significantly, the load put on these muscles would be reduced with an active exercise regimen. I would lose weight. Here, of course, assistive devices are helpful, but so is the assistance of my partner, especially in the grocery-carrying instance and other similar instances. Abstract muscular dystrophy does not benefit from the help of loved ones or loss of mass, whereas lived muscle disease can and, in my case, does. In sum, significantly more is 'up for grabs' in the viewpoint of physical therapy.

Even though I was able to take the lead in outlining subjective symptoms of muscle disease, it was always against the objectively present rubric of physical therapy, and not in the ontologically closer structure of care. That is, the ontological difference came into play even when I was outlining how muscular dystrophy is encountered in daily life. The experience and recording of falling is a good example. In making my experience of falling accountable to the clinical order, I sought to retroactively establish a causality of 'why I fell' in each case, and make it reportable to my therapist at the outset

we come to see our body in series of technologically and conceptually extended ways that otherwise would be unavailable." 
of each visit. 'What happens when you fall?' is a far more complicated question than it may seem. Falling-as-breakdown-of-walking and the reporting of falls to a clinician are two distinct entities. The first takes place in a particular time and space, the body emerging in thwarted walking and recovery, as a form of care. The latter takes place in objectively present time and space, in terms of 'where?' and 'when?' 'Why' I fell was reported in terms of the latter, a explanation of 'what went wrong' expressed in anatomical, rather than existential terms. Which falls are accountable is important as well: alcohol consumption, for instance, makes falling far more frequent. In this case, it is difficult to attribute a single cause to falling when multiple contributing factors are present. ${ }^{127}$ Similarly, on more than one occasion falling occurred on the way home from physical therapy, to which exercise related fatigue contributed. In each case, 'the fall' is not simply an event that happens, it must be carved out of the life-world to be useful datum for physical therapy. Accounting for falling is not a benign description of preexisting states of affairs. It is an exercise in ontological differentiation, the movement from care to the objectively present.

The most extreme example of the ontological difference emerged when I was asked to judge my subjective experience of muscle disease and its treatment according to so-called 'patient-specific functional scale' (Stratford et al., 1995), or some modification

\footnotetext{
${ }^{127}$ A common experience is having my peculiar gait 'explained away' as a symptom of intoxication, something similarly noted anecdotally in Michalko's The Two-in-One: Walking with Smokie, Walking with Blindness (1999, p. 13). Here we find another expression of the 'common-stock-of-knowledge' endemic to the life-world, where uncommon embodiments are encountered first as deviation-from-normalcy, drunkennessnot-sobriety, rather than as a complete corporeal existence.
} 
thereof. ${ }^{128}$ The exact scale is not important, but rather the ontology that such measures presuppose. The scale: the subject receiving physical therapy is given the opportunity to rank particular activities of everyday life at various time-points, prior to therapy and throughout the rehabilitative process, on an eleven point numerical scale, from "unable to perform activity" to "able to perform activity at pre-injury level" (Stratford et al., 1995, p. 261). ${ }^{129}$ This and similar scales are the very stuff of objective presence: the individual subject is isolated from the times and spaces of care, and asked to rank their 'functionality' qua daily comportment in a physically extended world. The scale deploys subjectivity as the baseline of healthy existence, to come up with a clear-cut trajectory for progress and further treatment, both in terms of clock-time. The difference between care and subjective measures is the ontological difference. Such scales are not, of course, the only measure employed in the therapeutic relationship, but their use supports my main argument well: both client and practitioner actively constitute the body as objectively present in the therapeutic relationship, as a living thing accountable to explicitly measurable criteria.

\section{Conclusions}

\footnotetext{
${ }^{128}$ I was not given a copy of any rubrics applied to my case (despite a request). Only my post-hoc research has led me to believe that this was, in fact, the 'patient-specific functional scale' to which my activities were judged. This after-the-fact search for 'what was really going on the whole time' seems to be rather ethnomethodological itself, in retrospect.

${ }^{129}$ Stratford et al. (1995) note that the latter end is modifiable in cases, like mine, where injury is not the reason for therapeutic intervention.
} 
We've come a long way. A review is in order. In the first two sections of this chapter, I identified some concepts and gave them some empirical substantiation. I discussed Husserl's concept of the life-world, and suggested aligning it with Heidegger's ontological difference. In my reading the life-world is not based in subjectivity-in either 'rational' or 'inter-' forms - but rather in the structures of care (at least initially). Next, I outlined the basics of ethnomethodology. There we saw how Garfinkel and Heidegger's work are compatible. In both cases, we found that the life-world is not preexisting. It is made and remade in the 'just-thisness' of the interaction order. Finally, I gave an account of my own experience of physical therapy. In physiotherapy, the objectively present body is an organizational achievement. However, it is not simply imprinted on the subject from above. Subjectivity as part of treatment is made and claimed with the participation of the client. This causes past and present moment of care to be made accountable to rubrics of measurement, to transform the time-spaces of care into objectively measurable data for the measure and prevention of future symptoms. While my care was palliative, I found that scales used to measure my case could be applied to all versions of physical therapy. My contention remains: all forms of physical therapy must participate in ontological differentiation.

If accepted, what might this argument yield in terms of future physical therapy research, and for future disability studies? In terms of physiotherapy, I want to make the following clear: subjectivity is an artifice. When 'subjective experiences of treatment' are ranked, ordered and compared, the data delivered to statistical analysis has already been 'membershipped' within a world reduced to measurable, objective presence. There 
is, so to speak, power in numbers. What is lost before these measures are applied is worthy of future phenomenological research, produced by patients, rather than those of the professional body. This will serve to compliment the critical work already being done by the latter, while highlighting the bounded scope of 'patient'- or 'client'-specificity. This is not to say that such measures are useless, but rather to suggest that the contours of subjectivity cannot fully encapsulate the human being that they are used to treat. Some aspects of livelihood will inevitably be lost when others are disclosed. Clients themselves should make evident the aspects that are more important than others. Phenomenology is my way of doing so.

Finally, the concept of medicalization: analyzing the thalidomide memorial earlier in this dissertation, I warned about the dangers of a 'biomedical boogeyman'. I do not think there is any great benefit to hypostatizing 'biomedicine' as an ever-present danger to disabled persons. To speak of 'biomedicalization' is not to say very much. ${ }^{130}$ Whereas Oliver and the social modelists— but not only Oliver and the social modelistsspeak of 'medicalization', we need to ask what medicalization is made out of and how it is put to work. Medicalization is not solely the application of medical knowledge to the disabled body. Following Heidegger, it is, I believe, a mode of technological being in which physical or mental difference is disclosed solely in terms of biological malfunction, a problem for particular medical disciplines (such as rehabilitative therapy) to solve, and never a social, political, moral or otherwise non-technical problem in need

\footnotetext{
${ }^{130}$ This is similar to Ian Hacking's (1999) critique of 'social constructionism.' To simply say something is socially constructed is akin to saying something has a history. The important task is to outline the particular processes that contributed to the object under investigation came to be.
} 
of a similar solution. The issue lies not in combating abstract biomedicine. I, like many other disabled persons, benefit from medical knowledge and intervention. We do not need to get rid of biomedicine. We need a free relation to it. Restated: if we conceive of biomedicine as an ever-present, larger-than-life evil, we miss the opportunity to find the mundane ways in which its practice might be made slightly more humane. This means finding the ways in which disability is disclosed only as medical malfunction, and finding out how it could be (ontologically) different. ${ }^{131}$ Again, phenomenology is my way of doing so.

131 If this more extensive version is, in fact, what social model thinkers have been proposing all along, then perhaps our 'medicalization critiques' align after all. 


\section{Chapter Six: To Conclude: Stepping back, Stepping Forward}

\section{Introduction}

In this dissertation, I have characterized the ontological difference as the central issue facing disability studies. The argument is this: disability studies, as a practical research enterprise that seeks to describe the cultural organization of ability and improve the lives of disabled people, must both represent the experience of disability and highlight how its administration could be improved. In this dissertation, my aim was not to 'challenge' or 'avert' the ontological difference-I am not sure how one would begin to do so. Rather, in order to achieve these administrative goals, we must trace the movement from being-in-the-world to objective presence and back again. After considering the dominant theoretical approaches to this task, Heidegger's ontological investigations are the most adept approach to this goal. Of course, other theoretical approaches have inspired the work here, but it was Heidegger's ontological difference that organized my thinking — and the organization of this dissertation.

In this final chapter, I first aim to do what I could not in the preceding chapters: step back. Whereas at the end of each ontological investigation I presented 'themes for future research', I was not able to address either disability studies or sociology as a whole. Such is the nature of the discipline (or at least my place in it at the moment): 
write articles and write them frequently. The 8,000-word journal article allows for paltry 'suggestions for future research', but a true meditation on the 'what does anything of this mean?' question needs a dedicated chapter. Accordingly, in part one of this conclusion, I want to reflect on this work in its entirety, against the backdrop of disability studies and sociology as a whole. In discussing Heidegger's work on technology, I introduced his notion of the 'enframing' of the modern age. In Western society, two modes of enframing physical difference are dominant. The first is medicine. Disability is frequently disclosed as a solely medical problem. After this framing, economic rationality comes a close second; disability costs the economy. In the second section of this paper, I examine a site where these two framings intersect: the Ontario Disability Support Program Employment Supports. Here I match Heidegger's ontological of technology can be with Michel Callon's ANT-inspired economic sociology, where technological enframing and economic framing intersect. This will show where more of my work will take place in the future, should others wish to follow. I don't want to suggest future research. I want to actually do it.

\section{Four Ontolologies}

Each theoretical approach to disablement has an outlook on what disability is. What disability is made of — and how it can be unmade — are different to each of them. I outlined four before looking to Heidegger's. Let's review them. First, the social model sees disablement as an exclusionary social process, reinforced through ideological, capitalist structures. Disability and impairment are ontologically distinct. Impairment is 
the preserve of biology; disability is a product of social oppression. Disability research is 'emancipatory research': its goal is the elimination of these exclusionary relations. I questioned the extent to which the social model impaired academic research, using Oliver, Barnes and Mercer's reading of Erving Goffman as an example. I believe we can read Erving Goffman as an emancipatory disability researcher; they clearly do not. Though the other ontological vectors do not share the social model's restricted view of what disability studies' aims should be, its environmental focus is undeniably felt in all later disability research. The three other ontological vectors formed themselves in a postsocial model research environment.

Next, I turned to the Foucauldian literature. There, the history of disability is a history of problematization. Disability is insofar as it is managed bureaucratically, medically, and economically. Disability is not simply 'out there', as an object that exists before it is known. Knowing and administering, two sides of the same coin, make disability what it is. Looking to the Canadian context, Titchkosky and Prince show us how disability is problematized in federal policy documents. Part of this story is about exclusion, as per the social model. But there is more to it than that. Titchkosky and Prince question the terrain on which inclusion is charted to take place. On what grounds we accept disability as part of and yet distinct from the Canadian population, and the ends to which we will go to make the problem—and it surely is treated as a problem—better. Initially, I discussed the economic governance of disability through the example of a government-sanctioned private sector economic report, Rethinking DisAbility in the 
Private Sector (2013a). I continued this line of questioning in the chapter three, and will do so again in the second part of this concluding chapter.

The phenomenological approaches I outlined in chapter one problematize the 'embodiment' of disability. Disabled embodiment, they argue, cannot be confined in an impaired body. Drawing on Maurice Merleau-Ponty's Phenomenology of Perception (1962), the phenomenology of disabled embodiment questions the inside/outside and mind/body dualisms. The chief source of these dualisms, they argue, is the residual philosophical and cultural influence of René Descartes' metaphysics. Disabled embodiment seeps into the world; neither its cultural production, nor personal experience, can be wholly described in terms of organic (mal)function. I turned to embodied sociology and disability studies, reading Crossley, Turner, Hughes and Paterson. They shared an opposition to Cartesian dualism, the division between thinking an extended substance, and used Merleau-Ponty to overcome it. Following Heidegger, I argued that this attempt to overcome Descartes' legacy did not go far enough: it did not fully address the problem of the ontological difference.

Finally, I outlined the actor-network ontology. Actor-networks are heterogeneous, temporary assemblies of human and nonhuman things. Network should be used as a verb: 'to network' implies action. The ANT approach to disability emphasizes disablement as process, rather than 'disability' as fixed identity. In this way it is similar to the social model. It is dissimilar to the social model in its understanding of what disability is an outcome of. The social model points singly to capitalism. ANT 
argues that the issue is far more heterogeneous. Biology does, sin fact, play a part in disability. In Haraway's "Manifesto for Cyborgs" drawing from the ANT tradition, we found an argument against the social model and other fixed identity categories. While Haraway's "Manfiesto" was reacting to standpoint theory (of which I took Hartsock's as representative), her rejection applies equally to the social model. Its clean-cut divide of impairment from disability is incompatible with her cyborg and situated knowledges. For Haraway, it is not uniformity that should align emancipatory politics, but rather difference. The ontological and epistemological multiplicity found in the cyborg shows a way forward. Though Siebers argued that Haraway's "Manifesto for Cyborgs" presented a roseate reading of disability, he nonetheless admits its emancipatory potential. Whereas the ANT examinations of disability hinted at emancipatory politics, Haraway's cyborg puts them front and centre.

My outline of the four ontological vectors is based in a simple argument: disability is a lot of different things to a lot of different people. This seems inevitable in naming a diverse spectrum of conditions. But disability is more than a sorting problem. It describes a particularly human way of being. To deal with disability as a human way of being, I argued, we needed another ontological vector, one sensitive to human existence. I selected Heidegger's existentialism, because I felt it let us ask new questions, while reformulating old questions anew. In my reading, the key concept underpinning Heidegger's existentialism is the ontological difference, the difference between the uniquely human way of being and the being of mere objects: In the second chapter of this dissertation, I aimed to show how Heidegger's philosophical problem of 
the ontological difference matters to the sociology of disability, and disability studies more generally. It presents both a theory of what human existence is, and a method to interrogate how human existence is reduced to mere being.

\section{The Ontological Difference}

In Sein und Zeit (1927), Heidegger sought to outline how Western philosophy passed over the basic problem of Being. This, in isolation, does not matter much to the sociological examination of disability. In chapter two, I aimed to show how this philosophical problem let us consider disability anew. In care, the mode of Dasein's everydayness, the times and spaces in which disability is lived are different than those of measurable time and space. In this way, the ontological difference moves from an abstract critique of Platonic, Cartesian and Kantian philosophy to one that describes what it means to be a person in the world (in this case a disabled one). Put more humbly, by reading Heidegger, I believe we can account for what it means to experience disability more effectively than we can with the four ontological vectors presented earlier. For the pragmatist, this makes it preferable.

To rethink what it means to be a human being, to distance our existence from that of mere things: such is the project of Being and Time. We live in a world that means something to us, mere things just are. There are, however, moments when the existence of human beings is made equal to that of 'everyday things' or 'mere objects'. Heidegger used the term 'objective presence' to describe the world of physically extended things 
that form the basis of Descartes' physics and the everyday understanding of things. Heidegger's later project sought to understand how human Being is 'enframed' as mere being in medical, scientific and technical practice. In the "Letter on Humanism" (1993a), Heidegger rebuffed his French existentialist contemporaries for a philosophical system ${ }^{132}$ that failed to "set the humanitas of man high enough" (p. 210). They did not account for the ontological difference. Similarly, I argued that none of the ontological vectors discussed in chapter one was able to deal with the ontological difference sufficiently, either in isolation or tandem. I looked to the existing Heideggerian literature in somatic philosophy and disability studies, to Drew Leder and Michael Schillmeier, respectively. Both authors brought Heidegger's work to new places, and did so with the graceful demeanor that Heidegger lacked. He was callous and dismissive. In his Zollikon Seminars, he presented a philosophy of the body quite similar to Merleau-Ponty's. While I find Heidegger's philosophy preferable, it would have been much more effective, and certainly more comprehensive, had he productively engaged his philosophical neighbours. He did not; accordingly, it was not.

\section{Three Cases of Ontological Differentiation}

With Heidegger's ontological difference established as a theory of human existence, and a method to examine how that existence is reduced to objective presence, I sought to put it to work in chapters three through five. In chapter three, I looked to the

132 I write 'a philosophical system' (singular) because Heidegger only referred to Sartre in the letter, and ignored potential similarities with other French philosophers at the time. 
Canadian income tax regime as a site of ontological differentiation, where particular embodiments are sorted as 'able' and others as 'disabled'. The 'seven categories of everyday life' used by the CRA are very different than the basic mode of human existence we found in Dasein. To be disabled and to be disabled for tax purposes are two different things. In some cases, as seen in the example of fibromyalgia, they are extremely different. I argued that Heidegger's reformulation of time and space gave a more accurate picture of disablement—understood as a materially situated, task-based process - than the static and objectively present criteria presented in the T2201 Disability Tax Credit Certificate. These criteria disclose, understood via aletheia, a technologically ordered understanding of what disability is. Here, of course, the tax regime is not unique: all forms like the $T 2201$ must include some embodiments as disabled and exclude others. Some people should count as disabled and some should not. This is why verification regimes exist. The point remains: all bureaucratic mechanisms sorting human experience must come to terms with the ontological difference. The knowledge of this fact can be used to make them slightly more human. This was my first foray into phenomenology and public policy. Another will follow this section.

While Heidegger's existential phenomenology has been applied to the problem of embodiment in disability studies, I found the use of his aesthetic insights noticeably lacking. Heidegger's aesthetics are deeply linked to the mode of truth ontologically closest to Dasein, first established in Being and Time. In both art and everyday existence, truth is first a mode of revealing of beings to Dasein - and only then an accurate or inaccurate representation of a state of affairs. Truth as correspondence is derivative of 
aletheia, or the disclosedness of beings in truth. Nor is truth as correspondence the only form: in artwork, truth is disclosed as beauty. In chapter two, I looked to the existing literature on disability aesthetics. On review, three features stood out. First, disability aesthetics shift disability politics from 'the textual' to 'the sensuous'. Secondly, disability aesthetics involved both perceived and perceiver. In terms of everyday sensation, art and dramatic performance, the audience is not passive; it is an active partner in aesthetic politics. Finally, and unlike many phenomenological contributions to disability studies, disability aesthetics are empirical. They give robust theoretical analysis to a site of sensuous apprehension.

My excursion into disability aesthetics presented a Heideggerian analysis of Chemie Grünenthal's international thalidomide memorial. ${ }^{133}$ In "The Origin of the Work of Art" (1993c), Heidegger establishes the aletheia-beauty relationship. In "Art and Space" (1973), he shows how the spaces closest to Dasein are realized in sculpture. I analyzed a sculpture disclosing the drug thalidomide. The thalidomide events are well known. They are known as the "thalidomide tragedy", as was reflected in the statement that Grünenthal CEO Harald Stock provided at the memorial's unveiling. Thalidomiders critiqued the statue immediately, arguing that its disclosure of the events, as past historical tragedy, failed to acknowledge their existence as disabled persons. I suggested that their use of 'tragedy' narrative in doing so was not regressive or antithetical to emancipatory disability politics. Rather, following Heidegger's "On the Essence of

${ }^{133}$ With no help from Chemie Grünenthal, I must add. 
Truth” (Heidegger, 1993b), I argued that thalidomiders' self-disclosure of tragedy was an instance of freedom — the same outcome desired by disability activists.

In chapter five I discussed physical therapy as a site of ontological differentiation. 'Medicalization' is a common theme in disability studies, medical sociology and the sociology of deviance. It is, taking a page from Oliver's classic Politics of Disablement (1990), the causal misattribution of medical cause to social oppression. While definitions may differ, the point is this: medicine is making non-medical things medical. ${ }^{134}$ In disability studies, the term rarely refers to a particular medical discipline, or a particular practice. I sought to use my own experience of physiotherapy to explain how the symptoms of muscle disease are disclosed in the life-world. To do so, I began by discussing Husserl's concept of the life-world, and its philosophical critiques. The concept was highly compatible with Heidegger's being-in-the-world, after a few minor adjustments. I suggested that ethnomethodology presented an empirical substantiation of the life-world, demonstrating how member's actions are accountable to and perpetuate the social order. Looking to Garfinkel's classic Studies and more recent use of those studies by Robillard and Michalko, I demonstrated the similarities between Garfinkel's 'accountability' and Heidegger's ontological difference.

With a hybrid ethnomethodolical-phenomenological apparatus in hand, I turned to the clinical practice of physical therapy. Though drawing on my own experience, I argued that all instances of physical therapy—if not medicine more generally—had to

134 A notable exception is Peter Conrad (1992), who aims to explain all applications of medicine with the term. 
come to terms with ontological differentiation. As in the case of the tax forms in chapter three, the experience of disability and its symptoms were quite diverse. While internal critiques written by physical therapists may wish to escape the dominant "bio-mechanical model' through a more humane patient-specific therapeutic method, they nonetheless must 'membership' the data presented in the clinical encounter outside of its initial disclosure to Dasein. I concluded that chapter with a discussion of medicalization. While many activists like Oliver might hope that 'medicalization' goes away, I argued that this is neither a likely or productive desire. We need medicine. The reformulated argument: we need a free relation to medicine in the same way that Heidegger argues we need a free relation to technology. In the following section of this chapter, and in the next stage of my research, I ask how we can attain this relation to an economic technology employing medical verification, the OSDP Employment Supports.

\section{Stepping Back}

Here is the lay of the land: I presented a theory of human experience, and the experience of humans being organized. ${ }^{135}$ This was the ontological difference. I showed three places where this mattered, tax forms, sculpture, and physical therapy. In these, and I would argue all, places, disability studies must come to terms with the ontological difference. Matching the transformative aims of the discipline, I used the term 'ontological differentiation': some forms of organization are more optimal than others, from the perspective of those being administered and their administrators. This is where

${ }^{135}$ Perhaps "human Being, organized" would be more apt. 
we stand. In stepping back from this project, I want to reflect on three themes. First, I want to ask questions about the role of theory. In doing so, I want think about the future of disability studies. Finally, I want to think about the life and work of Martin Heidegger in those future disability studies.

On theory: during each of the ontological investigations above, my criticism was hardly revolutionary (I'll leave that to the social model). Instead, I provided some small suggestions for future research and practice. This fit with the pragmatic motive I highlighted earlier in the dissertation. In his famous pragmatism lectures, James argued that theoretical truth is to be determined by the ability for theories to connect various parts of our experience. This was why I found Heidegger's philosophy preferable to the four ontological vectors introduced in the first chapter. It let me connect the experiences of disability together more effectively. Doing so gave rise to opportunities to make lives better. Of course, to examine philosophies as a whole versus others, to compare ontological doctrines and to contrast epistemologies-these are philosophical problems. To link these problems to the cultural organization of disability, however: this is where disability studies begin. The social theory of disability is a forever-unfinished project. It is unfinished because there will not be a concluding chapter to the experience of disability, nor to the ways we try and sort it out. This is what the pragmatist calls 'instrumentalism' (though the concept was Dewey’s; see Farr, 1999).

Now, there are different ways of pursuing this kind of thinking. One way, the path chosen by Michael Oliver (1992b; 2004), was to call all work that was not 
immediately useful to disabled people 'intellectual masturbation.' This is the basis for the social model's critique of Erving Goffman. The argument, again: Goffman's work is apolitical, individualistic, and fails to do more than describe social structures that exclude marginalized people. This is useless, and so is interpretive sociology more generally. It is intellectual masturbation. Now, I want to oppose this methodology for (at least) two reasons. First, it implies that masturbation—intellectual or otherwise-is uninteresting to disability studies. Among his many contributions to disability studies, Tom Shakespeare $(1999 ; 2000)$ has proven otherwise. Disability politics and sexual politics coincide in sociologically important ways. Secondly, this vulgar instrumentalism is committed to the very same methodological individualism it locates in Goffman's work. It suggests that each author's work, or worse — each author's individual works-can be judged immediately as useful or useless to disability studies' cause in themselves, in isolation from the greater scholarly community. This implies that every possible experience of disability is before us, and that individual agents make all worthwhile contributions to the lives of disabled people.

I have declined this individualist logic. However we define emancipation, either in research or in practice, it is never a strictly individual activity. As new experience faces members of the disability studies community, our own or others', we look to existing scholarship to make sense of it. On occasion we might look to Michael Oliver, on another, to Erving Goffman. Here I have predominately looked to Heidegger. Incrementally, this collective sense making can culminate into social change. By highlighting my experience with tax forms and physical therapy, for example, I hope to 
show how we might manage disability more effectively. Previously 'apolitical' theory can become a catalyst for change, depending on how we put it to work. Whereas Oliver might see a dead-end, or a simply 'descriptive account' in Goffman's writing, I found a way to speak about disability as it appears in the interaction order. To dismiss a particular theory or philosophy as inherently useless is to misunderstand how social science, as a community, works.

Using Heidegger to make sense of disability requires me to discuss his deplorable politics. As I write this conclusion, Heidegger's 'black notebooks', kept between 19311941 and named for their covers, are being published in German. Their publication has renewed debate about how deeply Heidegger's Nazi politics and his philosophy intertwine. At worst, Heidegger's philosophy is Nazi philosophy through and through. His Nazi past is undeniable. He joined the party in 1933, and as rector of Freiburg encouraged his colleagues to do the same. He remained in the party until after the war, and never apologized for his participation. On Heidegger's anti-Semitism: the notebooks support this, containing numerous anti-Semitic statements, with Heidegger describing Jewish 'wordlessness'. ${ }^{136}$ The question facing Heideggerians is this: can Heidegger's

${ }^{136}$ Not reading German, here I rely on Scheussler's (2014) review in The New York Times. On 'worldlessness': at the end of section two of Being and Time, Heidegger expresses how authentic temporality, the time closes to human existence, discloses itself in the history of a people. I do not find these arguments particularly compelling. The category of 'people' is ill defined, and at worst hypostatizes a manufactured entity, 'the nation', as the primordial place of existence. While I buy Heidegger's argument that we are thrown into a common world of meaning, I do not think that world is forever divided initially along pre-existing national or ethnic categories, which Heidegger's writings on das volk seem to suggest. At best, we can read Being and Time as part of national imagination, as described in Anderson's Imagined Communities (2006). 
philosophy be cleansed of these politics, or is it fully tainted in support of Hitler's Third Reich?

We need to ask what 'being a Heideggerian' is. If it is simply one who reads Heidegger, then I will accept the label. My reading of Being and Time and Heidegger's later work forms the basis of this dissertation. If being a Heideggerian means following his teachings and actions to the letter, then I refuse. To suggest that Heidegger's philosophy can be 'cleansed' of his politics is apologist. His actions were despicable; his philosophy should forever be read against them. The 'cleansing' process suggests a clean outcome. I doubt this is possible, and it is certainly not acceptable.

In arguing that Heidegger's philosophy continually be read against his Nazi past, I am arguing that his philosophy should continually be read. I think that he made many brilliant insights on what it means to be a human being. He lets us reflect on Being human, and Being disabled, in ways that other theories and philosophies do not. To return to the instrumentalism expressed above: it is more than possible to read Heidegger in support of the Nazi regime. But it is also possible to read him as a theorist of human difference, the same type of difference that the Nazis sought to extinguish. ${ }^{137}$ If, admitting his participation in Nazi politics, we can pursue the opposite, is it wrong to read him and read him critically? In writing this dissertation, my answer is no.

137 Siebers (2010) makes extensive use of Nazi aesthetics as an example of kitschy artwork that does not account for physical difference. By using Nazi art as counterexample, he demonstrates that good art must take physical and mental difference seriously. 


\section{Stepping Forward: From Existential Philosophy to Political Economy}

My argument, thus far, has been this: Heidegger's ontological difference is central to disability studies' founding concerns. In the work to follow this dissertation, I want to turn to another core problem: how is disability organized economically, and how could this organization be made more humane? This was the question posed by Michael Oliver in The Politics of Disablement. While I touched on political economy in my analysis of Canadian tax forms in chapter three, it was hardly a central concern. Here I want to align Heidegger's ontological focus with Michel Callon's ANT-inspired economic sociology of disability. Both projects are interested in the calculative agent: Heidegger's "The Question Concerning Technology" (1993d) abstractly outlines the technological relationships that "en-frame" Dasein as a calculative subject. Callon, in contrast, is interested in the kinds of economic agencies framed in 'the market' as a calculative

environment. By aligning Heidegger's enframing with Callon's framing, we can outline how agency emerges within the market, and ask which forms are more optimal than others. I look to disability labour policy in Ontario to show the utility of this analytical shift.

Two Paths to Economic Agency 
In chapter three, I outlined the process through which the T2201 Disability Tax Credit shapes 'everyday life' into rationally calculable, objectively present categories, so that human disability could be organized for tax purposes. Heidegger would call this an example of technological enframing, where the world of Dasein, as disclosed in care, becomes reduced to a world of extended substance. 'Rational economic subjectivity' emerges under particular historical conditions, where utility crowds out other modes of object-disclosure. Instead of the beauty of the Rhine River, Heidegger argues, we see the potential for economic surplus. ${ }^{138}$ This extends to human Being as well: as economic subjects, we reduce the being of Dasein to 'human resources', administered like any other economic good. This is the 'enframing' of people and things into a relation of utility maximization. The Being of Dasein is reduced to the being of homo economicus. ${ }^{139}$

Callon describes another path to economic agency in his Laws of the Markets (1998). Instead of an abstract philosophical critique of modernity, Callon seeks to align homo economicus and homo sociologicus by empirically tracing economic performance. Callon argues that economic framing is 'performed' in two senses, describing both a) the manner in which economics as a profession shapes economic markets; and, b) how calculative subjects perform rational calculations within them. ${ }^{140}$ Çalışkan and Callon's twin articles on 'economization' $(2009 ; 2010)$ further outline this practice-oriented

\footnotetext{
${ }^{138}$ This is similar to chapter four, where the rational subject-viewing object escapes the experience of artwork.

${ }^{139}$ This is not, of course, the only way that human being can be 'enframed'. It is not only 'rational economic subjectivity' that is produced in the technological age, but also subjectivity more generally, as critiqued in chapter five.

140 A crucial note: 'economic subjectivity' is not a pre-existing state of affairs, but rather is an interactive outcome, as we shall see below.
} 
understanding of markets, in describing the way that economics as a discipline shapes the way that economic subjects act. This falls under 'economization.'

This term is used to denote the process that constitutes the behaviours, organizations, institutions, and, more generally, the objects in a particular society which are tentatively and often controversially qualified, by scholars and/or lay people, as 'economic' (Çalışkan \& Callon, 2009, p. 370).

Çalışkan and Callon see the formation of markets and rational calculating subjects as dependent on processes of economization. The related process of 'marketization', then, can be seen as the "entirety of efforts aimed at describing, analyzing and making intelligible the shape, constitution and dynamics of a market sociotechnical arrangement" (Çalışan \& Callon, 2010, p. 3). Both individual economic rationality and greater market forms are framed in and through network processes, instances of which ANT adherents would call 'heterogeneous engineering', as discussed in chapter one. While Heidegger's critique is abstract, seeing all modes of economic performance as inauthentic ways of being, ${ }^{141}$ Callon's project seeks to assemble the environments in which this way of being unfolds ('authentic' or not).

Callon $(2007 ; 2008)$ expands on the emergence of economic performativity, described above. Drawing on his work on the AFM, he provides a revised understanding of economic agency, suggesting we expand its franchise past human bodies in isolation, to the 'sociomaterial agencement' or 'interactive diagram': an assemblage of materials,

${ }^{141}$ As noted in chapter five, Heidegger uses 'authenticity' in reference to ways of being that accept Dasein's decidedly human being, not as a bundle of preferences that judge objects based on utility calculus, as in the case of market behaviour. 
texts, discourses, skills and routines that make market behaviour possible. ${ }^{142}$ Instead of the market agent, seen as an ahistorical or pre-existing actor, Callon sees the interactive diagram,

[...] a socio-technical agencement configured in such a way that at the center of the action we find an individual who is capable of developing projects and is endowed with a will to accomplish them, and who holds herself (because she is held) responsible for her acts and their effects (Callon, 2008, p. 39).

This is consistent with ANT: individual actions are the outcome of the assemblages that make those actions possible, calculative agency included. Though agency is distributed within wider socio-technical systems, it is the resulting actor that is held accountable for the distributed action's success or failure. ${ }^{143}$

Callon turns to his work on the AFM to flesh out the interactive diagram and demonstrate its practical utility to both economic sociology and the sociology of disability. He introduces the 'life-projects' formed by those who utilized the AFM's regional services, which gave the individual disabled person the capacity to develop their own plans for future (inter)action:

These services consisted of pluri-disciplinary teams whose mission is not to adapt the patients but to set up interactions enabling them gradually to discover what they want and to try out solutions. [...] In its most extreme

142 Callon reminds us that Deleuze (1988) calls a particular agencement a 'diagram'.

${ }^{143}$ Callon draws on the cognitive anthropology of Edwin Hutchins for empirical support (for a brief introduction, I suggest reading Hutchins, 1995). Hutchins examines the extent to which complex cognitive activity can be made possible by prior arrangements of bodies and non-brain media. In the case of piloting a plane or docking a ship, agency is distributed throughout various components, and yet it is ultimately the pilots that are judged as competent or incompetent actors after the fact. 
form this approach consists in leaving aside the specific characteristics of the flesh-and-blood individual and working only on the agencement in which she is a stakeholder, thus making her an individual agency capable of having projects and being responsible for her acts (Callon, 2008, pp. 44-45).

Looking back to his collaborative AFM research, Callon (2008) is able to make a distinction between two types of economic policies, 'prosthetic' and 'habilitation' policies. Prosthetic policies look to adapt the individual to the environment (or vice versa) such that action is possible within that particular environment. ${ }^{144}$ Habilitation policies, in contrast, give the individual the role of the interactive agencement, who is able to shape and define her own projects, who is able to engineer environments outside of her immediate assemblage. Whereas the prosthetic model sees the individual with incapacities as problems to be accommodated as necessary, the habilitation model aims to "rearrange the world, that is, to construct socio-technical agencements which allow the deployment of individual agencies, i.e. the transformation of (more or less well-adjusted) individuals into interactive agencies" (Callon, 2008, p. 49). In the first model, the world is - for the most part—left as it is. In the second, it is up for grabs.

There is a clear difference between Heidegger's ontological approach to economic rationality and Callon's. That they diverge is obvious, but let me make the difference explicit. Heidegger sees calculative economic behaviour as a perversion of the more fundamental structures of Dasein, as disclosed in care. It is inauthentic. Both 'prosthetic' and 'habilitative' agencies gloss over the more fundamental issue, enframing. What we need is a free relation to technology. Manipulating an interactive assemblage,

${ }^{144}$ For an ANT-inspired critique of prosthetic policy, see Moser (2000). 
adapting the environment to the human component (or vice versa) does not put us on this path. Such is the position of the cantankerous critic. Callon, again in contrast, asks about the forms that economic rationality can take. Some of them are more self-directed than others. Just as I analyzed how we can make tax forms more reflective of the human way of being in chapter three, Callon asks how economic rationalities can be shaped in accordance with the will of those held to account by them; for this he used the term 'interactive agencement'. Heidegger's enframing is wholly inauthentic, the result a Bad Thing. Callon's framing presents forms that are more optimal to the performing agent than others. While Heidegger's ontological difference still informs my use of the latter, it takes a backseat, following Callon's more productive outlook.

Before I employ Callon's economic sociology of disability to Ontario labour policy (and later to Disability Studies) two final points need to be made. The first relates to his understanding of the 'economy' or 'economization'. Callon's focus on the economy will surely draw some initial criticism from the social model, due to its historical materialist heritage. What about exclusion, domination, oppression? Can we account for these classic sociological problems with Callon's economics? I believe so. Callon does address them, though in ontological rather than emancipatory terms: ${ }^{145}$

the ontological status of Homo economicus is not accessible to or even desired by everyone. Some human beings, differently shaped, arranged and equipped, are excluded from this mode of existence and may even refuse to play the part proposed for them (Callon, 2007, p. 143).

\footnotetext{
${ }^{145}$ I use 'emancipatory' in terms of the so-called 'emancipatory research' paradigm. For a reflection on the project's genesis and history, see Barnes (2003).
} 
Now, this statement is not going to make anyone doing Marxist Disability Studies very happy. Part of this dissatisfaction will stem from differing understandings of 'marketization' in the two approaches. Oliver (1990) views that process as part of capitalism. It is doubly excluding, first by historically eliminating those from economic life who did not fit the able-bodied mold demanded by wage labour, later by economically underpinned ideological mechanisms that falsely justify their neglect through pseudo-medical casualty.

Callon's approach has a different focus than Oliver's. While alienation and exclusion are undoubtedly important topics for disability studies, Callon asks us to shift our gaze to inclusion as a contingent, materially equipped process. The inclusion of disabled personhood in the labour market is an equally interesting, and equally problematic, topic. Just as the commodity relation is a socially organized process for Marx, Callon asks us to investigate the process where disabled bodies are brought to the market—an equally organized process. These processes are not always favourable to the disabled people who sell their labour. In my reading, and in line with this reality, Callon's anthropology of markets is a preferable theory when we look to improve the inclusion process.

Secondly, Disability Studies will rightly be wary of Callon and Rabeharisoa's (2004; 2008) treatment of the AFM. While they do note that there has been some academic criticism of the methods used to elicit funds for the group, they do not give them much credit. In fact, the opposite is the case. 
For a long time intellectuals were indignant about the show put on for the Téléthon, with its display of suffering intended solely, they claimed, 'to make grannies cry so that they'll donate money.' Gradually, their criticism abated in the public sphere, but critics are still set to pounce at the slightest opportunity. The AFM has been undeterred by this criticism and jealousy (Callon \& Rabeharisoa, 2008, p. 234).

While the AFM, and other muscular dystrophy groups internationally, may indeed have helped bring those with neuromuscular disorders new humanity, to dismiss academic criticism in such a manner is unhelpful. Here I will be reflexive: while I cannot speak to the activities of the AFM, I can address the actions of its Canadian counterpart. While I have participated and personally benefited from the efforts of Muscular Dystrophy Canada, both as a volunteer and person diagnosed with the condition, I still maintain some reservations about the organization's approach to garner public support. This position is not formulated out of envy. Rather, my concerns lie in the use of fundraising techniques that do not highlight, first and foremost, the contingent nature of ability and disability, that treat muscular dystrophy as lived disability rather than biological lack. Restated using Callon's terminology, my objection is to a projection of disabled personhood antithetical to the interactive diagram. Fundraising techniques are akin to labour markets: some are more beneficial to their objects than others.

To conclude this section, we should review our progress. Initially, I suggested that we read Callon's economic sociology as part of the earlier ANT literature. Next, I introduced the Laws of the Markets (1998), where Callon sought to align homo sociologicus and homo economicus through the ANT lens. Once the general contours of Callon's economic sociology were mapped, I turned to two crucial concepts, 
'marketization' and 'distributed agency'. Borrowing from Callon and Rabeharisoa's work on the AFM, we found that individual and economic abilities could be examined with the same set of analytical tools. We also found that those states of beings are emergent entities, heterogeneous actor-networks. As actor-networks, they take a variety of forms.

One of these forms is the interactive diagram. The interactive diagram helps us distinguish between two types of labour market interventions, prosthetic and habilitation policies. In this manner Callon and Rabeharisoa take us from economic sociology to disability studies and back again. In the third section of this paper, I hope to return to disability studies once more. I do so with an eye to the Canadian situation, showing processes of marketization that bring us from disabled persons as a group to rational, individual economic subjects-from homines inhabiles to homo economicus.

\section{Distributed Agency and Marketization at Work in Ontario}

Introduced in 1999, and with 2011-2012 provincial expenditures totaling $\$ 30.5$ million, the ODSP Employment Supports are designed to "provide employment assistance to people with disabilities who are interested in preparing for, obtaining competitive employment." (Ontario, 2012, p. 23) The program is described as being 'outcomes-based' rather than 'expenditure-based': third party service providers are given government funding should their clients meet job placement targets outlined by Ontario's Ministry of Community and Social Services (Hereafter: MCSS. I will elaborate on this funding scheme in the following paragraph, and its implications in the conclusion of this section). In 2011-2012, 4,465 clients entered the program, and 2,172 clients were placed 
in situations of employment (Ontario, 2012, p. 6). In what follows, I seek to show how the ODSP Employment Supports categorize and distribute disabled bodies and economic agency. The program offers empirical support for Callon's 'marketization' and 'distributed agency' concepts, and demonstrates the emergent, contingent nature of 'habilitation' and 'prosthetic' agencies.

Two simultaneous mechanisms of marketization are at work in the Employment Supports. Through the program, the MCSS establishes an industry dedicated to formatting disabled bodies for the labour market. The piece work funding scheme for the service providers, of which there are around 150 in the province, is as follows: they are paid $\$ 1000$ when a client is placed in a job and works for six consecutive weeks, and an additional $\$ 6000$ once that client works for thirteen (Ontario, 2010a). In the Employment Supports, the MCSS establishes an industry that aims to get, and keep, disabled bodies at work. In these dual marketization processes, disabled Ontarians become both economic subjects and objects: they become labouring subjects, and are distributed by a service industry that has the production of working disabled bodies as its goal. This is quite similar to the manner in which persons with neuromuscular disorders became both subjects and objects of the research enterprise through the intervention of the AFM.

To see how the Employment Supports distribute economic agency, we can look to the application process for the program. Among other things, ${ }^{146}$ applicants are required to

\footnotetext{
146 The application process and materials are outlined on the MCSS website here: http://www.mcss.gov.on.ca/en/mcss/programs/social/odsp/employment support/apply.as px. Note that applicants need not submit the Verification form if they are registered with
} 
fill out the Application for Employment Supports, the Employment Supports Funding Agreement and the Verification of Disability/Impairment forms (Ontario, 2010b; 2010d; 2010c). As in the T2201 form above, application forms of this kind participate in ontological differentiation: they are decidedly political, in that they judge which experiences count as disabled, and which do not. We have seen this before. In the Employment Supports program, these forms also highlight the various elements that allow homo economicus to emerge and sell her labour in conditions of 'competitive employment'.

Take, for example, the Verification form, which must be signed by a medical professional qualified to assess barriers faced by the applicant. As stated above, to qualify as disabled for the Employment Supports, individuals must be diagnosed with a condition "that is continuous or recurrent and expected to last one year or more, and that presents a substantial barrier to competitive employment" (Ontario, 2010d). Here the verifier acts as both a medical professional and, following Çalışkan and Callon, as an agent of 'economization.' That is, they must first judge which conditions qualify as impairment in the first place, then assess whether they are sufficiently long in their duration and then judge impaired individuals against an equally ambiguous rubric of 'competitive employment'. ${ }^{147}$ They play a fundamental role in which bodies count as disabled for the ODSP, and are crucial to those bodies being brought to the labour market. In terms of those that do not, Lightman et al. (2009) argue that this assessment

the CNIB, receive ODSP Income Supports, or have attended a provincial school for students with disabilities.

${ }^{147}$ As I noted in chapter three, sec. 4 of the ODSP act has a duration requirement quite similar to the prolonged requirement in the T2201 Disability Tax Credit Certificate. 
rubric frequently excludes individuals with episodic conditions that do not conform to the ODSP act's understandings of what disability is.

In living as partially able and partially disabled as their bodies vacillate between intervals of wellness and illness, capacity and incapacity, persons with episodic disabilities are disqualified as the "rightfully disabled" within the definitional currency of ODSP policy (Lightman et al., 2009).

Applicants for the ODSP Employment Supports find themselves between economic and medical discourses, or, following ANT's focus on process, between economization and medicalization $^{148}$. The hybrid medical professional/lay economist becomes a gatekeeper, what Callon (1986) calls an 'obligatory passage point', between the Employment Supports applicant and the labour market. ${ }^{149}$ In short, it is not enough for the applicant's condition to be medicalized in the verification process: it must undergo economization as well.

The Employment Supports not only serve to determine who will sell their labour to the market with MCSS assistance, they also contribute to the form that economic agency will take once it is so distributed. While the process excludes some bodies that are not 'rightfully disabled', those that are seen as fit for the labour market are formatted according to conditions of 'competitive employment'. This formatting is outlined in the Employment Supports Funding Agreement (Ontario, 2010c). The agreement contains a

\footnotetext{
${ }^{148}$ Here I use 'medicalization' in the same sense as in chapter five, by focusing on the just-thisness of a particular medical encounter, rather than abstract reference to medicine as a judge of statements of being. My argument is that we should focus on particular medical judgments than the activity of the profession as a whole.

149 In discussing the history of the electric car in France, Callon (1987) encounters another such hybrid professional: the engineer-sociologist.
} 
'Competitive Employment Plan', and the terms and conditions to which applicants are bound to receive services from the MCSS. I write 'bound' to refer to one of Callon's concepts: the Agreement is crucial in the assembly of an interactive diagram. This particular agencement does not fall in either the prosthetic or habilitation camps that Callon outlines above. Instead we have a case of hybridity, where economic and individual autonomy emerges, albeit within institutionally demarcated territory.

Reading the Agreement closely, we can see aspects of both habilitation and prosthetic agencies at work. The Plan is in many senses similar to the 'life plans' discussed in Callon's (2008) chapter on interactive agencements, examined above. The four-step plan unfolds as follows:

Step 1 - I have selected a service provider to help me to obtain and maintain competitive employment.

Step 2 - I will work with my chosen service provider to determine whether I am ready and able to prepare for, obtain and maintain competitive employment. I will work with my service provider to determine the steps of my employment plan and the goods and services that may be required to achieve my employment goal.

Step 3 - My goal is to be placed in competitive employment or to start a business.

Step 4 - I will continue to work with my service provider in order to retain my job, and where possible, increase my earnings (Ontario, 2010c).

Reading the Agreement as a map through the Employment Supports program, we find that successful applicants traverse both 'prosthetic' and 'habilitation' territory. The agreement does treat the applicant as 'an individual who is capable of developing projects and is endowed with a will to accomplish them' (Callon, 2008), but this development and endowment is pursued under conditions set out by the MCSS in advance. 
Turning to the critical social policy literature, interviews with ODSP clients have demonstrated that the kind of economic agency distributed within the Employment Supports comes at the expense of other potential varieties. As Heidegger would put it, its enframing is 'a challenging' to other forms of disclosure. In her work with income support recipients, Crooks (2004) argues that the ODSP focus on 'competitive employment' devalues other forms of work, particularly domestic labour. This is similar to the way in which the T2201 form excludes child-care and other domestic tasks in its daily living rubric. In short, marketization processes can be seen also as gendered processes, where work done disproportionately by women is not valued as meaningful work. ${ }^{150}$ These two forms of agency are made rival through the program's architecture. In the process of producing the competitive employment market for disabled persons in Ontario, other forms of labour are excluded from the realm deemed 'economic', from Çalışkan and Callon's economization processes.

When we restrict our understanding of work to that taking place outside the home, Vick and Lightman (2010) document the precarious work that program recipients typically find. ${ }^{151}$ Their interviews were restricted to the subset of women with complex episodic disabilities, defined "as fluctuating mental health issues that coexist with the volatility of physical health conditions in relation to changing bodily experiences, life

\footnotetext{
150 This is, obviously, similar to the forms of disability emphasized in the T2201, in chapter three.

151 Cranford et al. (2003, p. 454) define precarious employment as: "forms of employment involving atypical employment contracts, limited social benefits and statutory entitlements, job insecurity, low job tenure, low earnings, poor working conditions and high risks of ill health."
} 
circumstances, and physical environments" (2010, p. 71). ${ }^{152}$ Episodically disabled women are in a catch-22 scenario: flexible schedules allow these women the ability to work when they are able, but their semi-or-non-skilled, low-paying service sector jobs often exacerbate the conditions that caused them to seek ODSP Employment or Income Supports in the first place. They remind us that 'employment' is not a goal in itself: particular work arrangements are better and more maintainable than others. In this manner, they provide empirical footing for Callon's promotion of distributed action over an opaque understanding of 'economic agency' or employment.

Gewurtz (2011) examines the problems faced by mentally ill ODSP clients, onset by the Employment Supports' transition to the market-based model in 2006. From 1999 to reform, the ODSP Employment Supports regime covered a wide range of goods and services prior to employment placement, under a fee-for-service model. ${ }^{153} \mathrm{Her}$ government informants noted that service providers were accordingly rewarded for providing these services to clients or to unpaid positions that required further service provision, rather than sending them to market and severing client-provider relationships. The transition to objective-based, job placement outcomes eliminated many of these services in the name of efficiency. The transition to hard job placement numbers forced a divide between those who were easily marketable to employers, and those needing more

152 These persons are frequently denied ODSP benefits and supports, because their conditions' durations are frequently deemed not to meet the one-year duration requirement for impairments to qualify as 'prolonged disability', as set out in the ODSP Act (1997).

153 Citing then-ODSP Employment Supports directives, Gewurtz lists: "employment planning and preparation supports and services, employment skills training, trainer supports services, assistive devices and supplies, interpretor and intervenor services, transportation assistance, job coaching, and job placement services" (p. 90). 
comprehensive and more costly actions. Mentally ill clients were further marginalized from employment, in the name of the bottom line. The new reforms brought more disabled bodies to the competitive employment market, but eliminated costly instances of prosthetic (not to mention habilitation) agencement from the process altogether.

In each of the above cases, the marketization process brings bodies to market as competitive employees, but at the expense of disclosing other varieties of economic agencement, and the elimination of persons who cannot be easily accommodated in employment environments. By pursuing Callon's anthropology of markets, we can see how the employment supports distribute agency to market, while at the same time critically assessing the types of jobs that persons are being equipped for (and those foregone).

\section{Distributing Economic Agency in Ontario}

The ODSP Employment Supports marketization process requires a fair bit of both equipment and accompaniment. The road to 'competitive employment' is laden with a vast array of forms, rubrics, bureaucrats and verifiers. It is materially equipped as well: individuals are outfitted with material aids for competitive employment should they require them and exhaust the Ministry of Health and Long Term Care's Assistive Device

Program. ${ }^{154}$ Economic agency is distributed within this network. In order for ODSP

\footnotetext{
${ }^{154}$ For more information on the program, see the ADP website: http://www.health.gov.on.ca/en/public/programs/adp/pub adp.aspx
} 
clients to bring their labour to market via the Employment Supports, they need to go through an intricate process of modeling, shaping and coding that oscillates between Callon's habilitation and prosthetic categorizations. Further, as the work of Lightman et al. (2009) demonstrates, clients are only able to chart their own economic destiny if they meet rather stringent understandings of what disability is under the ODSP Act (1997). This negotiated and equipped nature of the journey to economic agency is described quite well by the concepts of 'marketization' and 'economization.' The Employment Supports show the plasticity of the habilitation and prosthetic agency concepts. Instead of seeing the concepts as mutually exclusive, a priori sociological categories, they should be thought of as part of a heuristic scale to understand the emergent nature of performative agency.

The disability, prosthesis and habilitation spectrum gives us new insight into how bodies are brought to market, the type of work they are equipped for, and the optimal forms this performative agency could take. Of course, the ontological difference is present here: applicants must continually make the trip from Dasein to objective presence and back again as they navigate the ODSP bureaucratic structure. But by turning primarily to Callon, and remembering Heidegger's lessons, we can highlight how administrative bureaucracies themselves can be made more human, rather than just their requirements for admission. This is the project that I will undertake in my future work, where I will continue to pursue the ontological politics of disablement. 


\section{Works Cited}

Abrams, T. (2009). Infernal Liberation? Emancipatory Research, and the Social Model of Disability. Carleton University, Ottawa.

. (2014). Taking Tragic Measures? Disability Studies' Anti-Metrology and the Global Government of Thalidomide. Theoria and Praxis, 1(2), 27-42.

Aho, K. (2007). Gender and Time: Revisiting the Question of Dasein's Neutrality. Epoché, 12(1).

Aho, K. A. (2005). The Missing Dialogue between Heidegger and Merleau-Ponty: On the Importance of the Zollikon Seminars. Body \& Society, 11(2), 1-23.

Anderson, B. (2006). Imagined Communities: Reflections on the Origin and Spread of Nationalism (Revised ed.). New York: Verso.

Annas, G., \& Elias, S. (1999). Thalidomide and the Titanic: Reconstructing The Technology Tragedies of the Twentieth Century. American Journal of Public Health, 89(1), 98-101.

Askay, R. R. (1999). Heidegger, the Body and the French Philosophers. Continental Philosophy Review, 32, 29-35.

Barnes, C. (1996). Disability and the Myth of the Independent Researcher. Disability \& Society, 11(1), 107-110.

—. (1999). Disability Studies: new or not so new directions? Disability \& Society, 14(4), 577-580. 
—. (2003). What a Difference a Decade Makes: Reflections on Doing Emancipatory Disability Research. Disability \& Society, 18(1), 3-17.

Barnes, C., \& Mercer, G. (2003). Disability. Cambridge: Polity.

BBC. (2012). German thalidomide maker Gruenenthal issues apology. http://www.bbc.co.uk/news/health-19443910.

Butler, J. (1993). Bodies that Matter: On the Discursive Limits of "Sex". London and New York: Routledge.

Çalışkan, K., \& Callon, M. (2009). Economization, part 1: shifting attention from the economy to processes of economization. Economy and Society, 38(3), 369-398.

—. (2010). Economization, part 2: a research program for the study of markets. Economy and Society, 39(1), 1-32.

Callon, M. (1987). Society in the Making: The Study of Technology as a Tool for Sociological Analysis. In W. Bijker, T. Hughes, \& T. Pinch (Eds.), The Social Construction of Technical Systems: New Dimension in the Sociology and HIstory of Technology (pp. 83-103). Cambridge: MIT Press. - (1998). Introduction: The Embeddedness of Economic Markets in Economics. In M. Callon (Ed.), The Laws of the Markets (pp. 1-57). Oxford: Blackwell Publishers/Sociological Review.

- (2007). An Essay on the Growing Contribution of Economic Markets to the Proliferation of the Social. Theory, Culture \& Society, 24(7-8), 139-163. . (2008). Economic Markets and the Rise of Interactive Agencements: From Prosthetic Agencies to Habilitated Agencies. In T. Pinch, \& R. Swedberg (Eds.), 
Living in a Material World: Economic Sociology Meets Science and Technology Studies (pp. 29-56). Cambridge, Mass: MIT Press.

Callon, M., \& Rabeharisoa, V. (2004). Gino's lesson on humanity: genetics, mutual entanglements and the sociologist's role. Economy and Society, 33(1), 1-27.

—. (2008). The Growing Engagement of Emergent Concerned Groups in Political and Economic Life: Lessons from the French Association of Neuromuscular Disease Patients. Science, Technology \& Human Values, 33(2), 230-261.

Canada. (2011a). Medical and Disability-Related Information 2011. Ottawa: Canada Revenue Agency.

. (2011b). T2201 Disability Tax Credit Certificate. Ottawa: Canada Revenue Agency.

_ (2013a). Rethinking DisAbility in the Private Sector: Report from the Panel on Labour Market Opportunities for Persons with Disabilities. Ottawa: Human Resources and Skills Development Canada.

Carr, D. (1970). Husserl's Problematic Concept of the Life-World. American Philosophical Quarterly, 7(4), 331-339.

Ciocan, C. (2008). The Question of the Living Body in Heidegger's Analytic of Dasein. Research in Phenomenology, 38, 72-89.

Clarke, A. E., \& Leigh Star, S. (2008). The Social Worlds Framework: A Theory/Methods Package. In E. J. Hackett, O. Amsterdamska, M. Lynch, \& J. Wajcman (Eds.), The Handbook of Science and Technology Studies (3rd ed., pp. 113-137). Cambridge: The MIT Press. 
Collins, P. H. (2000). Black Feminist Thought: Knowledge, Consciousness, and the Politics of Empowerment (2nd ed.). London and New York: Routledge.

Conrad, P. (1992). Medicalization and Social Control. Annual Review of Sociology, 18, 209-232.

Cott, C. A. (2004). Client-centered rehabilitation: client perspectives. Disability and Rehabilitation, 26(24), 1411-1422.

. (2008). Client-centered rehabilitation: what is it and how do we measure it? Physiotherapy, 94, 89-90.

Crooks, V. A. (2006). "I Go On The Internet; I Always, You Know, Check To See What's New": Chronically ill women's use of online health information to shape and inform doctor-patient interactions in the space of care provision. ACME: An Internaitonal E-Journal of Critical Geographies, 5(1), 50-69.

Crossley, N. (1995). Merleau-Ponty, the elusive body and carnal sociology. Body \& Society, 1(1), 43-63.

Daemmrich, A. (2002). A Tale of Two Experts: Thalidomide and Political Engagement in the United States and West Germany. Social History of Medicine, 15(1), 137158.

Deleuze, G. (1988). Foucault (S. Hand, Trans.). Minneapolis: University of Minnesota Press.

Descartes, R. (1998). The World and Other Writings (S. Gaukroger, Trans.). Cambridge: Cambridge University Press. - (2008). Meditations on First Philosophy with Selections from the Objections and Replies (M. Moriarty, Trans.). New York: Oxford University Press. 
Dreyfus, H. L. (1991). Being-in-the-World: A Commentary on Heidegger's Being and Time, Division I. Cambridge: The MIT Press.

_ (1993a). Heidegger on the connection between nihilism, art, technology, and politics. In C. Guignon (Ed.), The Cambridge Companion to Heidegger (pp. 289316). Cambridge: Cambridge University Press.

—. (1993b). Heidegger's Critique of the Husserl/Searle Account of Intentionality. Social Research, 60(1), 17-38.

_. (2004). Heidegger on Gaining a Free Relation to Technology. In H. Dreyfus, \& M. Wrathall (Eds.), Heidegger Reexamined, Volume 3: Art, Poetry and Technology (pp. 97-107). London and New York: Routledge.

Dreyfus, H. L., \& Wrathall, M. A. (2005). Martin Heidegger: An Introduction to His Thought, Work and Life. In H. L. Dreyfus, \& M. A. Wrathall (Eds.), A Companion to Heidegger (pp. 1-16). Malden: Blackwell.

Eisenberg, N. (2012). Post-structural conceptualizations of power relationships in physiotherapy. Physiotherapy Theory and Practice, 28(6), 439-446.

Farr, J. (1999). John Dewey and American Political Science. American Journal of Political Science, 43(2), 520-541.

Finkelstein, V. (1980). Attitudes and Disabled People: Issues for Discussion. New York: World Rehabilitation Fund.

Fleck, L. (1979). Genesis and Development of a Scientific Fact (F. Bradley, \& T. J. Trenn, Trans.). Chicago and London: University of Chicago Press.

Foucault, M. (1978). The History of Sexuality Volume 1: An Introduction (R. Hurley, Trans.). New York: Random House. 
- (2008). The Birth of Biopolitics: Lectures at the Collège de France 1978-79 (G.

Burchell, Trans.). New York: Palgrave Macmillan.

— (1997). The Ethics of the Concern for Self as a Practice of Freedom (R. Hurley, Trans.). In P. Rabinow (Ed.), Ethics: Subjectivity and Truth (pp. 281-301). New York: The New Press.

Frank, A. (2000). The Standpoint of the Storyteller. Qualitative Health Research, 10(3), $354-365$.

Franks, M. E., Macpherson, G. R., \& Figg, W. D. (2004). Thalidomide. The Lancet, 363(9423), 1802-1811.

French, S., \& Swain, J. (2004). Researching Together: A Participatory Approach. In Physiotherapy: A Psychosocial Approach. Oxford, UK: Butterworth-Heinemann.

Garfinkel, H. (1967). Studies in Ethnomethodology. Englewood Cliffs: Prentice-Hall.

Goffman, E. (1961). Asylums: Essays on the Social Situation of Mental Patients and Other Inmates. Garden City: Anchor Books.

_ (1963). Stigma; notes on the management of spoiled identity. Englewood Cliffs: Prentice-Hall. . (1967). Interaction Ritual: Essays on Face-to-Face Behaviour. New York: Pantheon.

_ (1971). Relations in Public: Microstudies of the Public Order. New York: Basic Books.

Guignon, C. (1983). Heidegger and the Problem of Knowledge. Indianapolis: Hackett Publishing Company. 
_ (1984). Heidegger's "Authenticity" Revisited. The Review of Metaphysics, 38(2), 321-339.

. (1990a). Philosophy after Wittgenstein and Heidegger. Philosophy and Phenomenological Research, 50(4), 649-672.

- (1990b). Truth as Disclosure: Art, Language, History. Southern Journal of Philosophy, 28 (Supplement), 105-120.

Hacking, I. (1983). Representing and Intervening: Introductory Topics in the Philosophy of Natural Science. Cambridge: Cambridge University Press.

- (1992). 'Style' for Historians and Philosophers. Studies in History and Philosophy of Science, 23(1), 1-20.

— (1999). The Social Construction of What? Cambridge: Harvard University Press.

—. (2005). The Cartesian Vision Fulfilled: Analogue Bodies and Digital Minds. Interdisciplinary Science Reviews, 30(2), 153-166.

Haraway, D. (1991). Simians, Cyborgs and Women: The Reinvention of Nature. New York: Routledge.

- (1994). A Game of Cat's Cradle: Science Studies, Feminist Theory, Cultural Studies. Configurations, 2(1), 59-71.

—. (1988). Situated Knowledges: The Science Question in Feminism and the Privilege of Partial Perspective. Feminist Studies, 14(3), 575-599.

Harding, S. (1991). Whose Science? Whose Knowledge? Thinking from Women's Lives. Ithica: Cornell University Press.

Hartsock, N. (1983). The Feminist Standpoint: Developing the Ground for a Specifically Feminist Historical Materialism. In S. Harding, \& M. Hintikka (Eds.), Discovering 
reality: feminist perspectives on epistemology, metaphysics, methodology, and philosophy of science (2nd ed., pp. 283-310). Boston: Kluwer Academic Publishers.

—. (1989). Postmodernism and Political Change: Issues for Feminist Theory. Cultural Critique, 14, 15-33.

Heidegger, M. (1962). Being and Time (J. MacQuarrie, \& E. Robinson, Trans.). New York: Harper \& Row.

_. (1971). Poetry, Language, Thought. New York: Harper \& Row.

_. (1973). Art and Space. Man and World, 6(1), 3-8.

. (1977a). Science and Reflection (W. Lovitt, Trans.). In W. Lovitt (Ed.), The Question Concerning Technology and Other Essays (pp. 155-182). New York: Harper \& Row.

—. (1977b). The Age of the World Picture (W. Lovitt, Trans.). In W. Lovitt (Ed.), The Question Concerning Technology and Other Essays (pp. 115-154). New York: Harper \& Row.

—. (1982). The Basic Problems of Phenomenology (A. Hofstader, Trans. Revised ed.). Bloomington: Indiana University Press.

—. (1992). The Concept of Time (W. McNeil, Trans.). Oxford: Blackwell.

_. (1996). Being and Time (J. Stambaugh, Trans.). New York: State University of New York Press.

—. (1998). Plato's Doctrine of Truth (W. McNeil, Trans.). In Pathmarks (pp. 155182). Cambridge: Cambridge University Press. 
—. (2001a). Phenomenological Interpretations of Aristotle: Initiation to

Phenomenological Research (R. Rojcewicz, Trans.). Bloomington: Indiana University Press. . (2001b). Zollikon Seminars (F. Mayr, \& R. Askay, Trans.). Evanston: Northwestern University Press.

_. (2011). The Concept of Time (I. Farin, Trans.). New York: Continuum.

—. (2012). Contributions to Philosophy (of the Event). Bloomington: University of Indiana Press.

- (1993a). Letter on Humanism. In D. F. Krell (Ed.), Martin Heidegger: Basic Writings (2nd ed., pp. 213-266). San Francisco: Harper Collins.

- (1993b). On The Essence of Truth. In D. F. Krell (Ed.), Martin Heidegger: Basic Writings (2nd ed., pp. 111-138). San Francisco: Harper Collins.

—. (1993c). The Origin of the Work of Art. In D. F. Krell (Ed.), Martin Heidegger: Basic Writings (2nd ed., pp. 143-212). San Francisco: Harper Collins.

—. (1993d). The Question Concerning Technology. In D. F. Krell (Ed.), Martin Heidegger: Basic Writings (2nd ed., pp. 307-342). San Francisco: Harper Collins.

Hoffman, P. (1993). Death, Time, and History: Division II of Being and Time. In The Cambridge Companion to Heidegger (Guignon, Charles ed., pp. 195-214). New York: Cambridge University Press.

Hughes, B. (1999). The Constitution of Impairment: modernity and the aesthetic of oppression. Disability \& Society, 14(2), 155-172.

—. (2000). Medicine and the Aesthetic Invalidation of Disabled People. Disability \& Society, 15(4), 555-568. 
Hughes, B., \& Paterson, K. (1997). The Social Model of Disability and the Disappearing Body: Towards a Sociology of Impairment. Disability \& Society, 12(3), 325-340.

Husserl, E. (1931). Ideas: General Introduction to Pure Phenomenology (W. R. B. Gibson, Trans.). New York: George Allen \& Unwin.

- (1970). The crisis of European sciences and transcendental phenomenology; an introduction to phenomenological philosophy (D. Carr, Trans.). Evanston: Northwestern University Press.

Hutchins, E. (1995). How a Cockpit Remembers its Speeds. Cognitive Science, 19, 265288.

James, W. (1918). Principles of Psychology. New York: Holt.

- (1978). Pragmatism: A New Name for Some Old Ways of Thinking; The Meaning of Truth: A Sequal to Pragmatism. Cambridge: Harvard University Press.

- (1996). Some Problems of Philosophy: A Beginning of an Introduction to Philosophy. Lincoln: Bison Books.

Juuso, Päivi, Skär, L., Olsson, M., \& Söderberg, s. (2011). Living with a double burden: Meanings of pain for women with fibromyalgia. International Journal of Qualitiative Studies of Well-being, 6(3), n.p.

Kämper, O. (2012). Too little, too late, say thalidomide victims. Deutsche Welle http://www.dw.de/too-little-too-late-say-thalidomide-victims/a-16214497.

Keller, P. (1999). Husserl and Heidegger on Human Experience. Cambridge: Cambridge University Press.

Klein, U. (2001). Paper Tools in Experimental Cultures. Studies in History and Philosophy of Science, 32(2), 265-302. 
Latour, B. (1988). The Pasteurization of France (A. Sheridan, \& J. Law, Trans.). Cambridge: Harvard University Press.

—. (1993). We Have Never Been Modern (C. Porter, Trans.). Cambridge: Harvard University Press.

—. (2004). Reassembling the Social: An Introduction to Actor-Network Theory. New York: Oxford University Press.

Law, J. (1987). Technology and Heterogeneous Engineering: The Case of Portuguese Expansion. In W. Bijker, T. Hughes, \& T. Pinch (Eds.), The Social Construction of Technical Systems: New Dimension in the Sociology and History of Technology (pp. 111-134). Cambridge: MIT Press.

Law, J., \& Singleton, V. (2005). Object Lessons. Organization, 12(3), 331-355.

Leder, D. (1990). The Absent Body. Chicago: University of Chicago Press.

Lightman, E., Vick, A., Herd, D., \& Mitchell, A. (2009). 'Not disabled enough': Episodic Disabilities and the Ontario Disability Support Program. Disability Studies Quarterly, 29(3), n.p.

López-Pousa, S., Garre-Olmo, J., de Gracia, M., Ribot, J., Calvó-Perxas, L., \& VilaltaFranch, J. (2013). Development of a Multidimensional Measure of Fibromyalgia Symptomatology: The Comprehensive Rating Scale for Fibromyalgia Symptomatology. Journal of Psychosomatic Research, 74(5), 384-392.

Luft, S. (2004). Husserl's Theory of the Phenomenological Reduction: Between LifeWorld and Cartesianism. Research in Phenomenology, 34(1), 198-234. 
McBride, W. (2004). Health of thalidomide victims and their progeny. The Lancet, 363(9043), 169-169.

McHoul, A. (1998). How can Ethnomethodology be Heideggerian? Human Studies, 21, 13-26.

Melchert, M., \& List, A. (2007). The Thalidomide Saga. International Journal of Biochemistry and Cell Biology, 39(7-8), 1489-1499.

Mental Health Commission of Canada. (2013b). Why Investing In Mental Health will contribute to Canada's Economic Prosperity and to the Sustainability of our Health Care System - Backgrounder, Key Facts. Calgary: Author.

Merleau-Ponty, M. (1962). Phenomenology of Perception (C. Smith, Trans.). New York: Routledge.

- (1968). The Visible and the Invisible (A. Lingis, Trans.). Evanston: Northwestern University Press.

Michalko, R. (1998). The Mystery of the Eye and the Shadow of Blindness. Toronto: University of Toronto Press.

- (1999). The Two-in-One: Walking with Smokie, Walking with Blindness. Philadelphia: Temple University Press.

Mohanty, C. T. (2003). Feminism without borders: decolonizing theory, practicing solidarity. Durham: Duke University Press.

Mohanty, J. N. (1995). The Development of Husserl's Thought. In B. Smith, \& D. W. Smith (Eds.), The Cambrige Companion to Husserl (pp. 45-77). Cambridge: Cambridge University Press. 
Mol, A. (1999). Ontological politics. A word and some questions. In J. Law, \& J. Hassard (Eds.), Actor Network Theory and After (pp. 74-89). Oxford: Blackwell.

- (2002). The Body Multiple: Ontology in Medical Practice. Durham: Duke University Press.

Moser, I. (2000). Against Normalisation: Subverting Norms of Ability and Disability. Science as Culture, 9(2), 201-240.

Moser, I., \& Law, J. (1999). Good Passages, Bad Passages. In J. Law, \& J. Hassard (Eds.), Actor-Network Theory and After (pp. 196-219). Oxford: Blackwell.

Nichols, D. A., \& Gibson, B. E. (2010). The body and physiotherapy. Physiotherapy Theory and Practice, 26(8), 497-509.

Oksala, J. (2010). Foucault's Politicization of Ontology. Continental Philosophy Review, $43(4), 445-466$.

Oldfield, M. (2013). "It's not all in my head. The pain I feel is real" How Moral Judgment Marginalizes Women with Fibromylagia in Canadian Health Care. Women's Health and Urban Life, 12(1), 39-60.

Oliver, M. (1983). Social Work with Disabled People. London: Macmillan.

- (1986). Social Policy and Disability: Some Theoretical Issues. Disability, Handicap \& Society, 1(1), 5-17.

- (1990). The Politics of Disablement. London: Macmillan.

- (1992a). Changing the Social Relations of Research Production? Disability, Handicap \& Society, 7(2), 101-114.

—. (1992b). Intellectual Masturbation: a rejoinder to Söder and Booth. European Journal of Special Needs Education, 7(1), 20-28. 
—. (2004). If I Had a Hammer: The social model in action. In J. Swain, C. Barnes,

S. French, \& C. Thomas (Eds.), Disabling Barriers, Enabling Environments (pp. 7-

12). London: Sage.

Ontario. (2010a). Ontario Disability Support Program Employment Supports Directives.

Toronto: Ministry of Community and Social Services.

—. (2010b). Ontario Disability Support Program Employment Supports:

Application for Employment Supports. Toronto: Ministry of Community and Social

Services.

- (2010c). Ontario Disability Support Program Employment Supports:

Employment Supports Funding Agreement. Toronto: Ministry of Community and

Social Services.

- (2010d). Ontario Disability Support Program Employment Supports:

Verification of Disability/Impairment. Toronto: Ministry of Community and Social

Services.

_. (2012). Ontario-Canada Labour Market Agreement for Persons with Disabilities

2011-2012 Annual Report. Toronto: Ministry of Community and Social Services.

Overboe, J. (1999). 'Difference in Itself': Validating Disabled People's Lived Experience.

Body \& Society, 5(4), 17-29.

Paterson, K., \& Hughes, B. (1999). Disability Studies and Phenomenology: the Carnal

Politics of Everyday Life. Disability \& Society, 14(5), 597-610.

Pickering, A. (2005). Decentering Sociology: Synthetic Dyes and Social Theory.

Perspectives on Science, 13(3), 352-405.

—. (2009). The Politics of Theory. Journal of Cultural Economy, 2(1), 197-212. 
Polanyi, M. (1969). Knowing and Being. In M. Grene (Ed.), Knowing and Being: Essays by Michael Polanyi (pp. 123-137). Chicago: University of Chicago Press.

Prince, M. J. (2001). Tax Policy as Social Policy: Canadian Tax Assistance for People with Disabilities. Canadian Public Policy, 27(4), 487-501.

— (Ed.). (2002). Designing Disability Policy in Canada: The Nature and Impact of Federalism on Policy Development. Montreal and Kingston: McGill-Queens University Press.

—. (2004). Canadian Disability Policy: Still a Hit-and-Miss affair. Canadian Journal of Sociology, 29(1), 59-82.

Rabeharisoa, V., \& Callon, M. (2004). Patients and Scientists in French Muscular Dystrophy Research. In S. Jasanoff (Ed.), States of Knowledge: The Co-production of Science and Social Order (pp. 142-160). London and New York: Routledge.

Raby, R. C. (2000). Re-Configuring Agnes: The Telling of a Transsexual's Story. torquere: Journal of the Canadian Lesbian and Gay Studies Association, 2, 18-35.

Reeve, D. (2012). Cyborgs, Cripples and iCrip: Reflections on the Contribution of Haraway to Disability Studies. In D. Goodley, B. Hughes, \& L. Davis (Eds.), Disability and Social Theory: New Directions and Developments (pp. 91-111). Houndmills, Basingstoke, Hampshire: Palgrave Macmillan.

Robillard, A. (1994). Communication Problems in the Intensive Care Unit. Qualitative Sociology, 17(4), 383-395.

_. (1996). Anger In-the-Social-Order. Body \& Society, 2(1), 17-30.

_. (1999). Wild Phenomena and Disability Jokes. Body \& Society, 5(4), 61-65.

Ryle, G. (1929). Review of Sein und Zeit. Mind, 38(151), 355-370. 
_ (1949). The Concept of Mind. Chicago: University of Chicago Press.

Schatzki, T. (2005). Early Heidegger on Sociality. In H. L. Dreyfus, \& M. A. Wrathall (Eds.), A Companion to Heidegger (pp. 233-247). Malden: Blackwell.

Schillmeier, M. (2008). Time-Spaces of In/dependence and Dis/ability. Time and Society, $17(2 / 3), 215-231$.

—. (2010). Rethinking Disability: Bodies, Senses, Things. New York: Routledge.

Schuessler, J. (2014). Heidegger's Notebooks Renew Focus on Anti-Semitism. The New York Times, $30^{\text {th }}$ March. p. C1.

Schütz, A. (1943). The Problem of Rationality In the Social World. Economica, 10(38), $130-149$.

Schütz, A., \& Luckmann, T. (1973). The Structures of the Life-world (R. M. Zaner, \& T. J. Engelhardt, Trans.). Evanston: Northwestern University Press.

Shakespeare, T. (1994). Cultural Representations of Disabled People: Dustbins for Disavowal? Disability \& Society, 9(3), 283-299.

— (1999). The Sexual Politics of Disabled Masculinity. Sexuality and Disability, 17(1), 53-64.

—. (2000). Disabled Sexuality: Towards Rights and Recognition. Sexuality and Disability, 18(3), 159-166.

_. (2006). Disability Rights and Wrongs. London: Routledge.

Shapin, S., \& Schaffer, S. (1985). Leviathan and the Air Pump: Hobbes, Boyle and the Experimental Life. Princeton: Princeton University Press.

Shaw, J. A., \& DeForge, R. T. (2012). Physiotherapy as bricolage: Theorizing expert practice. Physiotherapy Theory and Practice, 28(6), 420-427. 
Siebers, T. (2006). Disability Aesthetics. Journal for Cultural and Religious Theory, $7(2), 63-73$.

_. (2008). Disability Theory. Ann Arbor: University of Michigan Press.

—_. (2010). Disability Aesthetics. Ann Arbor: University of Michigan Press.

Smith, B., \& Smith, D. W. (Eds.). (1995). The Cambrige Companion to Husserl. Cambridge: Cambridge University Press.

Stiker, H.-J. (1999). A History of Disability (W. Sayers, Trans.). Ann Arbour: University of Michigan Press.

Stratford, P., Gill, C., Westaway, M., \& Binkley, J. (1995). Assessing Disability and Change on Individual Patients: A Report of a Patient Specific Measure. Physiotherapy Canada, 47(4).

Thalidomide Trust (2011). Securing Our Future: The disability and health costs of UK thalidomide-affected people. Surrey: Author.

Thompson, E. (2007). Mind in Life: Biology, Phenomenology, and the Sciences of Mind. Cambridge: Belknap Press of Harvard University Press.

Timmermans, S., \& Leiter, V. (2000). The Redemption of Thalidomide: Standardizing the Risk of Birth Defects. Social Studies of Science, 30(1), 41-71.

Titchkosky, T. (2000). Disability Studies: the Old and the New. Canadian Journal of Sociology, 25(2), 197-224.

—. (2001). From the Field--Coming Out Disabled: The Politics of Understanding. Disability Studies Quarterly, 21(4), 131-139.

—. (2003). Governing Embodiment: Technologies of Constituting Citizens with Disabilities. Canadian Journal of Sociology, 28(4), 517-542. 
—. (2007). Reading and Writing Disability Differently: The Textured Life of Embodiment. Toronto: University of Toronto Press.

—. (2011). The Question of Access: Disability, Space, Meaning. Toronto: University of Toronto Press.

Titchkosky, T., \& Michalko, R. (2012). The Body as The Problem of Individuality: A Phenomenological Disability Studies Approach. In D. Goodley, B. Hughes, \& L. Davis (Eds.), Disability and Social Theory: New Directions and Developments (pp. 127-142). Houndmills, Basingstoke, Hampshire: Palgrave Macmillan.

Trede, F. (2012). Emancipatory physiotherapy practice. Physiotherapy Theory and Practice, 28(6), 466-473.

Turner, B. S. (2001). Disability and the Sociology of the Body. In G. Albrecht, K. Seelman, \& M. Bury (Eds.), Handbook of Disability Studies (pp. 252-266). Thousand Oaks: Sage.

Union of the Physically Impaired Against Segregation. (1975). Fundamental Principles of Disability. London.

von Moos, R., Stolz, R., Cerny, T., \& Gillessen, S. (2003). Thalidomide: From Tragedy to Promise. Swiss Medical Weekly, 133, 77-87.

Watson, S. (2006). Heidegger, Paul Klee, and the Origin of the Work of Art. The Review of Metaphysics, 60(2), 327-357. 